\title{
Implementation of a $1 / 4$ Inch Hollow Cathode into a Miniature Xenon Ion Thruster (MiXI)
}

\author{
A Thesis \\ Presented to \\ the Faculty of California Polytechnic State University, \\ San Luis Obispo
}

\author{
In Partial Fulfillment \\ of the Requirements for the Degree \\ Master of Science in Aerospace Engineering
}

by

David W. Knapp

June 2012 
(C) 2012

David Wayne Knapp

ALL RIGHTS RESERVED 


\section{COMMITTEE MEMBERSHIP}

TITLE:

Implementation of a $1 / 4$ Inch Hollow Cathode into a Miniature Xenon Ion Thruster (MiXI)

AUTHOR:

David Wayne Knapp

DATE SUBMITTED:

June 2012

COMMITTEE CHAIR:

Kristina K. Jameson, Assistant Professor Cal Poly Aerospace Department

COMMITTEE MEMBER:

Kira J. Abercromby, Assistant Professor Cal Poly Aerospace Department

COMMITTEE MEMBER: $\quad$ Daniel J. Wait, Assistant Professor

Cal Poly Aerospace Department

COMMITTEE MEMBER: $\quad$ Dan M. Goebel, Senior Research Scientist Jet Propulsion Laboratory 


\begin{abstract}
Implementation of a $1 / 4$ Inch Hollow Cathode into a Miniature Xenon Ion Thruster (MiXI)

David W. Knapp
\end{abstract}

Over the last decade, miniature ion thruster development has remained an active area of research do to its low power, low thrust, and high efficiency, however, due to several technical issues; a flight level miniature ion thruster has proved elusive. This thesis covers the design, fabrication, assembly, and test of an altered version of the Miniature Xenon Ion thruster (MiXI), originally developed by lead engineer Dr. Richard Wirz, at the California Institute of Technology (Caltech). In collaboration with Dr. Wirz, MiXI-CP-V3 was developed at Cal Poly San Luis Obispo with the goal of implementing of a $1 / 4$ inch hollow cathode and $3 \mathrm{mmx} 3 \mathrm{~mm}$ plasma confinement magnets in order to improve the plasma confinement characteristics, reliability, and performance of the MiXI design. Operational testing revealed a mass utilization efficiency of $35-75 \%$ and a discharge loss of 550-1200 eV/ion over plasma discharge currents of $0.5-1.5 \mathrm{~A}$ and propellant flow rates of $0.8-1.3$ SCCM. Testing revealed that the MiXI thruster can be operated with a hollow cathode and observations and data gained from this study have led to a greater understanding of the operational parameters of the MiXI thruster, and will contribute to the development and advancement of the MiXI baseline design, with the goal of creating an efficient and reliable flight level miniature ion thruster. 


\section{ACKNOWLEDGMENTS}

It is nearly impossible to acknowledge all those who had a hand in helping me throughout this thesis. First and foremost, I need to thank Dr. Dan Goebel for his seemingly limitless patience in answering a constant stream of emails and phone calls, and especially for his willingness to offer face to face help in his lab at JPL when I broke lab equipment (which seemed, frustratingly, to happen consistently). I would not have been able to complete this thesis without his help. I would also like to thank Dr. Tina Jameson for opening up the world of electric propulsion to me and pushing me to do be the best engineer possible. Her influence on my life cannot be measured, and I will be forever in her debt. I would like to acknowledge Dr. Richard Wirz for donating the MiXI accelerator grids for use in this thesis, thruster testing would have been impossible without them. I would also like to acknowledge Dr. Kira Abercromby, for her patience towards me as lab equipment broke, seemingly whenever I touched it, I really appreciate it. I also need to acknowledge the contribution of Max Glicklin, for the pain of an experimental thesis is greatly reduced as someone else is battling through it with you. His willingness to help at the drop of a hat helped me keep my sanity through most of my thesis. I would also like to thank my family for their unending support over these last few years; I would never have made it this far without you. Last, but certainly not least, I would like to thank Nicole Black, for putting up with my endless rants and explanations on the world of plasma physics even though she had no interest in it, for motivating me to keep moving forward when things looked bleak, for making me eat food which literally kept me going, and for generally being the most amazing person in my life. Thank you all so much. 


\section{TABLE OF CONTENTS}

\section{Page}

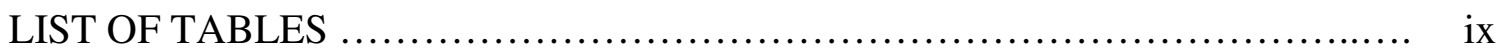

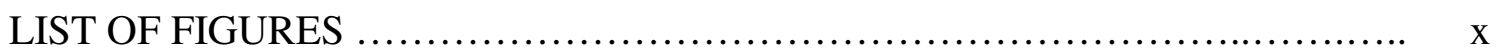

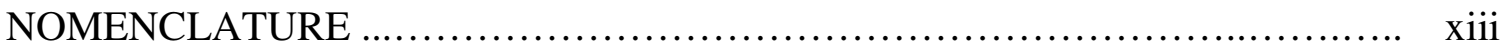

Chapter 1: Introduction ................................................................................................ 1

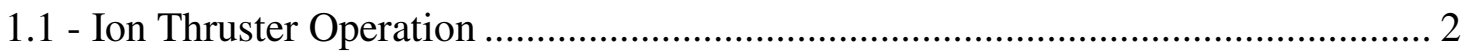

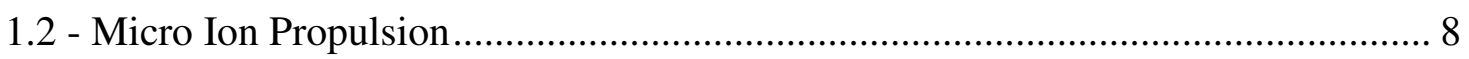

1.2.1 - The Miniature Ion Xenon Thruster........................................................... 8

1.2.2 - MiXI Mission Candidates........................................................................ 9

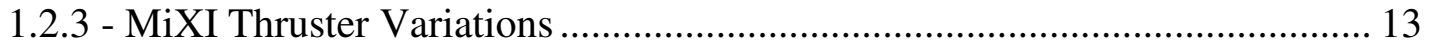

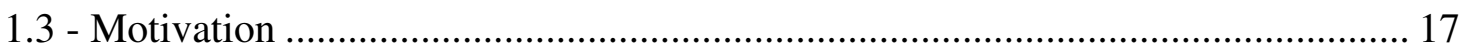

Chapter 2: Magnetic Confinement Design .................................................................. 19

2.1 - Magnetic Plasma Confinement ............................................................................. 19

2.2 - Magnet Selection and Analysis ........................................................................ 25

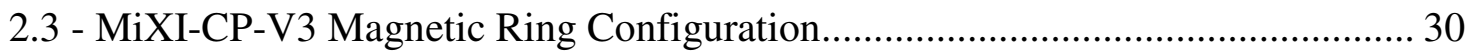

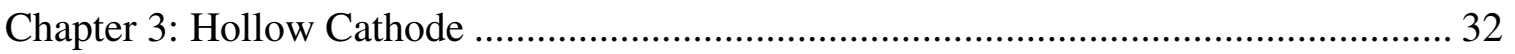

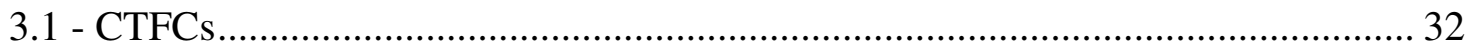

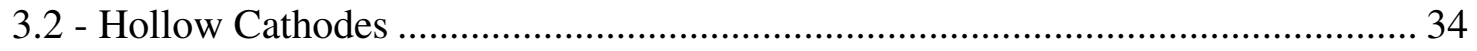

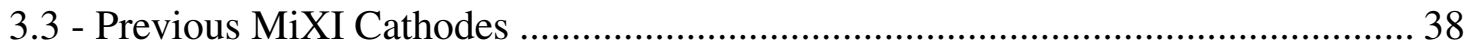

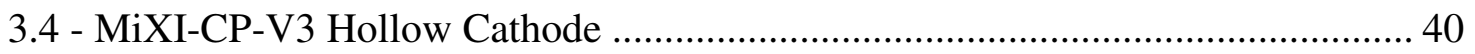


4.1 - Component Design ................................................................................... 45

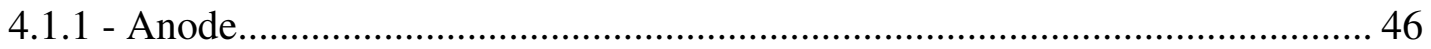

4.1.2 - Anode Pole Piece \& Cap Piece.................................................................... 47

4.1.3 - Lower Magnet Mount \& Magnets Shield................................................. 48

4.1.4 - Grid Isolation Mount \& Cathode Isolation Sheath.................................... 49

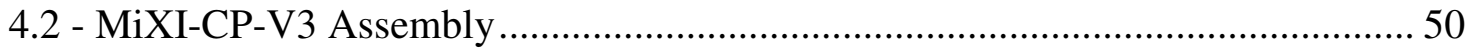

4.2.1 - Magnetic Ring Assembly ............................................................. 51

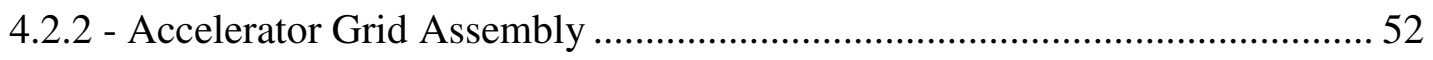

4.1.3 - MiXI-CP-V3 Final Assembly ................................................................. 54

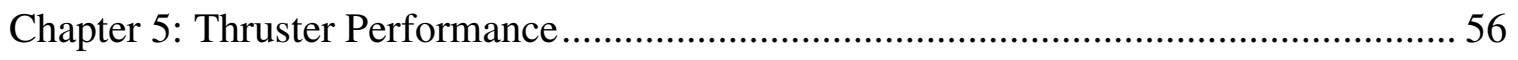

5.1 - Operational Parameters............................................................................ 56

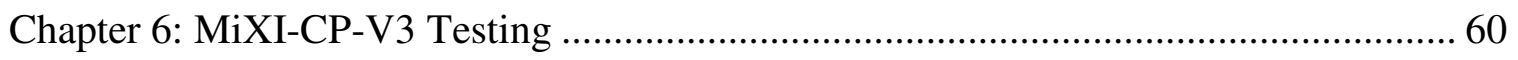

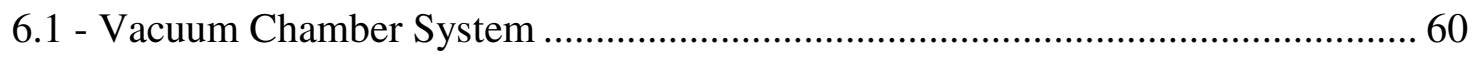

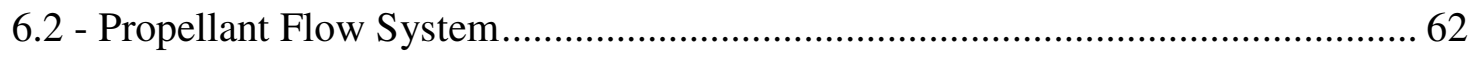

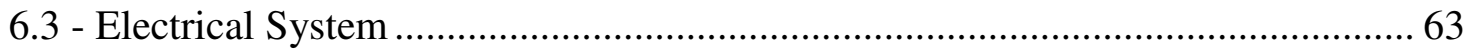

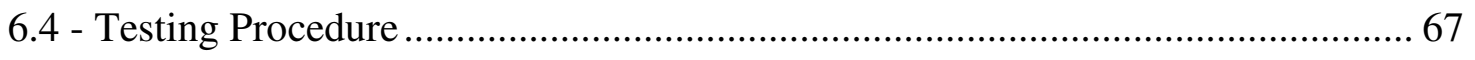

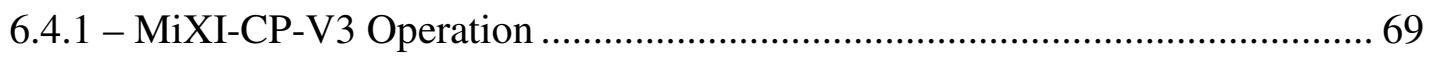

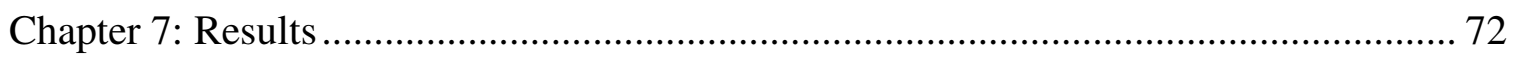

7.1 - MiXI-CP-V2 \& MiXI-CP-V3 Comparison ..................................................... 79 


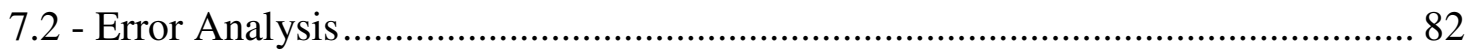

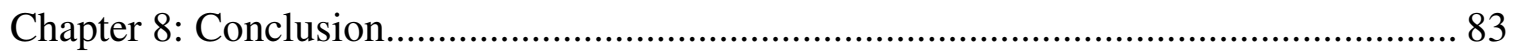

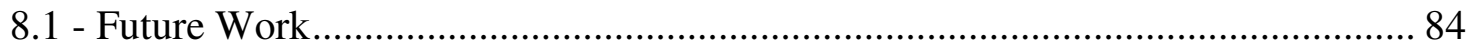

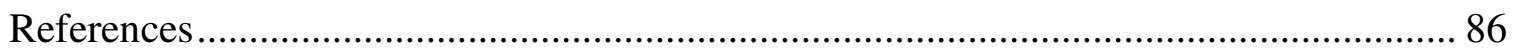

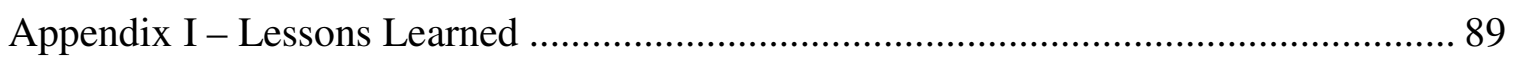

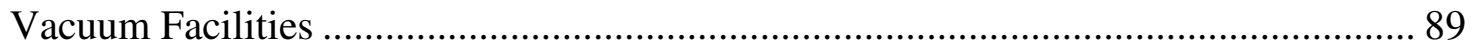

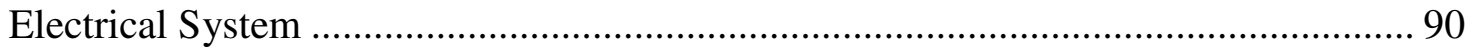

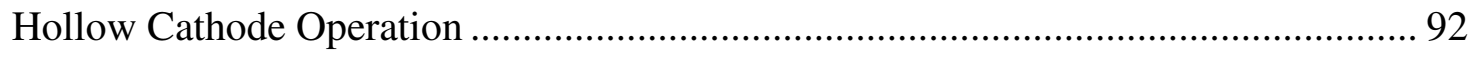

Appendix II - High Vacuum Operation Procedure ................................................... 94 


\section{LIST OF TABLES}

Table

Page

Table 1: List of all Small SmCo Magnets Analyzed for use in MiXI-CP-V3 ................. 25

Table 2: Magnetic Analysis Results for a Variety of SmCo Magnet Sizes ..................... 28

Table 3: 6.25mm Diameter Hollow Cathode Stand Alone Test Data............................ 41

Table 4: Power Supplies Utilized for MiXI-CP-V3 Testing ......................................... 66

Table 5: List of Typical Operational Parameters of MiXI-CP-V3 during Testing ........... 70

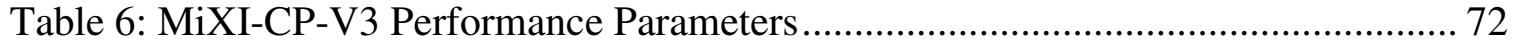

Table 7: Comparison of MiXI-CP-V2 and MiXI-CP-V3 Design Differences ................. 79

Table 8: Comparison of the Performance Parameters of the MiXI-CP-V2 and

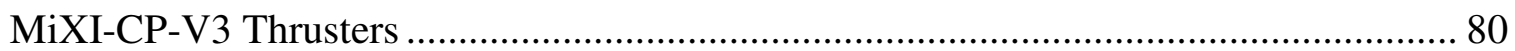

Table 9: Error Propagation of the MiXI-CP-V3 Performance Parameters ....................... 82 


\section{LIST OF FIGURES}

Figure

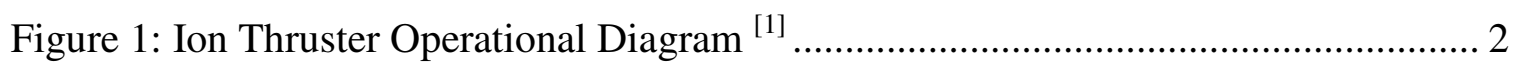

Figure 2: Ion Trajectories in Half Beamlet for a 3-grid Accelerator System ${ }^{[1]}$................ 6

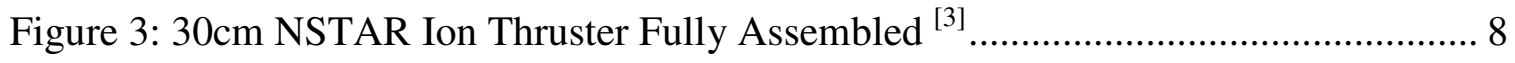

Figure 4: Representation of TPF-EMMA while in Formation Flight ${ }^{[7]}{ }^{[. \ldots \ldots \ldots \ldots \ldots \ldots \ldots \ldots . . . . . . . . . . . .10}$

Figure 5: Representation of GRACE Follow-On while in Formation Flight ${ }^{[4]}$.............. 11

Figure 6: Representation of a 3U CubeSat designed for a Lunar Mission ${ }^{[10]}$.................. 12

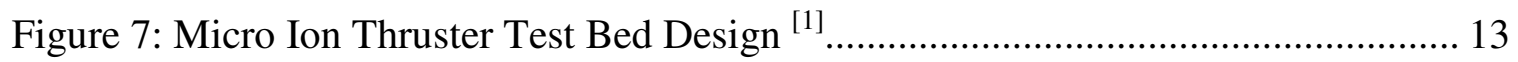

Figure 8: Miniature Xenon Ion Thruster Assembled Configuration ${ }^{[1]}$............................ 14

Figure 9: MiXI-CP-V1 fully assembled in its test configuration ${ }^{[5]}$................................ 16

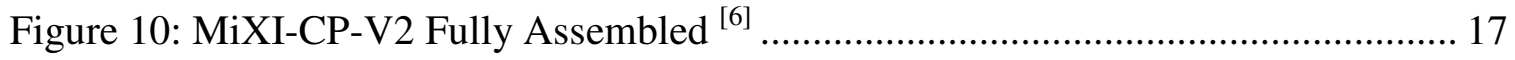

Figure 11: Primary Electron Collision Probability Comparison for MiXI and

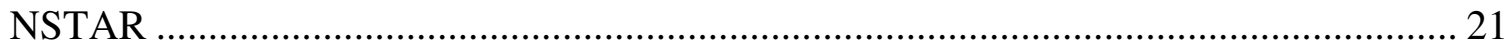

Figure 12: MiXI-CP-V3 Plasma Potential vs. Magnetic Field Strength ......................... 24

Figure 13: Comparison of Different SmCo Magnet Sizes for Magnetic Strength

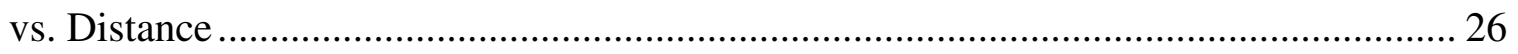

Figure 14: 1mmx3mm SmCo Magnet selected for MiXI-CP-V3 .................................. 29

Figure 15: Diagram of the Magnetic Ring locations around the Anode (Not to

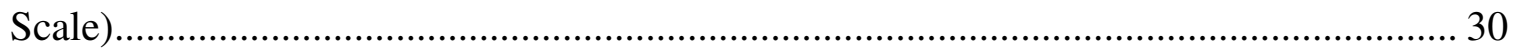

Figure 16: Resulting Magnetic Field Lines and Magnetic Field Directions for the MiXI-CP-V3 3-ring Cusp Magnetic Configuration.................................................... 31

Figure 17: Hollow Cathode Cross Section Excluding the Keeper Electrode ${ }^{[2]}$............... 35 
Figure 18: Comparison of Electron Emission Currents and Temperature for

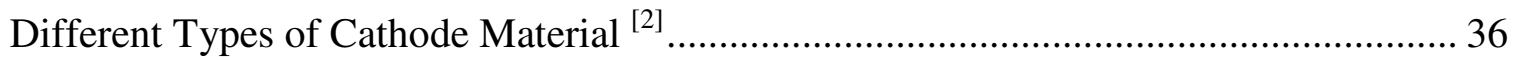

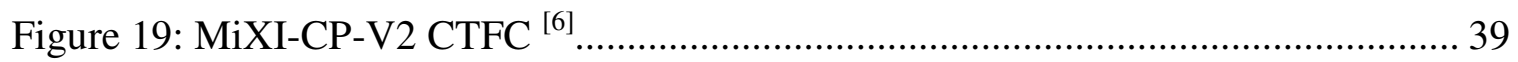

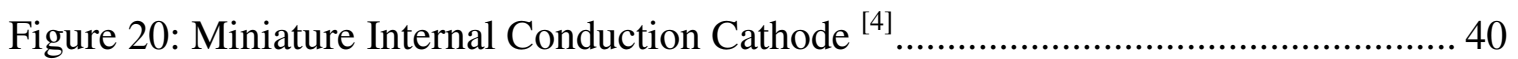

Figure 21: Picture of $6.25 \mathrm{~mm}$ (1/4 inch) Hollow Cathode during Stand-Alone Testing (Left) and Outside the Vacuum Chamber with Penney for Size Reference (Right)

Figure 22: Magnetic Field Strength Axially Through MiXI-CP-V3

Figure 23: Solid Model Cross Section of MiXI-CP-V3 with all Components Labeled 45

Figure 24: MiXI-CP-V3 Anode Solid Model 46

Figure 25: MiXI-CP-V3 Anode Pole Piece and Cap Piece from Left to Right Respectively 48

Figure 26: MiXI-CP-V3 Lower Magnet Mount and Magnet Shield form Left to Right respectively (with false coloring).

Figure 27: MiXI-CP-V3 Grid Isolation Mount with the Eight countersunk grid mount holes clearly visible.

Figure 28: Anode Pole Piece with Fully Assembled Upper and Middle Magnetic Rings

Figure 29: MiXI-CP-V3 Screen Grid and Accel Grid from Left to Right

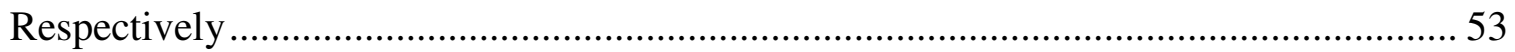

Figure 30: Diagram of the MiXI-CP-V3 Accelerator Grid Spacing .............................. 54 
Figure 31: Fully Assembled MiXI-CP-V3 with two Different Hollow Cathode

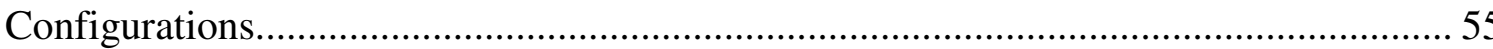

Figure 32: Minimum Atmospheric Experimentation Chamber in the Cal Poly San

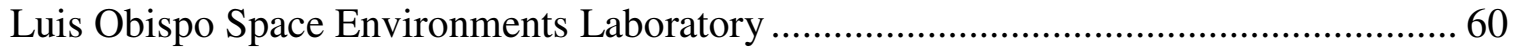

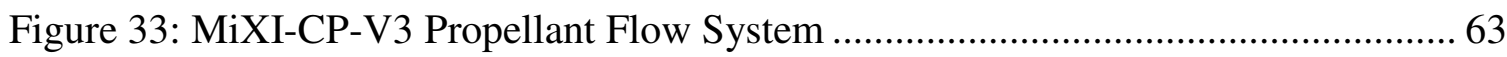

Figure 34: Voltage Potential at Different Components of an Ion Thruster ${ }^{[2]} \ldots \ldots \ldots \ldots \ldots \ldots . . . . . . .65$

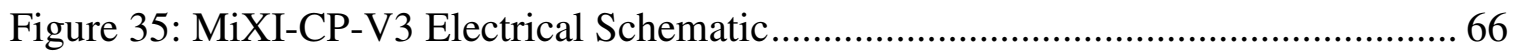

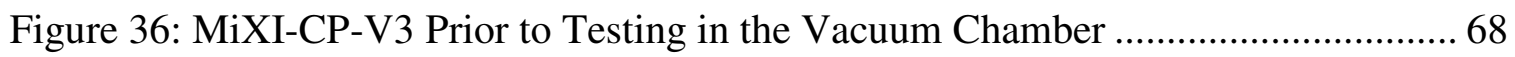

Figure 37: Picture of MiXI-CP-V3 during Testing................................................. 71

Figure 38: MiXI-CP-V3 Mass Utilization Efficiency vs. Discharge Loss ..................... 73

Figure 39: Performance Graph for an Ideal Ion Thruster with a 30cm Plasma

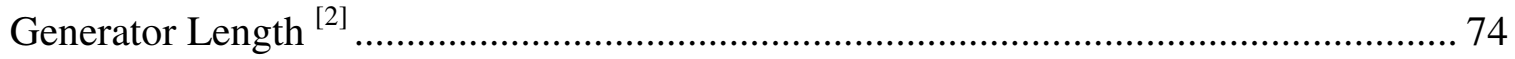

Figure 40: MiXI-CP-V3 Discharge Current vs. Discharge Loss for a Flow Rate of

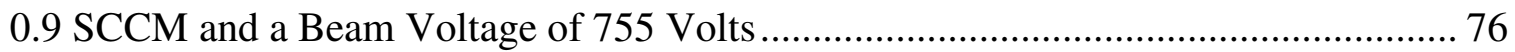

Figure 41: Comparison of Mass Utilization and Discharge Loss vs. Beam Voltage for Varied Discharge Currents at a propellant flow rate of 0.78 SCCM ........................ 77 Figure 42: Mass Utilization Efficiency vs. Discharge Loss for Xenon and Argon in the MiXI-CP-V3 Thruster for a propellant flow rate of 0.9 SCCM 81 


\section{NOMENCLATURE}

\begin{tabular}{|c|c|c|c|c|}
\hline Variable & $=$ & Name & - & Unit \\
\hline$A$ & $=$ & Area & - & $\mathrm{m}^{2}$ \\
\hline$A C$ & $=$ & Alternating Current & _ & $\mathrm{V}$ \\
\hline$B$ & $=$ & Magnetic Field Strength & - & $\mathrm{G}$ \\
\hline$D C$ & $=$ & Direct Current & - & $\mathrm{V}$ \\
\hline$e$ & $=$ & Electron Charge & - & $\mathrm{C}$ \\
\hline$e V$ & $=$ & Electron Volt & - & $\mathrm{eV}$ \\
\hline$f_{c}$ & $=$ & Ion Confinement Factor of Bohm Current Loss & - & N/A \\
\hline$g$ & $=$ & Earth Gravity & - & $\mathrm{m} / \mathrm{s}^{2}$ \\
\hline Isp & $=$ & Specific Impulse & - & seconds \\
\hline$J$ & $=$ & Current & - & Amperes \\
\hline$L$ & $=$ & Liter & - & $\mathrm{L}$ \\
\hline$K$ & $=$ & Kelvin & - & $\mathrm{K}$ \\
\hline$M$ & $=$ & Ion Mass & - & $\mathrm{kg}$ \\
\hline$m$ & $=$ & Meter & - & meters \\
\hline$m_{p}$ & $=$ & Propellant Atomic Mass & - & $\mathrm{Kg}$ \\
\hline$\dot{m}^{\prime}$ & $=$ & Propellant Mass Flow Rate & - & $\mathrm{kg} / \mathrm{sec}$ \\
\hline $\mathrm{n}$ & $=$ & Plasma Density & - & particle $/ \mathrm{m}^{3}$ \\
\hline SCCM & $=$ & Standard Cubic Centimeters per Minute & - & SCCM \\
\hline$T$ & $=$ & Temperature & - & $\mathrm{eV}$ \\
\hline V & $=$ & Voltage & - & Volts \\
\hline$v$ & $=$ & Velocity & - & $\mathrm{m} / \mathrm{s}$ \\
\hline$W$ & $=$ & Watt & - & watts \\
\hline$\eta$ & $=$ & Efficiency & - & percent \\
\hline$\theta$ & $=$ & Beam Half Angle Divergence & - & degrees \\
\hline$\rho$ & $=$ & Propellant Density & - & $\mathrm{g} / \mathrm{cm}^{3}$ \\
\hline$\sigma$ & $=$ & Ionization Cross Section & - & $\mathrm{m}^{2}$ \\
\hline
\end{tabular}

$\begin{array}{lll}\text { Subscript } & \\ a & = & \text { Electron loss } \\ \text { as } & = & \text { Total discharge chamber loss } \\ B & = & \text { Beam } \\ D & = & \text { Discharge } \\ e & = & \text { Electron } \\ E & = & \text { Electrical } \\ i & = & \text { Ion acoustic } \\ p & = & \text { Primary } \\ P & = & \text { Propellant } \\ m & = & \text { Mass Utilization } \\ O & = & \text { Total } \\ s & = & \text { Screen grid loss }\end{array}$




\section{Chapter 1: Introduction}

The need for efficient spacecraft thrusters that delivers a high specific impulse and low thrust has steadily increased over the last 20 years, due to the increased complexity and scope of many satellite missions. Electric propulsion has risen as a prominent class of thrusters to fulfill this roll due to its high specific impulse ( $>1000$ seconds), high efficiency ( $>60 \%)$ and low thrust (0.01-700 milli-Newtons). Specifically, gridded ion thrusters have been gaining acceptance in the space industry due to their commercialization in the mid 1990's for orbit raising and station keeping on high powered communication satellites. Due to the wide range of operating and performance parameters of ion thrusters, they have been used on a variety of missions. The high specific impulse of ion thrusters ( $>3000$ seconds) enables the thruster to be used for orbit raising of large satellites from low earth orbit to a geostationary orbit, with a relatively small amount of fuel comparatively to chemical thrusters that have a specific impulse less than 450 seconds. The high specific impulse also makes ion propulsion an attractive option for interplanetary travel as the primary form of propulsion; however, due to the high power requirement of large ion thrusters, the use of ion thrusters in interplanetary propulsion has remained minimal.

In addition to the previously mentioned uses of ion propulsion, micro ion propulsion (a subset of ion propulsion) has also been gaining interest in recent years because of its thrust range of $0.01 \mathrm{mN}-10 \mathrm{mN}$ while maintaining the high specific

impulse and efficiency ${ }^{[1]}$. The unique performance offered by micro ion propulsion 
enables the thruster to be proposed for high precision attitude control satellite mission such as formation flight and precision maneuvering. However, an efficient micro ion thruster with a thrust of $0.1-1 \mathrm{mN}$ has proven challenging to develop. This has lead to a gap in available micro ion thruster designs capable of this thrust, which currently limits the use of micro ion propulsion in space. Several universities and research laboratories are currently working to fill this technology gap with the goal of creating an efficient thruster with $0.1-1 \mathrm{mN}$ of thrust ${ }^{[1]}$.

\section{1 - Ion Thruster Operation}

Ion thrusters are a type of electric propulsion known as electrostatic propulsion, which utilize electric fields to accelerate charged propellant atoms out of a discharge chamber to create thrust. Ion thrusters achieve this ability specifically through the use of three primary components: the plasma generator, the plasma confinement system, the ion accelerator system ${ }^{[2]}$, and the ion beam neutralization system. A diagram of an ion thruster is shown in Fig. 1.

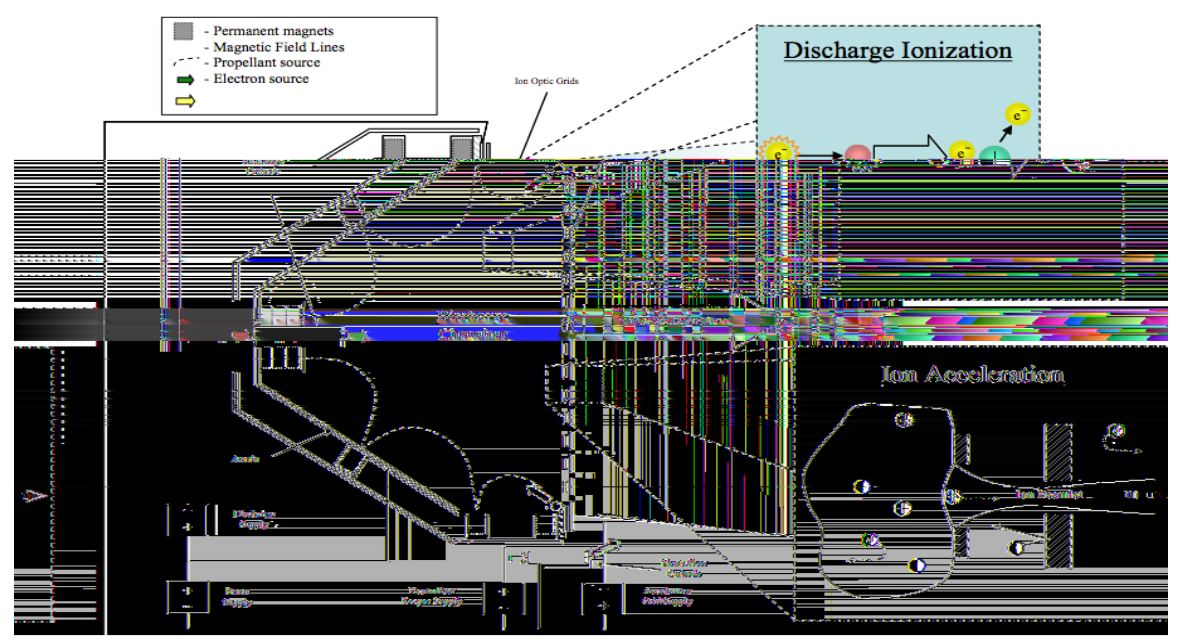

Figure 1: Ion Thruster Operational Diagram ${ }^{[1]}$ 
The plasma generator is responsible for creating the ionized plasma inside of the discharge chamber of the ion thruster. An electron source is used to emit electrons, which collide with incoming neutral propellant atoms and ionize them. Typically, a cathode known as a hollow cathode is used as the electron source to ionize the injected propellant due to its reliability, relatively low work function, and its flight heritage in space. Xenon is also typically used as a neutral propellant due to the large atomic and its low ionization energy, which increase ion thruster performance. In university laboratory settings however, a cathode known as a coiled tungsten filament cathode is sometimes used due to the low cost, simplicity, and ease in fabrication that filament cathodes offer. Argon is also sometimes used as the propellant in laboratory settings due to similar thruster plasma physics using argon and its low cost as compared to xenon. However, use of argon and coiled tungsten filament cathodes lack the performance characteristics of hollow cathodes and xenon, and are often used for proof of concept development as opposed to performance evaluation of a thruster.

Whether xenon or argon is used, the propellant must be $99.9995 \%$ pure, so called 'propulsion-grade' purity, to limit trace gases within the propellant that may damage thruster components ${ }^{[2]}$. Impure propellant gases can diminish thrust efficiency and can cause instabilities within the plasma by damaging the cathode and coating the inner surface of the discharge chamber with contamination.

The cathode itself, regardless of whether a hollow cathode or coiled tungsten filament cathode is used, is one of the most important parts of an ion thruster. The 
emitted electrons from the cathode, commonly known as primary electrons, collide with the incoming neutral propellant atoms with enough energy that a valance electron is knocked off of the propellants outer electron shell, thus ionizing the propellant ${ }^{[2]}$. The electrons that are knocked off of the propellant atoms, commonly known as secondary electrons, subsequently collide with separate neutral propellant atoms and cause further ionization.

Plasma confinement in an ion thruster is achieved through the use of magnetic fields produced by magnets placed on the outside of the discharge chamber containing the plasma. The strength of the magnets is designed to easily confine the plasma electrons within the chamber, while also allowing the plasma ions to easily be accelerated out of the thruster. The exact design and placement of magnets around the discharge chamber has varied over the years, but it commonly takes the form of individual rings of magnets for optimal confinement ${ }^{[2]}$. The number of rings and number of magnets in those rings depend on the plasma conditions inside the discharge chamber and the discharge chamber geometry. The section of the discharge chamber wall immediately above the magnetic rings is known as the magnetic cusp. It is the location where the magnetic field lines emitted from the magnetic rings come into contact with the plasma. The magnetic cusp is designed to ensure high energy primary electrons within the plasma are not immediately lost to the discharge chamber wall and be reflected back into the chamber. This causes the primary electrons to be confined in the discharge chamber, which helps to stabilize the plasma ${ }^{[2]}$. However, the magnetic field strength further inside the discharge chamber must drop off sufficiently to allow plasma to not become over confined, which can lead 
to deterioration of the accelerator grids and plasma instabilities ${ }^{[1,2]}$. The exact magnetic field strength at the cusp and inside the discharge chamber is determined during the thruster design phase and becomes a permanent aspect of the thrusters' functional design.

The ion accelerator system for a gridded ion thruster is designed to create the electric field within the discharge chamber, which creates the acceleration of the ions out of the thruster. The accelerator grids are also commonly known as the ion optics of an ion thruster, because they define the acceleration, shape, and behavior of the accelerating ion beam $^{[1,2]}$. The grids are made out of an electrically conductive material, commonly carbon composite or molybdenum in flight ion thrusters, to attract the contained plasma ions. Ion thrusters contain two to three accelerator grids with small, aligned aperture holes to allow for the ions to pass through the grids after being accelerated. The grids are commonly known as the screen grid, accel grid, and, if 3 grids are present, the decel grid from upstream to downstream in the ion flow respectively.

The screen grid is either electrically 'floated' from the system, meaning that it is not electrically connected to any thruster components, or more commonly, biased to the cathode potential of the plasma generator in an attempt to provide additional electron confinement $^{[2]}$. The screen grid is used to shield the accel grid from ions that are off axis from the grid aperture hole direction. Off axis ions would normally impact the accel grid and form pits and grooves in the grid, which limits the lifespan of the ion thruster as the accel grid erodes. The aperture holes in the screen grid are designed to be as large as possible to allow for maximum ion current to reach the accel grid ${ }^{[2]}$. 
The accel grid is electrically biased to a negative voltage as compared to the common ground of the thruster (sometimes called the neutralizer or spacecraft ground), and is responsible for the acceleration of the plasma ions. The electric field between the positively charged plasma within the discharge chamber and the negatively charged accel grid, cause the positively charged ions to accelerate towards the accel grid and escape through the aperture holes in the grid, which creates thrust per Newton's Second Law. The accel aperture holes, unlike the screen grid, are designed to be as small as possible to retain unionized propellant atoms and prevent neutral propellant loss through the grids ${ }^{[2]}$.

The decel grid is designed to shield the accel grid from ions that may back stream from the expelled ion plume, which, like the off-axis ions that the screen grid prevents, can cause pitting and erosion of the accel grid and limit the thrusters life ${ }^{[2]}$. The decel grid helps to extend the lifespan of the thruster more so than a 2-grid system, however, the added complexity of a 3-grid system can offset the benefit of the added decel grid and longer lifespan. A figure of the projected ion trajectories through a 3-grid ion optics assembly in a half beamlet is shown in Fig. 2 to demonstrate the relative grid spacing and aperture hole diameter of each grid.

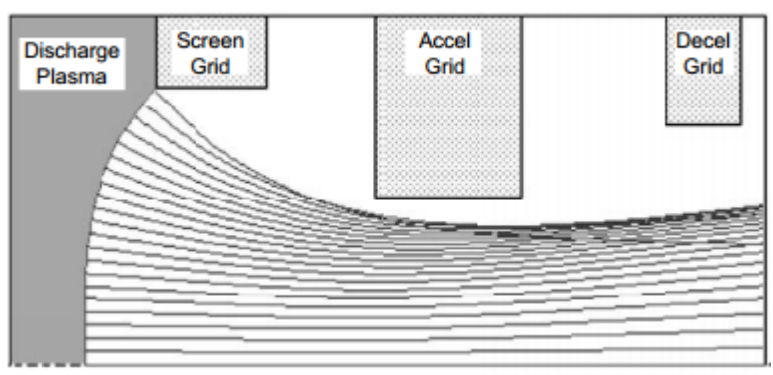

Figure 2: Ion Trajectories in Half Beamlet for a 3-grid Accelerator System ${ }^{[1]}$ 
The ion trajectories through the accelerator grid assembly are high dependent on the grid aperture size, grid spacing, and the plasma parameters of the incoming ions. If the grids are spaced too far apart, then some of the ion current may be lost in the space between the grids, and can also possibly increase the rate of erosion of the grids due to ion collisions; where as if the grids are spaced too close together, electrical breakdown between the grids may interrupt the electric field within the discharge chamber.

Once the ion beam has exited the accelerator grid assembly, the ion beam requires neutralization to avoid dramatic beam expansion, which severely impacts thrust and causes spacecraft contamination and charging from the ejected plume ${ }^{[2]}$. A neutralizer cathode is used downstream of the ejected ion beam to neutralize it by inserting electrons into the ion beam, thus causing the ions to become neutral once again. It is common in flight ion thrusters to use a hollow cathode for this process for similar reasons as to why a hollow cathode is used in the plasma generator. The NASA Solar Electric Propulsion Technology Application Readiness (NSTAR) 30cm diameter ion thruster is shown in Fig. 3 with its accelerator grids and neutralizer cathode clearly visible for size reference. 


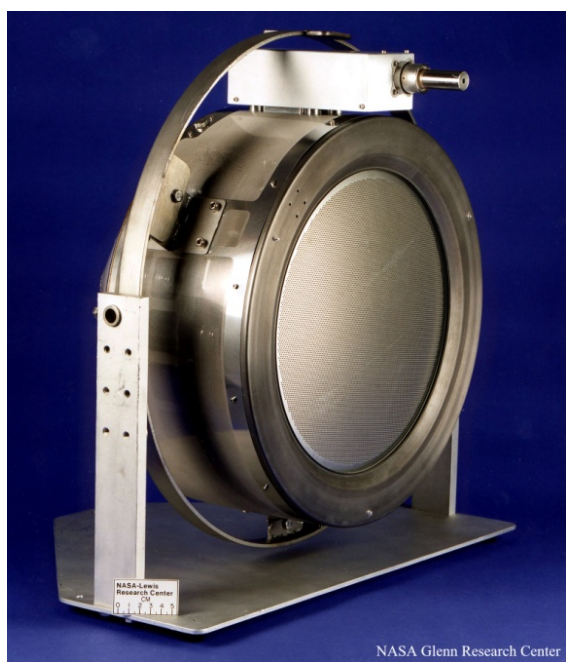

Figure 3: 30cm NSTAR Ion Thruster Fully Assembled ${ }^{[3]}$

\section{2 - Micro Ion Propulsion}

While larger and more powerful ion and hall thrusters ( $>50 \mathrm{mN}$ of thrust) are used for satellite orbit raising and primary satellite propulsion, smaller EP thrusters $(<50 \mathrm{mN}$ of thrust) are tasked primarily for attitude adjustment and control. Micro EP propulsion is a subset of small EP thrusters used for applications requiring $<1 \mathrm{mN}$ of thrust with a high Isp and efficiency. An EP thruster of this class has proved elusive to efficiently implement over the last few decades.

\subsection{1 - The Miniature Ion Xenon Thruster}

In 2001, Dr. Richard Wirz began working on a micro ion thruster called the Miniature Xenon Ion thruster (MiXI) at the Jet Propulsion Laboratory (JPL) while completing his master's degree at the California Institute of Technology (Cal Tech) and made a great deal of advancements to the initial design ${ }^{[1]}$. Dr. Wirz began development 
of the thruster with the goal of creating an ion thruster that is capable of filling the technology gap in micro ion propulsion. The MiXI thruster is designed to deliver a thrust of $0.1-1.5 \mathrm{mN}$ with an efficiency $>50 \%$ and an Isp of 3000 seconds ${ }^{[1]}$. MiXI is designed to utilize xenon at flow rates $<1$ SCCM as a propellant due to its flight heritage and high performance characteristics. The thruster was also designed to require a low amount of power $(\sim 50 \mathrm{~W})$ for its operation in an attempt to expand is potential use on satellite missions ${ }^{[1,4]}$. For example, larger ion thrusters commonly require over $1000 \mathrm{~W}$ of power during operation, and thus, are limited to large satellites that are capable of producing the required power. MiXI's unique operating parameters and abilities make it an attractive option for precise orbit control and formation flight of medium satellites (100-1000kg), as well as its possible use as a primary propulsion thruster on microsatellite and picosatellite missions ${ }^{[1,4,5]}$.

Due to MiXIs' small size, specific improvements in thermal heat management, magnetic plasma confinement, ion optics, and plasma generation are still being pursued by Dr. Wirz through the Wirz Research Group at UCLA, as well as research collaborations with several universities ${ }^{[1,4,5,6]}$.

\subsection{2 - MiXI Mission Candidates}

Several proposed satellite missions have expressed interest in the implementation and use of MiXI as a form of micro propulsion while on orbit. Many of the performance characteristics of MiXI lead its logical use for fine attitude adjustments required by currently proposed missions, as well as use in satellite formation flying. 


\subsubsection{1 - TPF-Emma}

The Terrestrial Planet Finder (TPF) is a space interferometer mission concept that is currently being analyzed by NASA. TPF would study many aspects of extra solar planets from chemical makeup and formation processes to their ability to sustain life. The Emma design of TPF has five spacecraft flying in close formation. While in formation, four of the five satellites are telescope satellites space up to $1200 \mathrm{~m}$ away from a central combiner satellite ${ }^{[7]}$. The formation flight configuration of TPF-EMMA is shown in Fig. 4.

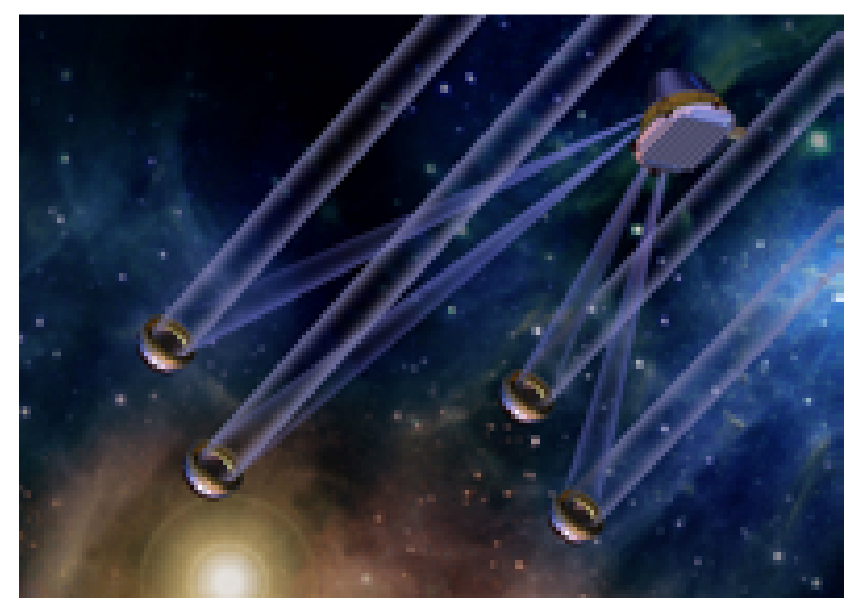

Figure 4: Representation of TPF-EMMA while in Formation Flight ${ }^{[7]}$

These spacecraft must maintain one-centimeter accuracy in their formation flight configuration in order to achieve the proper performance of the TPF array. An analysis was conducted on the propulsion system of TPF-Emma and it was deemed that thrusters with an Isp of 1200-3000 seconds would be required for fine attitude control while in formation to keep propellant mass low ${ }^{[7]}$. Due to the small size of the satellites and close proximity to one another, thruster plume contamination was a chief concern. Further 
analysis and research lead to the proposition to use several thruster pods containing four MiXI thrusters each, to achieve the necessary attitude adjustment capability required by TPF-Emma ${ }^{[1,7]}$.

\subsubsection{2 - GRACE Follow On}

The Gravity Recovery and Control Experiment (GRACE) is a satellite formation consisting of two satellites that are capable of taking detailed measurements of Earth's gravity in order to make a more detailed model of Earth's gravitational field ${ }^{[8]}$. In a current configuration being considered for the mission, the two spacecraft fly in close proximity to one another and are allowed to drift naturally within their orbit as pictured in Fig. 5. Their position is measured by GPS and the drift between the spacecraft is then used to determine changes in Earth's gravitational field. MiXI is proposed as a means of counteracting the atmospheric drag during orbit operations due to its low thrust and low propellant mass flow rate ${ }^{[8]}$.

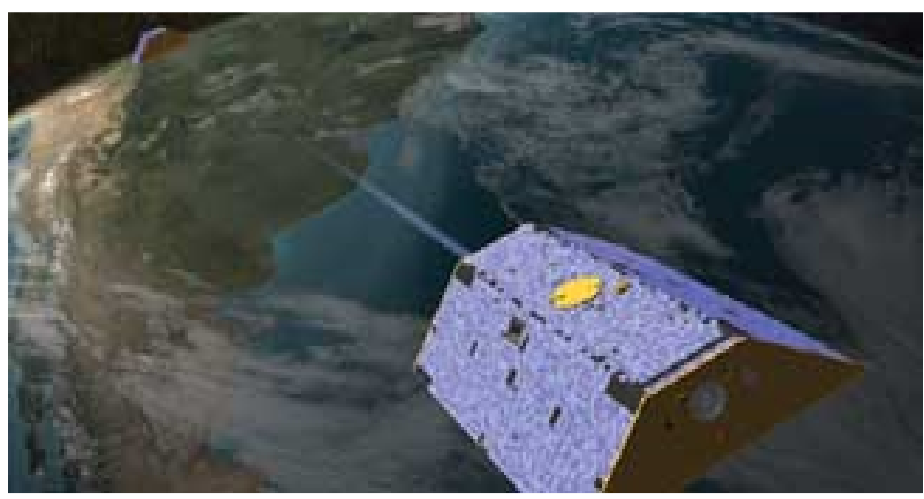

Figure 5: Representation of GRACE Follow-On while in Formation Flight ${ }^{[4]}$ 


\subsubsection{3 - CubeSat}

CubeSat has become the picosatellite standard for low cost, fast access to space for technology development and testing. A standard CubeSat is a cube, $10 \mathrm{~cm}$ on a side with a weight no larger than $1 \mathrm{~kg}{ }^{[9]}$. CubeSats ride as a secondary payload aboard larger satellite launches and are inserted into an orbit similar to the primary payload orbit through use of a Poly Picosatellite Orbital Deployer (P-POD) ${ }^{[9]}$. The faces of a CubeSat are typically covered with solar cells on all sides (except if a side is required for an experiment) because CubeSats do not have a system for attitude control or propulsion. Also a single CubeSat does not produce enough power to operate a MiXI thruster. However, a $3 \mathrm{U}$ CubeSat, which is essentially a combination of 3 CubeSat frames, is capable of producing 50-60W with deployable solar panels, which is more than the $43 \mathrm{~W}$ required by the current MiXI design to operate ${ }^{[1,10]}$. Future CubeSat developers may wish to use MiXI as a way of providing attitude adjustments and propulsion while on orbit in a 3U CubeSat. A representation of a $3 \mathrm{U}$ CubeSat designed for a lunar mission with deployed solar panels is shown in Fig. 6.

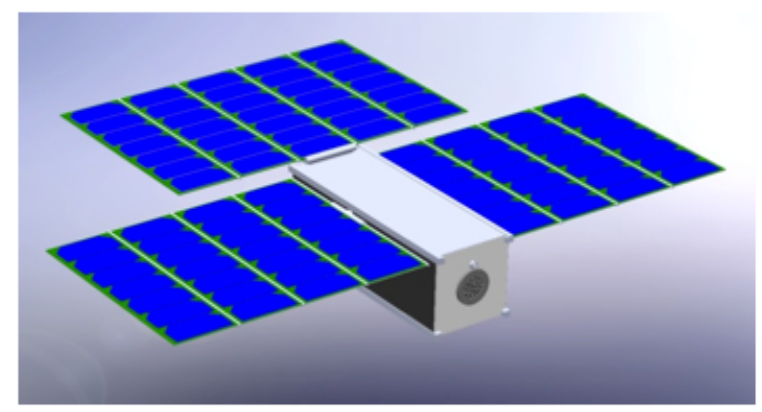

Figure 6: Representation of a 3U CubeSat designed for a Lunar Mission ${ }^{\text {[10] }}$ 


\subsection{3 - MiXI Thruster Variations}

Since its creation in 2001 under the guidance of Dr. Wirz, the MiXI thruster has undergone several design variations in an attempt to optimize different performance parameters and gain a deeper understanding of its operational performance ${ }^{[1,4,5,6]}$.

\subsubsection{1 - The Micro Ion Thruster}

The micro ion thruster was the first $3 \mathrm{~cm}$ ion thruster in the MiXI series worked on by Dr. Wirz in $2001^{[1]}$. This thruster was used as a test bed model for what would eventually become MiXI, and was the first working version of the thruster in the MiXI series. The thruster tested many of the key operating components of MiXI and lead to many of the initial design improvements for the thruster ${ }^{[1,4]}$. The micro ion thruster is shown in its fully assembled state in Fig. 7.

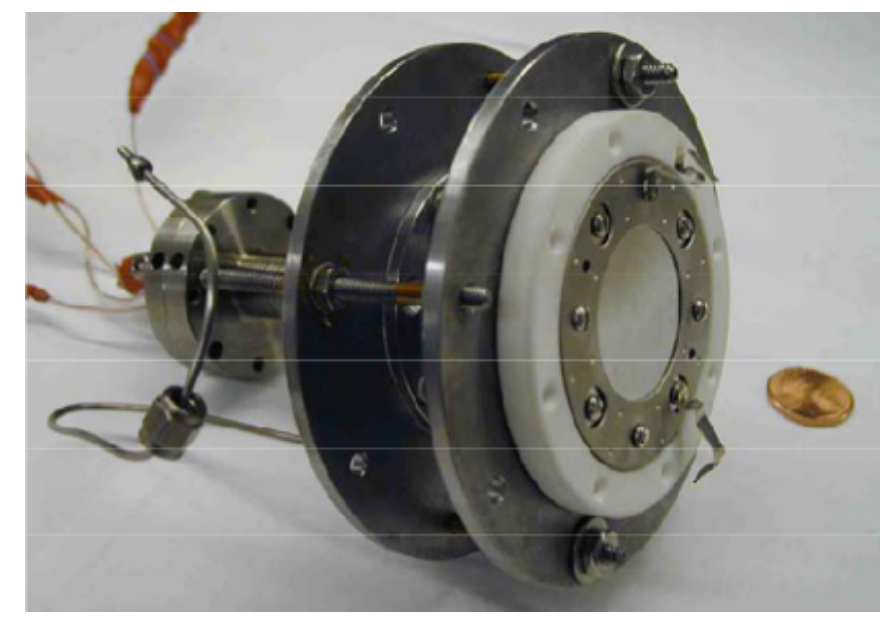

Figure 7: Micro Ion Thruster Test Bed Design ${ }^{[1]}$ 


\subsubsection{2 - Miniature Xenon Ion Thruster (MiXI)}

The initial design and fabrication of the $3 \mathrm{~cm}$ Miniature Xenon Ion (MiXI) thruster represented a huge leap forward in the development of an ion thruster of this size and operating capabilities. MiXI incorporated many of the design improvements and insights gained from the micro ion thruster including, most notably, an overall minimized design as compared to the largely overbuilt micro ion predecessor ${ }^{[1,4]}$. MiXI also has an anode length over diameter ratio of 1 and a 3 ring magnetic cusp design which was determined to be the optimal configuration through testing done on the micro ion thruster ${ }^{[1]}$. The ion optics was also refined in MiXI after several different accelerator grids combinations and configurations were examined in the test bed design. MiXI was designed to mimic a "flight like" configuration and size, but was still designed to incorporate different cathode and accelerator grid variants to continue thruster design improvements. The fully assembled MiXI thruster design is shown in Fig. 8 with a quarter for size reference.

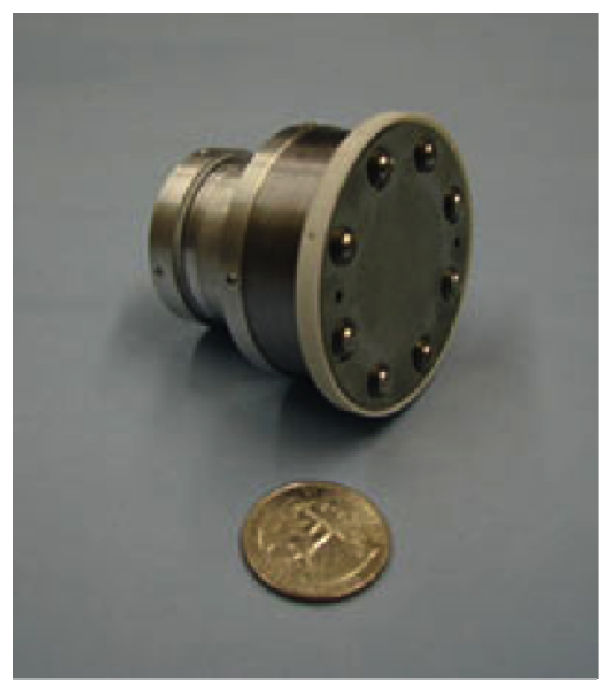

Figure 8: Miniature Xenon Ion Thruster Assembled Configuration ${ }^{[1]}$ 


\subsubsection{3 - MiXI-II}

Caltech began a collaboration with Dr. Wirz on the MiXI thruster design shortly after Dr. Wirz's original testing, which resulted in the fabrication of MiXI-II. The new thruster was built by the Caltech team, and was based off of Dr. Wirz's MiXI design with few design alterations ${ }^{[5]}$. MiXI-II testing took place at JPL and focused on analyzing ion beamlet behavior through the MiXI grids over a wide range of operating parameters in an attempt to optimize the MiXI accelerator grid configuration and operation ${ }^{[5]}$. However, their testing was completed on a very low budget and as a result; they were not able to duplicate many aspects of Dr. Wirz's MiXI design. MiXI-II was unable to produce the magnetic plasma confinement of MiXI, and as a result was not able to produce impressive discharge performance characteristics ${ }^{[5]}$. However, MiXI-II did serve as a valuable grid analysis test bed for the MiXI design, and lead to many improvements in MiXIs' ion optics.

\subsubsection{4 - MiXI-CP-V1}

Coleman Younger began Cal Poly's collaboration with Dr. Wirz on the MiXI Thruster with the assistance of Dr. Dan Goebel of JPL and Dr. Kristina Jameson of Cal Poly in early 2009 as part of his graduate work at Cal Poly San Luis Obispo. Mr. Younger sought to model and verify the thermal performance of MiXI with a coiled tungsten filament cathode as the plasma generator ${ }^{[4]}$. MiXI-CP-V1was designed and manufactured as a thermal test bed for Mr. Younger's thermal model verification and was

modeled after Dr. Wirz's micro ion thruster design. Many components of the current 
MiXI design, such as magnetic confinement and fuel insertion, were omitted due to the focus on thermal testing on the thruster ${ }^{[4]}$. Testing of MiXI-CP-V1 consisted primarily of running the filament cathode inside the discharge chamber and taking thermal measurements on the anode wall, however, no plasma discharge was created inside the thruster. The heating due to plasma and the cathode were calculated and modeled in a software program and the model was validated using the cathode heating data obtained during MiXI-CP-V1 testing ${ }^{[5]}$. The fully assembled MiXI-CP-V1 is shown in Fig. 9.

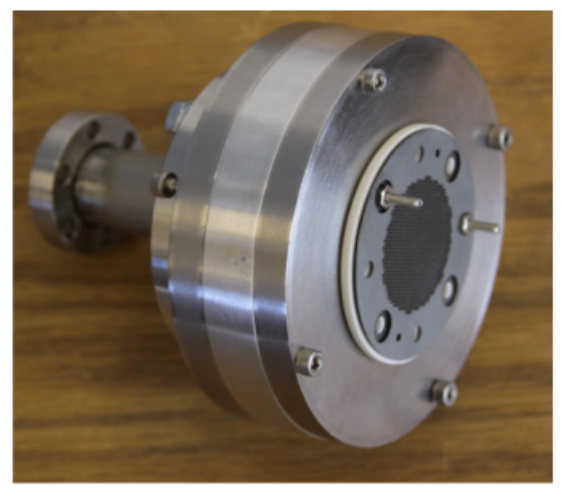

Figure 9: MiXI-CP-V1 fully assembled in its test configuration ${ }^{[5]}$

\subsubsection{5 - MiXI-CP-V2}

Cal Poly's collaboration with Dr. Wirz, Dr. Goebel, and Dr. Jameson on the MiXI design continued with the creation of MiXI-CP-V2 in 2011. This thruster was modeled after Dr. Wirz's MiXI design, and was created to examine the operating parameters of the thruster in Cal Poly's vacuum chamber testing facilities ${ }^{[6]}$. Argon was used in place of xenon as a propellant due to its low cost, and similarly to MiXI-CP-V1, a small coiled tungsten filament cathode was used as the plasma generation source due to its ease of fabrication and low cost. During full thruster operation testing, MiXI-CP-V2 was capable of a thrust of $0.3-1.0 \mathrm{mN}$, an Isp of 2000 seconds, and a mass utilization efficiency of $40 \%$ 
[6]. The low efficiency was largely due to the lack of in depth analysis of several of the key components of MiXI-CP-V2, including the magnetic plasma confinement design and the use of argon as a propellant. Although the thruster was not able to replicate the performance of MiXI, it served as a valuable teaching tool in the development of this thesis. MiXI-CP-V2 is shown in Fig. 10 in its fully assembled state.

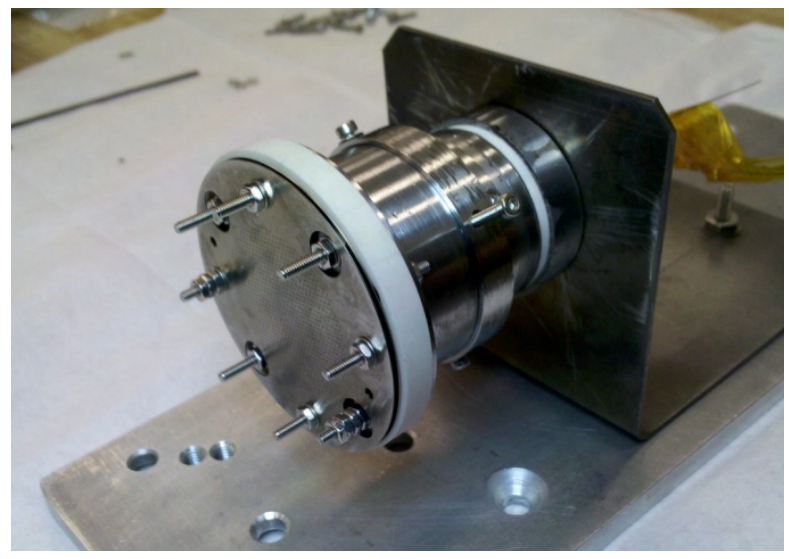

Figure 10: MiXI-CP-V2 Fully Assembled ${ }^{[6]}$

\section{3 - Motivation}

The motivation for writing this thesis is to investigate the implementation of a hollow cathode and small plasma confinement magnets into the MiXI design, and explore the validity of these additions to MiXI. The development and implementation of a flight level cathode into the design of MiXI has remained a challenging problem due to the small size of the discharge chamber of MiXI as well as the low flow rate and plasma current demanded by the small design.

The thruster designed for this thesis is not intended to change the baseline design of MiXI, but investigate the implementation of a hollow cathode and small magnets into the MiXI baseline design. To that effect, this work is designed to gain insight into the 
challenges associated with a miniature ion thruster and explore possible solutions to those issues in the hope of advancing the MiXI design. 


\section{Chapter 2: Magnetic Confinement Design}

The design of the magnetic plasma confinement system is key to the stable operation of an ion thruster. The magnetic fields inside an ion thruster prevent primary electrons from being lost immediately to the anode wall, and reflect them back into the

discharge chamber to continue ionizing neutral propellant atoms ${ }^{[2]}$. The magnetic field also acts as a shaping device for the internal plasma because it dictates where the plasma is allowed to flow and how easily it is allowed to diffuse inside the discharge chamber ${ }^{[2]}$.

The magnetic fields are often constructed with permanent magnets placed around the outside of the anode to create the appropriate magnetic field geometry. It is common to place the magnets in several individual rings around the anode in a configuration know as a ring cusp design ${ }^{[2]}$. The magnetic cusp is defined as the location where the magnetic field enters the discharge chamber and begins to interact with the plasma. The specific number of magnetic rings, and strength of the magnets in those rings, is dependent on the geometry and plasma characteristics of the ion thruster being examined. Dr. Wirz's original work on MiXI revealed that the optimal magnetic configuration for MiXI is a 3-ring cusp configuration, with two magnetic rings around the anode and a third ring around the cathode at the base of the discharge chamber ${ }^{[1]}$.

\section{1 - Magnetic Plasma Confinement}

The strength of the magnetic field required in the discharge chamber is dependent on two primary factors: the primary electron collision probability and the plasma potential. The primary electron collision probability is defined as the probability that a 
primary electron will collide with a neutral particle and not be directly loss to the anode wall ${ }^{[2]}$. To calculate this collision probability, the anode loss area for primary electrons must first be calculated which is expressed as

$$
A_{p}=\frac{2}{B} \sqrt{\frac{2 m v_{p e}}{e}} L_{c}
$$

where $\mathrm{V}_{p e}$ is the voltage through which the primary electron has been accelerated in $\mathrm{J} / \mathrm{C}$, and $\mathrm{Lc}$ is the total magnetic cusp length in $\mathrm{m}^{[2]}$. As can be seen, the primary electron loss area is inversely proportional to the strength of the magnetic field. It should be noted that the magnetic field strength will drop off with the order of $1 / \mathrm{r}^{2}$, with $\mathrm{r}$ being the distance from the magnet. As a result, the primary electron loss area is highly dependent on the placement of the magnets around the anode especially if small magnets are being used. The primary electron collision probability can now be calculated by

$$
P=\left[1-E X P^{-n_{0} \sigma V / A_{P}}\right]
$$

where $\mathrm{V}$ is the volume of the discharge chamber ${ }^{[2]}$. Herein lies one of the main challenges with designing an efficient micro ion thruster. The $3 \mathrm{~cm}$ diameter discharge chamber of the MiXI design leads to a relatively large surface area to volume ratio as compared to larger ion thrusters. This leads to a small volume for the primary electrons to collide and ionize neutral propellant particles before being deflected by the magnetic fields. In order to achieve a high primary electron collision probability in this environment, the magnetic field strength at the cusp must be very large. Due to the small size of MiXI, the magnetic field at the cusp must be much larger than in larger ion 
thrusters to provide similar collision probabilities. A comparison of the magnetic field strength versus collision probability for MiXI in a 3-ring cusp magnetic configuration and the NSTAR thruster with a 4-ring cusp configuration is shown in Fig. 11 where the MiXI data was calculated by the author and the NSTAR data was taken from Dr. Goebels' textbook $^{[2]}$.

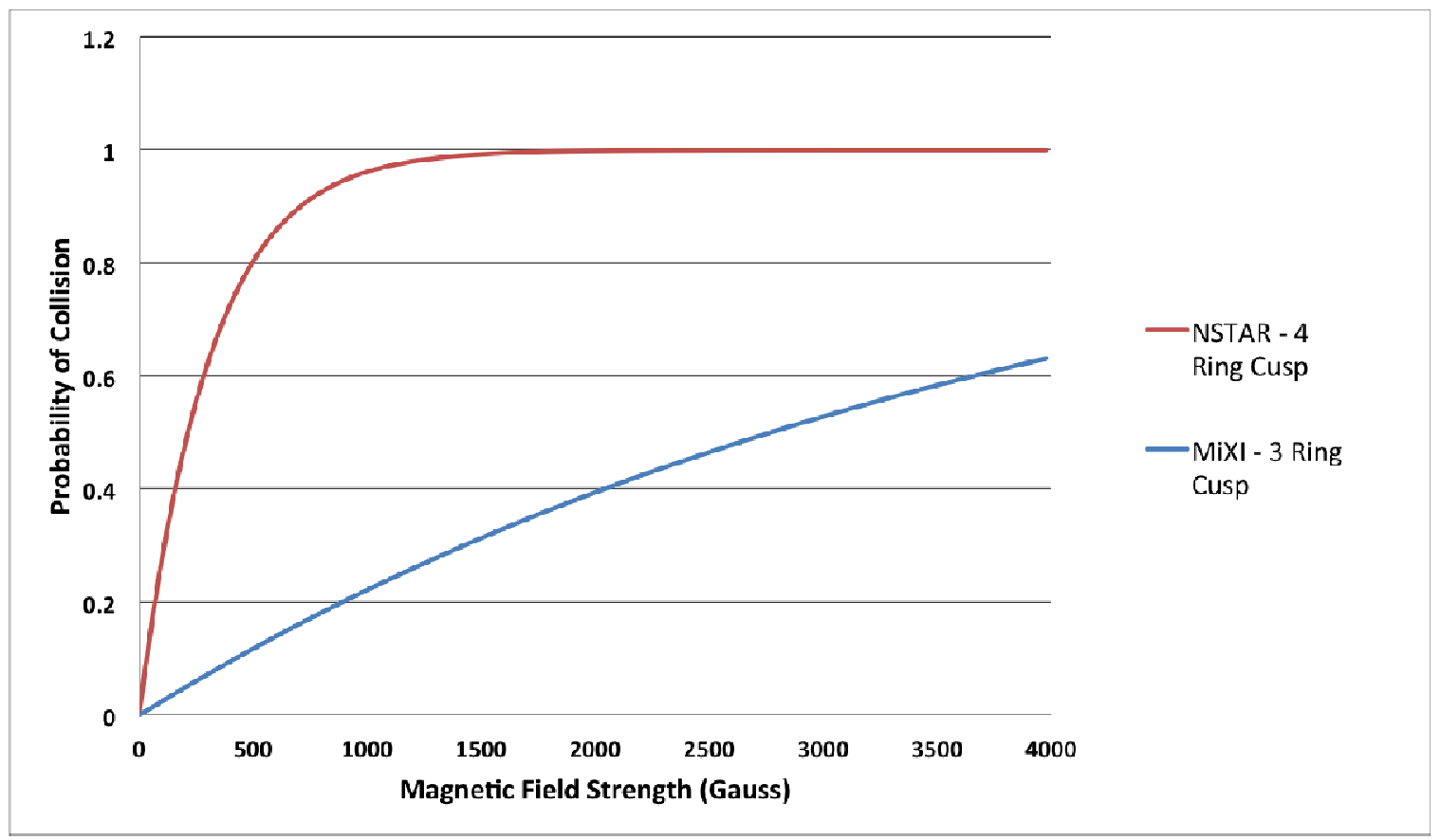

Figure 11: Primary Electron Collision Probability Comparison for MiXI and NSTAR

Figure 11 illustrates the large difference in primary electron collision probability for NSTAR and MiXI. For example, a magnetic field strength of $1500 \mathrm{G}$ causes the NSTAR thruster with a 4-ring cusp configuration to achieve a primary electron collision probability of over $99 \%$, where as the MiXI thruster with a 3-ring cusp configuration has a collision probability of only $32 \%$. The relationship of the number of magnetic cusps to electron probability can also be determined from Eq. 1 where a larger magnetic cusp 
length (i.e. a larger number of magnetic rings) increases the primary electron loss area, and thus decreases the primary electron collision probability in Eq. 2. As a result, MiXI cannot increase its number of magnetic cusps to increase the collision probability, and it also cannot decrease its number of cusps, for even though it would theoretically increase the primary electron collision probability. It was also shown in Dr. Wirzs' MiXI magnetic design that a 3-ring cusp configuration yielded the most efficient design for MiXI. This leads to MiXI requiring as large of a magnetic field strength as possible at its cusps while maintaining a 3-ring cusp configuration, to sustain a high primary electron collision probability. However, a strong magnetic field can lead to an insufficient electron loss from the plasma and cause the plasma to become unstable during operation.

The magnetic field strength at the cusp in an ion thruster not only serves to confine the primary electrons within the discharge chamber, but it also dictates the total electron loss area within the thruster. The electron loss area serves to regulate the plasma potential within the discharge chamber, where the plasma potential is defined as the overall potential voltage of the plasma. As primary electrons are inserted into the discharge chamber via the cathode, and collide with neutral propellant particles, thus resulting in two negatively charged electrons and one positively charged ion. However since the plasma electrons are being lost to the discharge chamber to form the discharge current, the resulting potential voltage of the plasma is dependent on the amount of electrons lost to the anode wall. It has been shown in previous ion thruster and plasma research, that the plasma potential must remain positive to maintain plasma stability ${ }^{[2]}$. The plasma potential can be calculated by 


$$
\phi=\frac{k T_{e}}{e} \ln \left[\frac{\sqrt{\frac{2 M}{\pi m A_{s} T_{s}}}}{\frac{J_{d}}{J_{b}}+\frac{A_{a s} f_{c}}{A_{S} T_{S}}-\frac{2 n_{p} v_{p} A_{p}}{n_{e} v_{a} A_{S} T_{S}}}\right]
$$

where $\mathrm{k}$ is the Boltzmann constant ${ }^{[2]}$. It is clear from inspection of Eq. 3 that as the electron loss area $\left(\mathrm{A}_{a}\right)$ decreases; the plasma potential will also decrease. Since the electron loss area is calculated by

$$
A_{a}=\frac{4}{B} \sqrt{\sqrt{\frac{2 m v_{p e}}{e}} \sqrt{\frac{2 M v_{i}}{e}}} L_{c}
$$

where $\mathrm{V}_{\mathrm{i}}$ is the ion energy; it can be seen that as the magnetic field increases, the electron loss area will decrease. This relationship, although good for primary electron collision probability, will cause the plasma potential to decrease. If the plasma potential decreases to a negative value, an insufficient amount of plasma electrons are being allowed to reach the anode wall. This can lead to instabilities within the plasma that can interrupt or halt plasma formation. So even though the magnetic field needs to be very strong to provide an adequate primary collision probability, it mustn't be too strong to cause the plasma potential to become negative. Using Eq. 3, the magnetic field strength versus plasma potential for MiXI is shown in Fig. 12. As can be seen in Fig. 12, the plasma potential becomes negative at a magnetic field strength of $\sim 3800 \mathrm{G}$, and thus causes the plasma to become unstable. As a result the magnetic field strength at the cusp is limited $3800 \mathrm{G}$ and 
below, resulting in a theoretical maximum primary electron collision probability of $\sim 62 \%$.

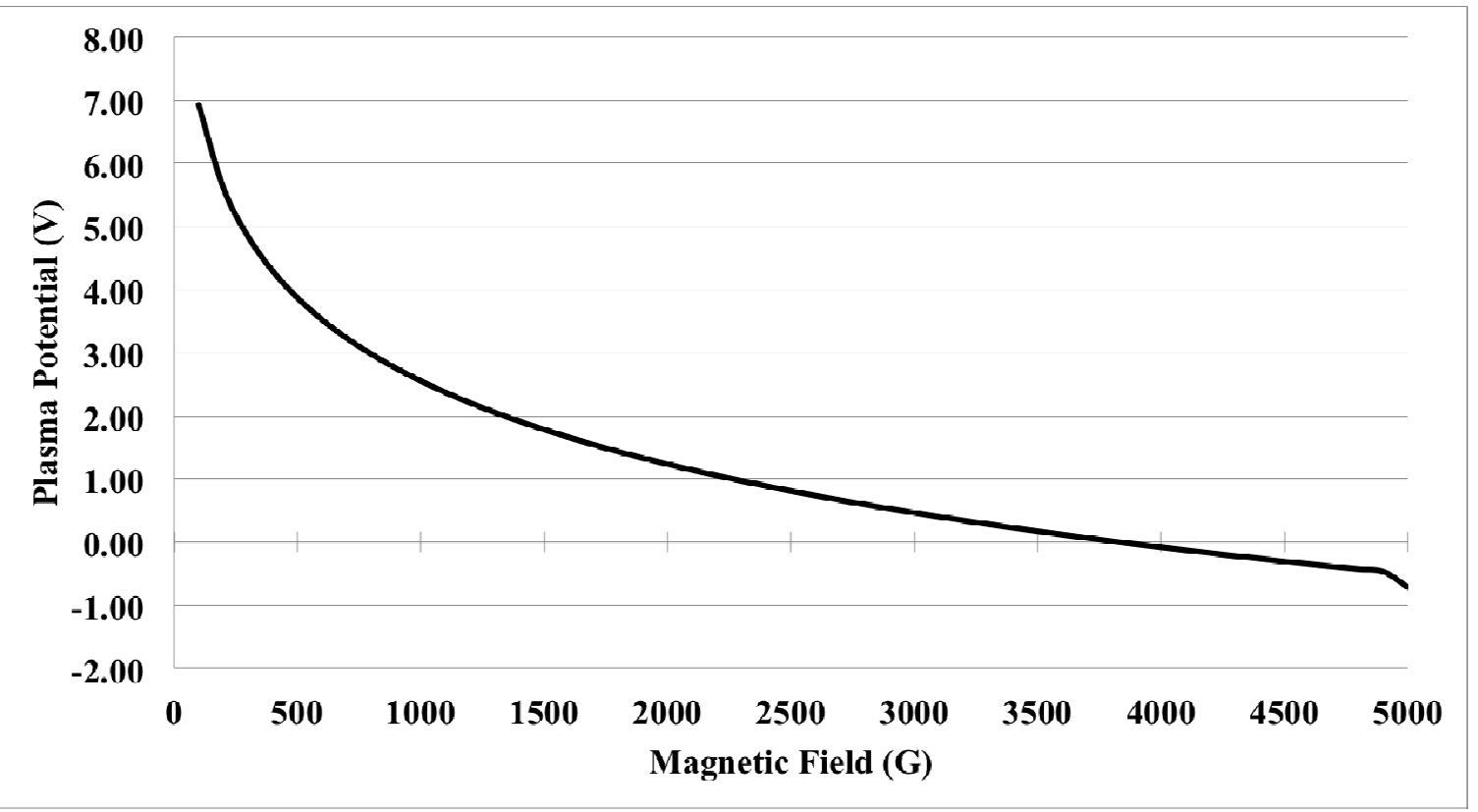

Figure 12: MiXI-CP-V3 Plasma Potential vs. Magnetic Field Strength

This challenge is not as prevalent in larger ion thrusters due to their small surface area to volume ratio and lower magnetic field strength required for optimal primary electron collision probability (as displayed in Fig. 11 for the NSTAR thruster). However, for MiXI, the challenge of balancing the primary electron collision probability and the plasma potential is problematic due to the small size of the discharge chamber. As a result the magnetic field design of MiXI is integral to the thrusters' operational efficiency and performance. 


\section{2 - Magnet Selection and Analysis}

Several different sizes of Samarium Cobalt ( $\mathrm{SmCo}$ ) rare earth magnets were analyzed in the search for an optimal magnet to be used in the MiXI-CP-V3 design. Samarium Cobalt magnets were chosen due to their high operational temperatures of 300$350^{\circ} \mathrm{C}$ before permanent demagnetization occurs ${ }^{[11]}$. Similarly to MiXI-CP-V2, the precursor to MiXI-CP-V3, magnets smaller than $3 / 8$ inch in size were examined for use as plasma confinement magnets due to the expressed interest by Dr. Wirz of using small magnets within the Cal Poly MiXI design. However, only easily available disk and rectangular magnets were included in the design analysis, and a custom magnet size was not pursued due to the funding limitations of the project. Table 2 lists all easily available small magnet sizes considered for this project.

Table 1: List of all Small SmCo Magnets Analyzed for use in MiXI-CP-V3

\begin{tabular}{|c|c|}
\hline & Magnet Size \\
\hline \multirow{9}{*}{ Disk Magnets } & $3 \mathrm{~mm} \times 2 \mathrm{~mm}$ \\
\hline & $2 \mathrm{~mm} \times 2 \mathrm{~mm}$ \\
\hline & $3 \mathrm{~mm} \times 3 \mathrm{~mm}$ \\
\hline & $2 \mathrm{~mm} \times 8 \mathrm{~mm}$ \\
\hline & 0.25 inch $\times 0.1$ inch \\
\hline & 0.25 inch $\times 0.25$ inch \\
\hline & 0.375 inch $\mathrm{x} 0.0625$ in \\
\hline & 0.375 inch $x 0.125$ in \\
\hline & 0.375 inch $x 0.375$ in \\
\hline \multirow{3}{*}{$\begin{array}{c}\text { Rectangular } \\
\text { Magnets }\end{array}$} & $1.4 \mathrm{mmx} 1.4 \mathrm{mmx} 4 \mathrm{~mm}$ \\
\hline & 0.375 inch $x 0.375$ in $x .0625$ \\
\hline & 0.375 inch $x 0.375$ in $x .125$ \\
\hline
\end{tabular}

The disk magnet $1 \mathrm{~mm} \times 3 \mathrm{~mm}$ in size was analyzed as if it was stacked to form a disk magnet $2 \mathrm{~mm} \times 3 \mathrm{~mm}, 3 \mathrm{~mm} \times 3 \mathrm{~mm}$ and $4 \mathrm{~mm} \times 3 \mathrm{~mm}$ in size for a larger variety of 
magnets to analyze. The magnetic strength of each of the magnets versus distance was calculated for disk magnets by

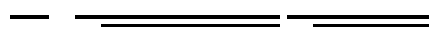

and for rectangular magnets by

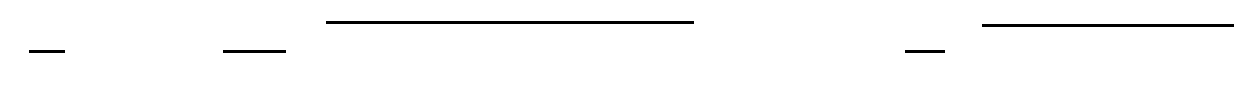

where $\mathrm{B}_{r}$ is the residual induction of the magnet, $\mathrm{d}$ is the distance from the magnet surface, $\mathrm{L}$ is the length of the magnet in the direction of the magnetic field polarization, $\mathrm{r}$ is the radius of the magnet (disk magnets), $\mathrm{t}$ is the thickness of the magnet (rectangular magnets), and $w$ is the width of the magnet (rectangular magnets) ${ }^{[12]}$. Using Eq. 5 and 6 , a comparison of all magnets being examined is shown in Fig.13.

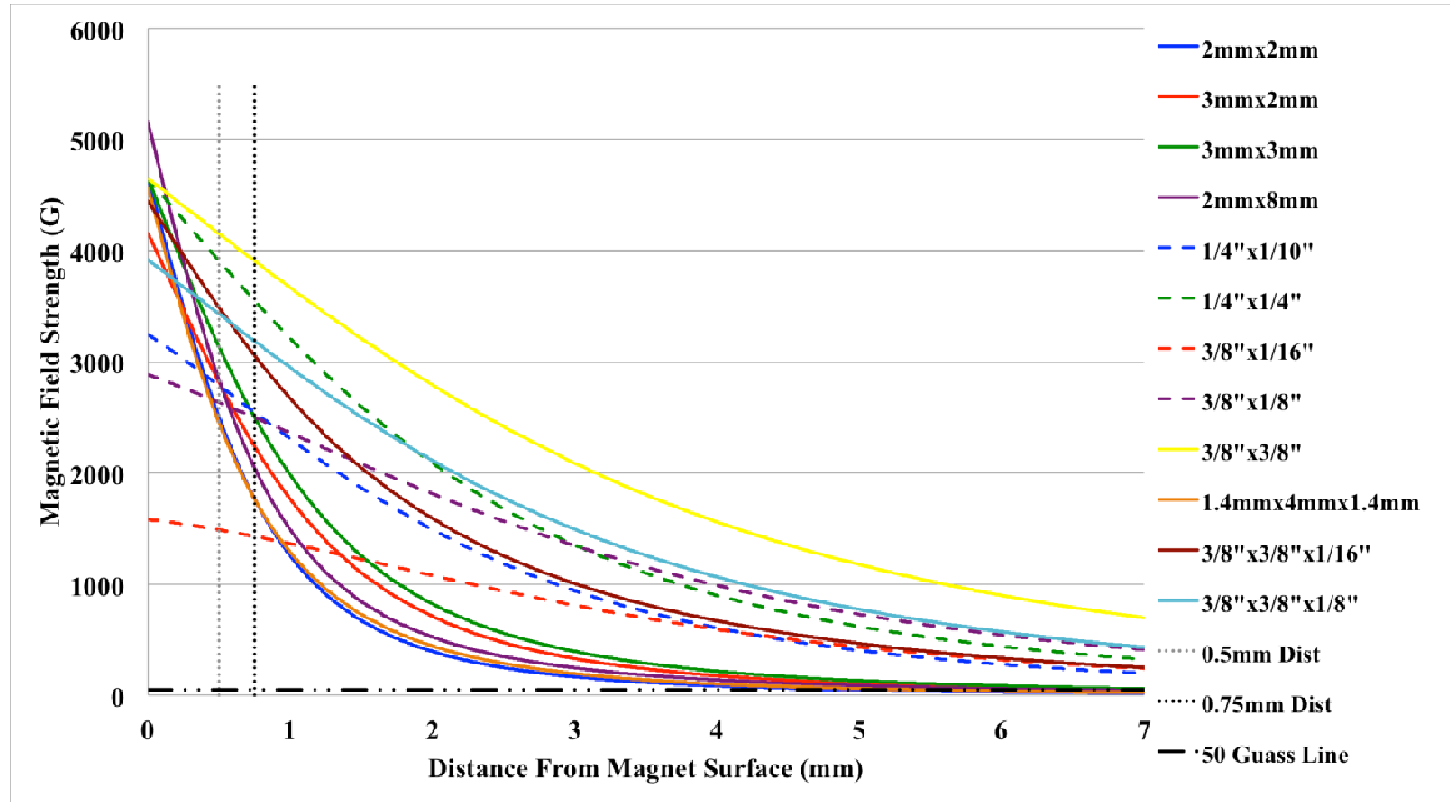

Figure 13: Comparison of Different SmCo Magnet Sizes for Magnetic Strength vs. Distance 
Several interesting observations can be drawn from this initial magnetic analysis. All of the magnets $3 \mathrm{~mm}$ in diameter and smaller, roughly follow the same exponential curve and have a magnetic field strength less than $50 \mathrm{G}$ at6-7mm away from the surfaces. The larger magnets $(\geq 3 \mathrm{~mm}$ in diameter) roughly started with magnetic field strengths similar to the smaller magnets, but maintained a much stronger magnetic field strength as the distance increased from the magnets' surfaces. For simplicity, the magnetic selection analysis will be focused at a point $0.5 \mathrm{~mm}$ from the magnet surface due to $0.5 \mathrm{~mm}$ being the thinnest anode wall thickness easily machinable. This was done in an attempt to increase the field strength at the cusp, and thus maximize the primary collision probability without causing plasma instabilities. Figure 13 showed the magnets have a range of $1500-4200$ gauss at a distance of $0.5 \mathrm{~mm}$, which leads to collision probabilities of $28-61 \%$. However, before a selection can be made, the plasma potential at the varying magnetic field strengths must first be analyzed.

As explained earlier, if the plasma potential becomes negative within the discharge chamber, the plasma will become unstable due to a lack of electron loss to the anode. Using Eq. 3, the plasma potential was found to become negative at a magnetic field strength of $\sim 3800 \mathrm{G}$. This constrains the magnet selection to a magnet that is capable of producing a strong magnetic field for primary electron collision probability, while keeping the magnetic cusp at $0.5 \mathrm{~mm}$ below $3800 \mathrm{G}$. The results of this analysis can be seen in Table 2. 
Table 2: Magnetic Analysis Results for a Variety of SmCo Magnet Sizes

\begin{tabular}{|c|c|c|c|c|}
\hline & Magnet Size & $\begin{array}{l}\text { Magnetic } \\
\text { Strength at } \\
0.5 \mathrm{~mm}(\mathrm{G})\end{array}$ & $\begin{array}{c}\text { Collision } \\
\text { Probability at } \\
0.5 \mathrm{~mm}(\%)\end{array}$ & $\begin{array}{l}\text { Plasma } \\
\text { Potential } \\
\text { (V) }\end{array}$ \\
\hline \multirow{9}{*}{ Disk Magnets } & $3 \mathrm{~mm} \times 2 \mathrm{~mm}$ & 2839.5 & 47.5 & 0.57 \\
\hline & $2 \mathrm{~mm} \times 2 \mathrm{~mm}$ & 2537.3 & 43.8 & 0.78 \\
\hline & $3 \mathrm{~mm} \times 3 \mathrm{~mm}$ & 3162.7 & 51.2 & 0.36 \\
\hline & $2 \mathrm{~mm} \times 8 \mathrm{~mm}$ & 2876.2 & 47.9 & 0.54 \\
\hline & 0.25 inch $\times 0.1$ inch & 2796.9 & 46.9 & 0.6 \\
\hline & 0.25 inch $\times 0.25$ inch & 3923.5 & 58.9 & -0.15 \\
\hline & 0.375 inch $\times 0.0625 \mathrm{in}$ & 1490.3 & 28.7 & 1.79 \\
\hline & 0.375 inch $x$ 0.125in & 2639.9 & 45.1 & 0.71 \\
\hline & 0.375 inch $x 0.375$ in & 4163.6 & 61.1 & -0.31 \\
\hline \multirow{3}{*}{$\begin{array}{l}\text { Rectangular } \\
\text { Magnets }\end{array}$} & $1.4 \mathrm{~mm} \times 1.4 \mathrm{mmx} 4 \mathrm{~mm}$ & 1787.9 & 33.3 & 1.45 \\
\hline & $\begin{array}{c}0.375 \text { inch } \mathrm{x} 0.375 \text { in } \mathrm{x} \\
.0625 \\
\end{array}$ & 3073.4 & 50.2 & 0.42 \\
\hline & $\begin{array}{c}0.375 \text { inch } \mathrm{x} 0.375 \text { in } \mathrm{x} \\
.125\end{array}$ & 3196.1 & 51.6 & 0.32 \\
\hline
\end{tabular}

The magnets highlighted in red are the magnets that would have caused the plasma to become unstable at a distance of $0.5 \mathrm{~mm}$, and thus, were not considered ideal candidates for plasma confinement regardless of their high primary collision probabilities. The magnets highlighted in yellow are magnets that, although fall within promising primary electron collision probabilities and plasma potentials as compared to the other magnets, were not chosen to be used due to the relatively high cost of these magnets as compared to the $3 \mathrm{~mm} \times 3 \mathrm{~mm}$ magnets which displayed similar plasma confinement characteristics.

The $3 \mathrm{mmx} 3 \mathrm{~mm}$ magnets highlighted in green in Table 1, achieved the highest primary electron collision probability while maintaining a positive plasma potential, and a fast drop off of the magnetic field strength farther within the discharge chamber. As a result, the $3 \mathrm{mmx} 3 \mathrm{~mm}$ SmCo Grade-26 magnets were chosen as the optimal small 
magnets to be used in MiXI-CP-V3. A picture of the $1 \mathrm{mmx} 3 \mathrm{~mm}$ SmCo magnets used to form the $3 \mathrm{mmx} 3 \mathrm{~mm}$ magnets is shown in Fig. 14 with a penny for size reference.

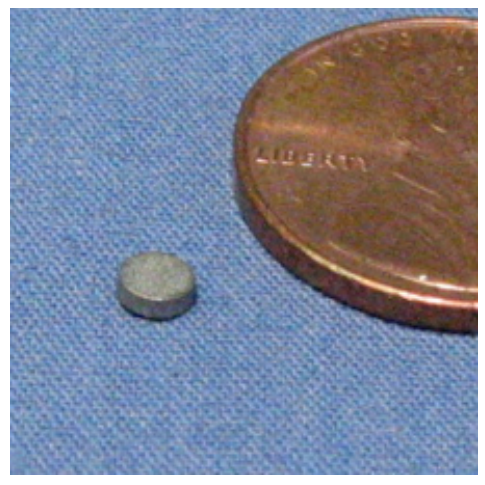

Figure 14: 1mmx3mm SmCo Magnet selected for MiXI-CP-V3

The strength of the transverse magnetic field must also be taken into account for MiXI when selecting the plasma confinement magnets properly. A strong transverse magnetic field deep within the discharge chamber can cause an over confinement of the plasma contained within, and not allow the plasma to diffuse properly throughout the chamber. This can lead to only a fraction of the grid area being utilized for ion acceleration, which, for high plasma densities, can lead to premature erosion of the accelerator grids and a shortened thruster lifespan ${ }^{[2]}$. However, since the transverse magnetic field is calculated by $\mathrm{B}^{*} \mathrm{H}$ where $\mathrm{B}$ is the magnetic induction field and $\mathrm{H}$ is the magnetic field produced by the magnets, the transverse magnetic field will be very small for MiXI-CP-V3 due to the fast drop off of the magnetic field strength of the small magnets, and plasma over confinement will not be an issue. Furthermore, during full magnetic field analysis for an ion thruster, the strength of the transverse magnetic field is also important in maintaining 
plasma stability between magnetic cusps, however, this thesis focused on the axial magnetic field strength to limit the scope of the magnetic analysis.

\section{3 - MiXI-CP-V3 Magnetic Ring Configuration}

Now that the magnets for plasma confinement have been selected, the magnetic configuration for the thruster can be chosen. As stated earlier, Dr. Wirz discovered that a 3-ring cusp configuration is optimal for the magnetic confinement design of MiXI, and thus a similar configuration will be utilized in MiXI-CP-V3 based on Wirz's findings ${ }^{[1]}$. The resulting configuration called for the upper magnetic confinement ring (closest to the accelerator grids) to be positioned $24 \mathrm{~mm}$ axially from the anode base, $0.5 \mathrm{~mm}$ radially from the inner anode wall. The middle magnetic ring will be positioned $17 \mathrm{~mm}$ axially from the anode base, $0.5 \mathrm{~mm}$ radially from the inner anode wall also. The lower magnetic confinement ring around the cathode will be positioned $13.5 \mathrm{~mm}$ radially from the center of the thruster, below the anode. A diagram of the general magnetic ring positions around the anode is shown in red and the polarity direction is depicted with arrows in Fig. 15.

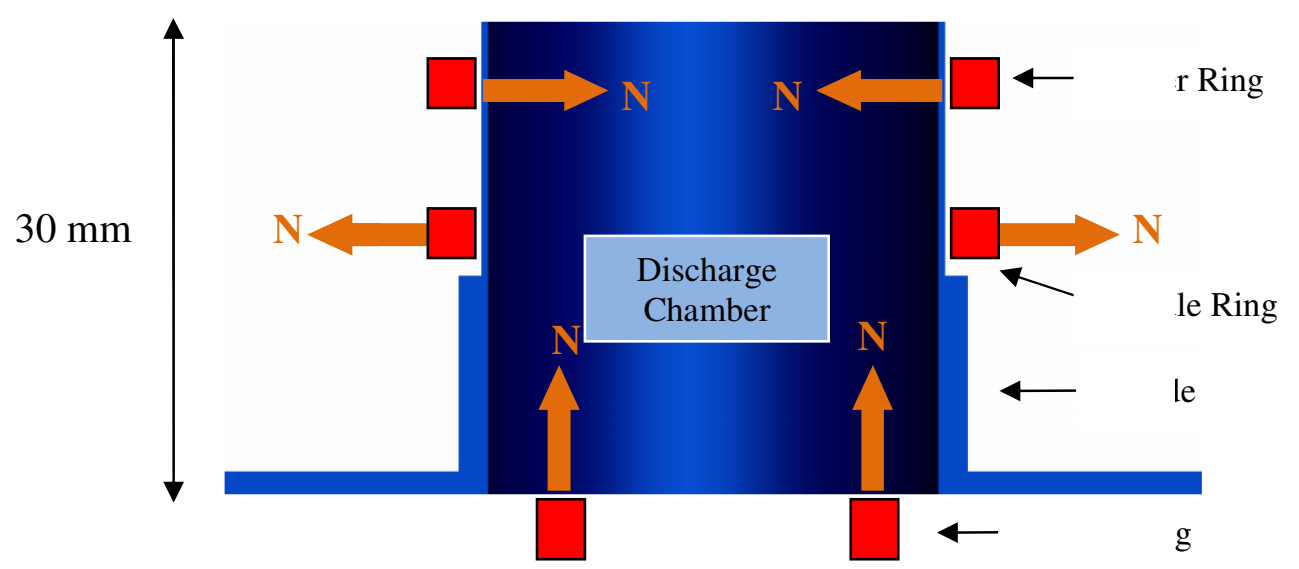

Figure 15: Diagram of the Magnetic Ring locations around the Anode (Not to Scale) 
The configuration also dictates that the upper and lower magnetic rings will have their north polarity facing into the discharge chamber, where as the middle ring will have its north polarity facing away from the discharge chamber. This is done to connect the magnetic field lines of each of the magnetic rings to properly confine the plasma ${ }^{[2]}$. Figure 16 displays the resulting magnetic field lines and directions of the magnetic field within the discharge chamber, and illustrates that the magnetic field lines are connecting properly within the discharge chamber. The axes on Fig. 16 are in units of millimeters.

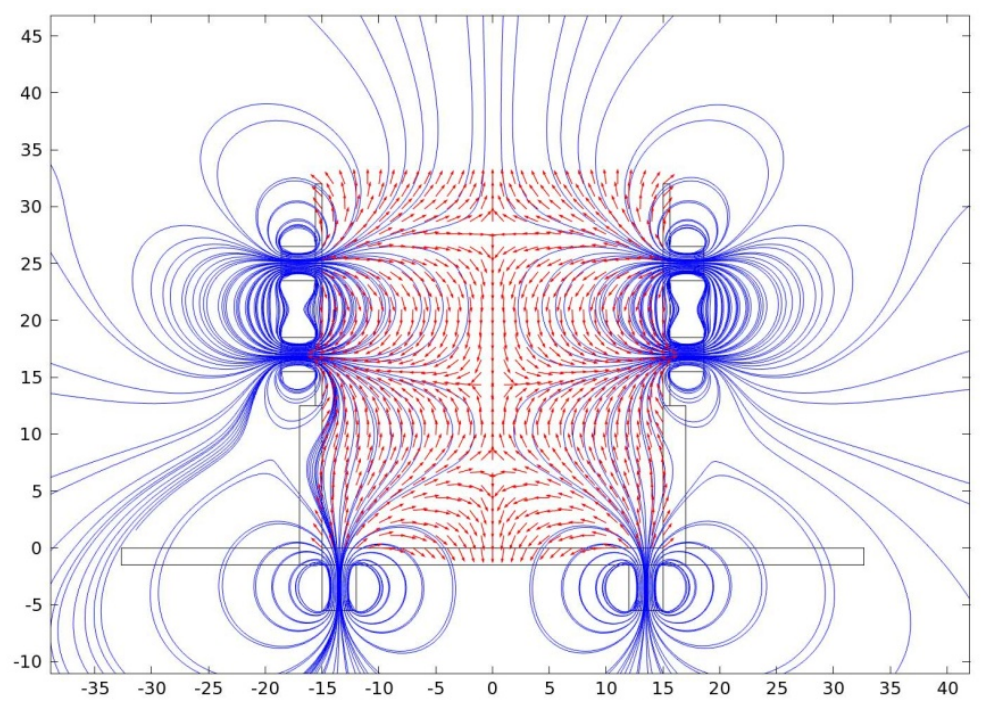

Figure 16: Resulting Magnetic Field Lines and Magnetic Field Directions for the MiXI-CP-V3 3-ring Cusp Magnetic Configuration

To conclude, MiXI-CP-V3 will use 3mmx3mm SmCo magnets to achieve a 52\% primary electron collision probability while maintaining plasma stability with a plasma potential of $0.36 \mathrm{~V}$. The magnets will be arranged in a 3-ring cusp design with the ring positions mimicking the magnetic ring placement of Dr. Wirz's original MiXI design. 


\section{Chapter 3: Hollow Cathode}

The primary component of the plasma generator within an ion thruster is the cathode, which serves as the electron source to ionize the incoming neutral propellant atoms. Several different types of cathodes have been used for plasma generation in ion thrusters, but the most common are coiled tungsten filament cathodes (CTFC), and hollow cathodes.

\section{1 - CTFCs}

The simplest form of a cathode used in ion thrusters is called a coiled tungsten filament cathode (CTFC). It is made from a coiled wire of tungsten and as an electric current is passed through the wire, the tungsten begins to heat. As the tungsten heats up, it begins to emit electrons, but due to the high work function of tungsten $(4.55 \mathrm{eV})$, it must heat to over $2600^{\circ} \mathrm{C}$ to emit electrons at a current greater than $1 \mathrm{~A} / \mathrm{cm}^{2}$, which is required for neutral propellant ionization ${ }^{[1,2,4]}$. CTFC's are commonly used in laboratory settings due to their low cost, ease of fabrication, and scalability. However, due to the high temperatures required for tungsten to become a viable electron emitter, a powerful heater supply is required to heat the filament. This greatly reduces the efficiency of the thruster because a large amount of the power is being lost to heat the filament. The large amount of heat produced by tungsten filament cathodes can also lead to excessive heating of the discharge chamber, and thus the plasma confinement magnets, which can lead to permanent demagnetization of the magnets during operation. 
Once plasma has been created by a CTFC, direct plasma bombardment on the tungsten wire filament causes it to sputter and erode ${ }^{[2]}$. This causes CTFCs to have an extremely limited lifespan. The sputtering and erosion often cause the CTFC to burn out after several hundred hours of operation, or less, depending on the size of the tungsten wire being used and necessary current ${ }^{[2]}$. As a result, CTFCs are not use for long duration space applications.

The purity of the propellant used for ionization can also have a large impact on the lifespan of a CTFC. Relatively low purity propellants, between $97 \%$ and $99.9 \%$, can often lead to surface contamination on the tungsten wire ${ }^{[1,2]}$. The contamination causes the work function to increase for the tungsten, resulting in more power required for the CTFC to emit electrons, and also causes excess sputtering and erosion of the tungsten surface, which further limits the CTFCs lifespan ${ }^{[2]}$.

Thoriated tungsten wire has been proposed as an alternative filament material to conventional tungsten filaments used in CTFCs. Thoriated tungsten wire is made from tungsten infused with $2 \%$ thorium in the manufacturing process ${ }^{[4]}$. The added thorium decreases the work function of the filament, and allows the tungsten to emit electrons at much lower temperatures. Thoriated tungsten filaments have been shown to have an average operational temperature of $1900^{\circ} \mathrm{C}$ as compared to $2600^{\circ} \mathrm{C}$ required by pure tungsten ${ }^{[1,4,13]}$. There are, however, drawbacks to the use of thoriated tungsten filament cathodes. The thorium in the wire must undergo a special activation process before it can be operated as an electron emitter. The activation process involves heating the wire to 
over $2900^{\circ} \mathrm{C}$, then 'baking' it at $2000^{\circ} \mathrm{C}$ for 30 minutes to allow for the thorium to collect at the surface of the tungsten ${ }^{[13]}$. The layer of thorium at the surface allows the filament to be run at lower temperatures while emitting the desired electron current. However, thoriated tungsten filaments still suffer from many of the challenges encountered during CTFC operation, and in many cases, the added activation process negates the benefit of a lower operation temperature.

\section{2 - Hollow Cathodes}

Hollow cathodes were developed in the mid 1960's as a way to counter many of the problems faced when using CTFCs ${ }^{[2]}$. A hollow cathode consists of a refractory tube with a small orifice plate at its end. The tube contains a cylindrical insert, which acts as the electron source, pressed up against the orifice plate. The tube is wrapped in a heater to provide the initial heat required for electron emission ${ }^{[2]}$. Once electron emission and plasma generation is obtained within the hollow cathode, the heater can be turned off because the heat released from the plasma generation will continue to heat the insert on its own. An electrode known as the keeper, commonly encloses the hollow cathode to help initiate the plasma discharge, maintain the cathode temperature, and to protect the orifice plate and heater from ion bombardment during operation ${ }^{[14]}$. The keeper is generally made out of graphite and biased positive to help attract the plasma electrons out of the hollow cathode while deflecting ions within the discharge chamber. A crosssectional diagram a hollow cathode without the keeper electrode is shown in Fig. 17 for reference. 


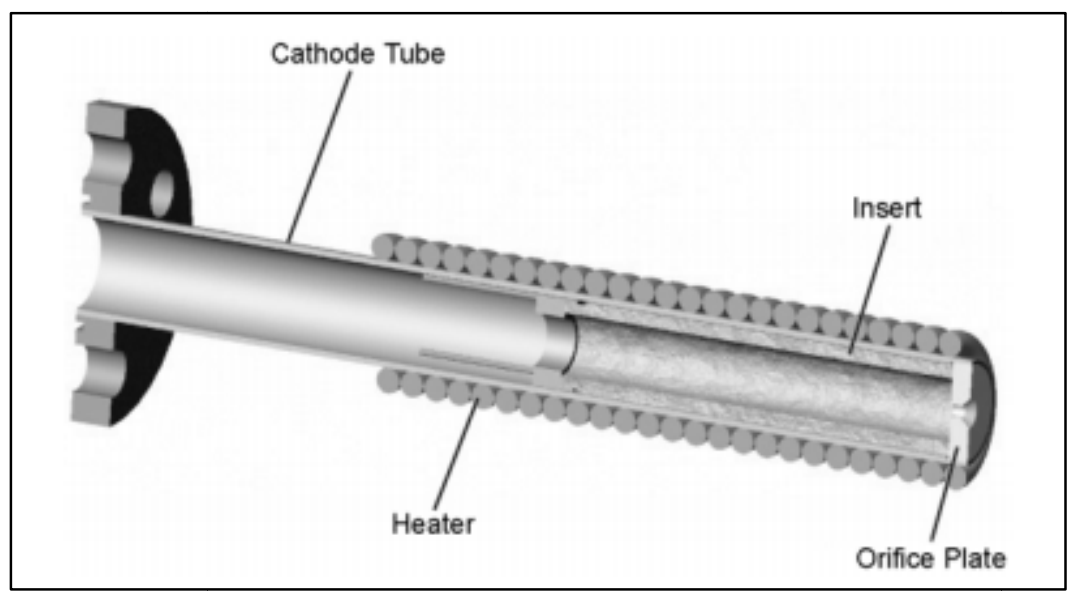

Figure 17: Hollow Cathode Cross Section Excluding the Keeper Electrode ${ }^{[2]}$

The insert can be made out of a variety electron emitting materials, but most commonly, barium oxide with tungsten impregnate $(\mathrm{BaO}-\mathrm{W})$ or lanthanum hexaboride $\left(\mathrm{LaB}_{6}\right)$ is used in modern hollow cathodes ${ }^{[2,4,13,14]}$. The Barium oxide infused with tungsten has a work function of $1.56 \mathrm{eV}$, which is one of the lowest work functions of materials used for hollow cathodes. The low work function allows a temperature of only $1100^{\circ} \mathrm{C}$ to initiate electron emission of over $1 \mathrm{~A} / \mathrm{cm}^{2}{ }^{[2,4]}$. However, $\mathrm{BaO}-\mathrm{W}$ inserts are extremely sensitive to contamination, and can become poisoned quickly if impurities are introduces from the propellant during operation. Cathode insert poisoning alters the chemical makeup of the insert surface, which can greatly increase the work function of the insert and interrupt electron emission ${ }^{[2]}$. Mild cases of poisoning can often be reversed through cathode conditioning (heating the cathode for long periods of time in high vacuum environments to 'cook off' contaminants), however, extreme cases of cathode poisoning can often lead to permanent damage of the insert and required fabrication of an entirely new inserts. Due to $\mathrm{BaO}-\mathrm{W}$ sensitivity to poisoning, many users require 'propulsion grade' propellants with a purity of $99.9995 \%$ to be used during 
operation, which can lead to additional costs during the manufacturing and testing phase of a thruster ${ }^{[2,14]}$.

Lanthanum hexaboride inserts have a work function of $2.67 \mathrm{eV}$, which means that it must be heated to higher temperatures than barium oxide ${ }^{[2,4]}$. To obtain an electron emission greater than $1 \mathrm{~A} / \mathrm{cm}^{2}, \mathrm{LaB} 6$ inserts must be heated to $1300-1500^{\circ} \mathrm{C}$ and as a result, require more powerful heaters and power supplies during plasma initiation. A graph of several different cathodes and their electron emission currents versus temperate is shown in Fig. 18 for reference.

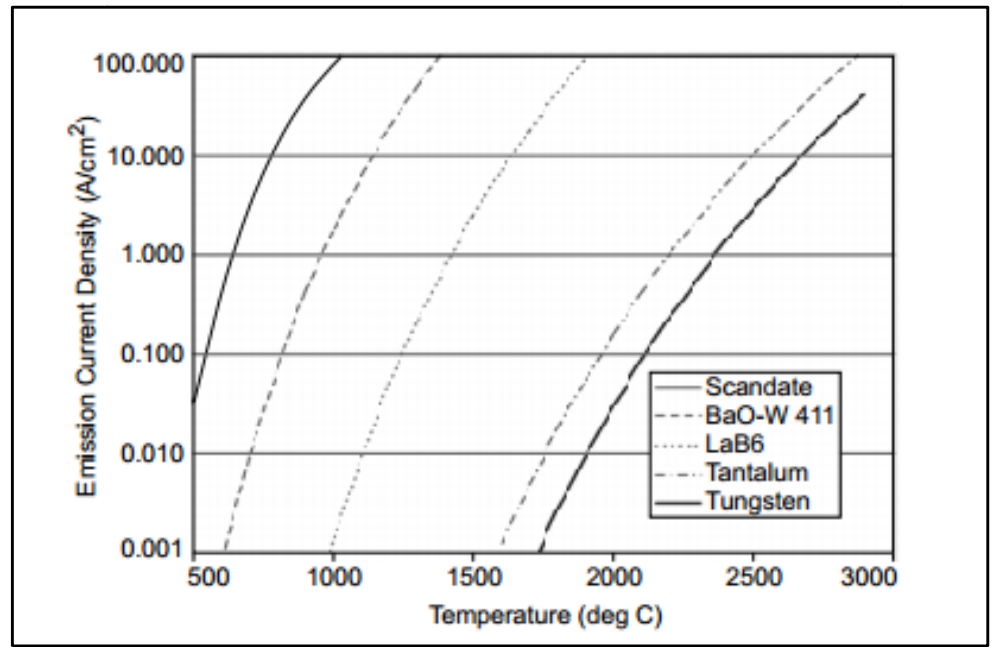

Figure 18: Comparison of Electron Emission Currents and Temperature for Different Types of Cathode Material ${ }^{[2]}$

However, as compared to $\mathrm{BaO}-\mathrm{W} \mathrm{LaB}_{6}$ is much more resilient to propellant impurities and contamination. $\mathrm{LaB}_{6}$ inserts are capable of withstanding propellant impurities two orders of magnitude greater than $\mathrm{BaO}-\mathrm{W}$ at similar electron emission 
currents ${ }^{[2]}$. $\mathrm{LaB}_{6}$ has also been shown to have a lower evaporation rate during operation than $\mathrm{BaO}-\mathrm{W}$, thus giving it a longer life ${ }^{[2]}$.

The propellant flow rate into a hollow cathode is dependent on the plasma discharge current required by the thruster and the size of the insert. If the propellant flow into the hollow cathode is too high, a large fraction of the incoming propellant will not be ionized and will escape into the discharge chamber as unionized neutral particles ${ }^{[1,14]}$. This can lower the thrusters' mass utilization and total efficiency and degrade its performance over time. Alternatively, if the propellant flow rate is too low for the hollow cathode, the plasma being created may become unstable due to an imbalance of electron emission current and neutral propellant flow. This can lead to an interruption of plasma generation due to the lack of heat created from insufficient plasma densities, and may cause plasma creation to cease entirely. Current hollow cathodes often have an operational propellant flow rate between 2 and 10 SCCM for plasma discharge currents of $2-20 \mathrm{~A}^{[1,2,15]}$. For example the $30 \mathrm{~cm}$ NSTAR hollow cathode with a $3.6 \mathrm{~mm}$ insert operated at a discharge current of $13.1 \mathrm{~A}$ at a flow rate of 3.7 SCCM at its highest thrust condition as the $57 \mathrm{~cm}$ NEXIS hollow cathode with a $12.7 \mathrm{~mm}$ insert operated at a plasma discharge current of $25 \mathrm{~A}$ and a flow rate of $5.5 \mathrm{SCCM}^{[2]}$. It should be noted that although the NSTAR and NEXIS ion thruster hollow cathode only operated with a propellant flow rate of 3.7-5.5 SCCM, additional propellant was inserted into the discharge chamber to allow for proper plasma formation within the discharge chamber $[15,16]$. 
Hollow cathodes are commonly classified by the maximum current of plasma that they are capable of creating. As the inner diameter of the refractory tube is increased within a hollow cathode, the insert thickness and inner diameter can also increase, thus allowing a larger area of the insert to be used for electron emission, and larger discharge currents.

\section{3 - Previous MiXI Cathodes}

Flight EP thrusters (ion thrusters included) commonly require the use of hollow cathodes due to the longevity and reliability that hollow cathodes offer, whereas the limited lifespan of CTFCs relegate their use to laboratory settings. However, this presents a problem for small ion thrusters, and thus MiXI. Hollow cathodes often cannot be operated at propellant flow rates lower than 1 SCCM due to plasma instabilities, and MiXI is designed to be operated at propellant flow rates between 0.1 and 0.7 SCCM $^{[1]}$. Conventional hollow cathodes also cannot be easily scaled to the size of MiXI due to problems with cathode fabrication and operation at that scale. Previous variants of MiXI were forced to use CTFC's because of the ease of fabrication on a small scale as well as the ability of CTFCs to operate with low propellant flow rates that ${ }^{[1,4,13]}$. CTFCs fabricated for past MiXI thruster variants have required coiled tungsten filament wire $0.127 \mathrm{~mm}(0.005 \mathrm{inch})$ in diameter in an effort to minimize the size of the cathode inside

of the discharge chamber ${ }^{[1,4,6]}$. A photograph of the CTFC used for MiXI-CP-V2 is shown in Fig. 19 with a penny for size reference. 


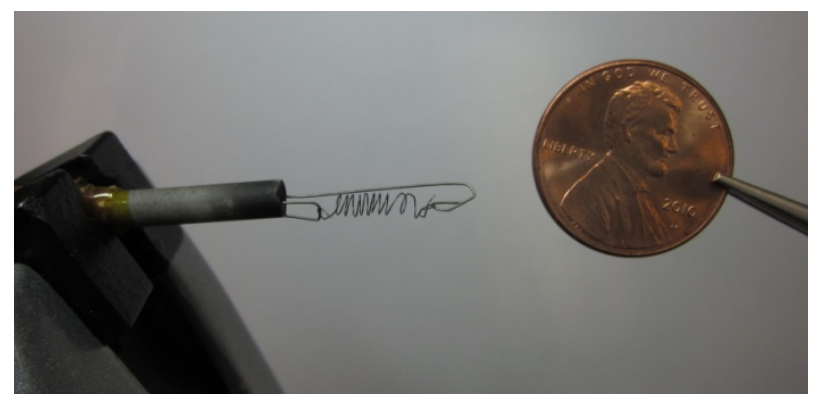

Figure 19: MiXI-CP-V2 CTFC ${ }^{[6]}$

The utilization of CTFCs has led to several difficulties in the operation of past MiXI variants. The large amount of heat required to initiate and sustain electron emission in a CTFC has lead to excessive heating of past MiXI thrusters ${ }^{[4]}$. The excessive heating causes the plasma confinement magnets to quickly exceed $300^{\circ} \mathrm{C}$ during operation, which is the permanent demagnetization of the magnets being used for plasma confinement. This will cause a breakdown of the plasma confinement as the magnetic field strength of the magnets diminishes, and will lead to a loss of plasma stability within the discharge chamber ${ }^{[4,5,6]}$. Analysis of the excessive heating while using a CTFC was explored specifically in the MiXI-CP-V1 variant, and deemed that an alternate cathode would be required for sustained MiXI operation ${ }^{[4]}$. Furthermore, the large amount of heat required by a CTFC leads to large losses in the efficiency of MiXI as will be discussed in Ch. 5 .

Development of miniature hollow cathodes and miniature internal conduction cathodes to replace the inefficient CTFCs is currently under development by Dr. Wirz at UCLA, in the hope of developing a small robust cathode designed for low flow rate and low discharge current operation ${ }^{[13]}$. These miniature cathodes are designed to operate at propellant flow rates below 1 SCCM, and produce discharge currents with less than $1 \mathrm{~A}$ of plasma efficiently, which is ideal for MiXI operation. However, development and 
testing of these cathodes has not yet yielded an optimal miniature cathode design for use in MiXI. A picture of the initial design of a miniature internal conduction cathode is shown in Fig. 20.

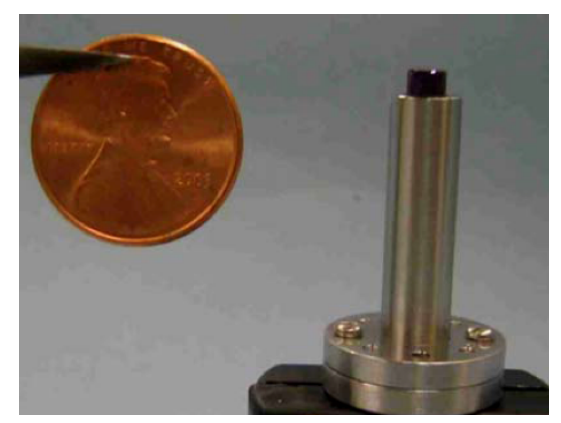

Figure 20: Miniature Internal Conduction Cathode ${ }^{[4]}$

\section{4 - MiXI-CP-V3 Hollow Cathode}

As explained earlier, in past variants of MiXI, hollow cathodes have not been considered a viable cathode due primarily to the relatively high propellant flow rates and high plasma discharge emissions that hollow cathodes often require for stable operation, as well as the relatively large size of hollow cathodes as compared to MiXI. However, small, $6.25 \mathrm{~mm}(0.25 \mathrm{inch})$ diameter hollow cathodes, similar to those used in the $30 \mathrm{~cm}$ NSTAR ion thruster, have the potential to be run at low flow rates and emission currents. To examine this possibility, a $6.25 \mathrm{~mm}$ diameter hollow cathode was donated from JPL and tested at the Cal Poly San Luis Obispo Space Environments Laboratory to evaluate the operating parameters of the hollow cathode at levels suitable for MiXI ${ }^{[16]}$.

The hollow cathode was placed into a vacuum chamber and configured for a stand-alone test, which involves operating the hollow cathode on its own with a stainless steel anode placed in front of the orifice plate for discharge current collection. Xenon was 
chosen as the propellant for the test to mimic MiXI operating conditions as accurately as possible, and to achieve high performance. Plasma creation was initiated in the hollow cathode, and experimental data was taken at several operating conditions over the course of an hour to ensure steady state operation has been achieved. The results of the standalone test for the specific propellant flow rate, keeper voltage and current, and the discharge voltage and current are displayed in Table 3.

Table 3: 6.25mm Diameter Hollow Cathode Stand Alone Test Data

\begin{tabular}{|c|c|c|c|c|c|}
\hline $\begin{array}{c}\text { Operating } \\
\text { Point }\end{array}$ & $\begin{array}{c}\text { Flow Rate } \\
\text { (SCCM) }\end{array}$ & $\begin{array}{c}\text { Keeper } \\
\text { Voltage (V) }\end{array}$ & $\begin{array}{c}\text { Keeper } \\
\text { Current (A) }\end{array}$ & $\begin{array}{c}\text { Discharge } \\
\text { Voltage (V) }\end{array}$ & $\begin{array}{c}\text { Discharge } \\
\text { Current (A) }\end{array}$ \\
\hline $\mathbf{1}$ & 2.0 & 12.75 & 1.0 & 26.5 & 1.0 \\
\hline $\mathbf{2}$ & 1.0 & 13.8 & 1.5 & 27.7 & 1.0 \\
\hline $\mathbf{3}$ & 0.9 & 13.0 & 1.5 & 26.0 & 1.0 \\
\hline $\mathbf{4}$ & 0.81 & 14.2 & 1.5 & 28.2 & 1.0 \\
\hline $\mathbf{5}$ & 0.72 & 14.2 & 1.6 & 28.1 & 1.0 \\
\hline $\mathbf{6}$ & 0.6 & 14.7 & 1.75 & 29.1 & 1.0 \\
\hline $\mathbf{7}$ & 0.6 & 15.1 & 1.75 & 24.4 & 0.75 \\
\hline $\mathbf{8}$ & 0.5 & 15.5 & 1.75 & 25.0 & 0.75 \\
\hline
\end{tabular}

As can be seen from the data obtained during testing of the hollow cathode, the $6.25 \mathrm{~mm}$ diameter hollow cathode is capable of creating stable plasma at low propellant flow rates effectively. Based on the evidence that the $6.25 \mathrm{~mm}$ cathode could operate stably at propellant flow rates $\leq 1 \mathrm{SCCM}$, and plasma discharge currents $\leq 1 \mathrm{~A}$, MiXI-CPV3 will be designed to implement a $6.25 \mathrm{~mm}$ hollow cathode into the MiXI design to explore the effect that the hollow cathode will have on the performance and efficiency of MiXI. A photograph of the $6.25 \mathrm{~mm}$ hollow cathode during and prior to the stand-alone test is shown in Fig. 21. 

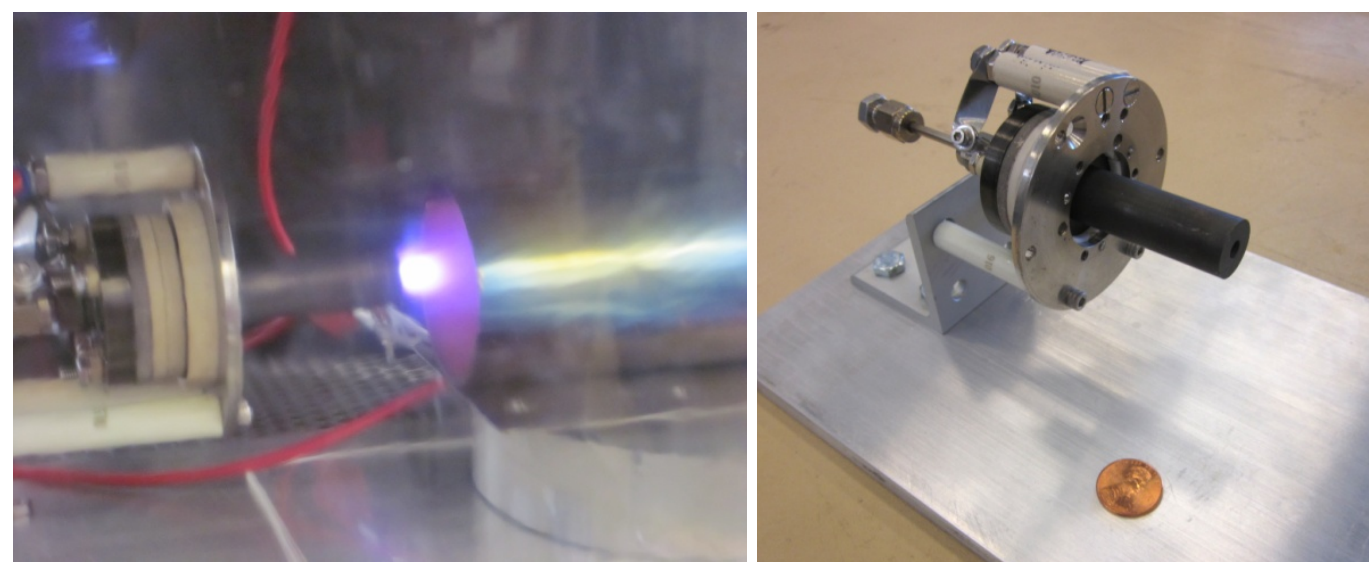

Figure 21: Picture of $6.25 \mathrm{~mm}$ (1/4 inch) Hollow Cathode during Stand-Alone Testing (Left) and Outside the Vacuum Chamber with Penney for Size Reference (Right)

Once the cathode selection occurred for MiXI-CP-V3, the placement of the hollow cathode inside the discharge chamber must be determined. The hollow cathode placement within the discharge chamber is highly dependent on the magnetic field strength at the orifice plate of the hollow cathode. The orifice of the hollow cathode must be placed at a location where the magnetic field is decreasing downstream of the hollow cathode, to allow the plasma emitted from the orifice plate to diffuse into the discharge chamber. If the magnetic field is increasing at the orifice plate downstream of the hollow cathode, the plasma may be reflected back into the hollow cathode, which can stall thruster operation $^{[2]}$.

The magnetic field within the discharge chamber of MiXI-CP-V3 using the magnetic ring configuration discussed in Ch. 2 was measured using a magnetic field probe axially through the center line of the thruster from end to end. The resulting magnetic field strength vs. axial distance in the discharge chamber is shown in Fig. 22 with the distance of 0 being the anode base. 


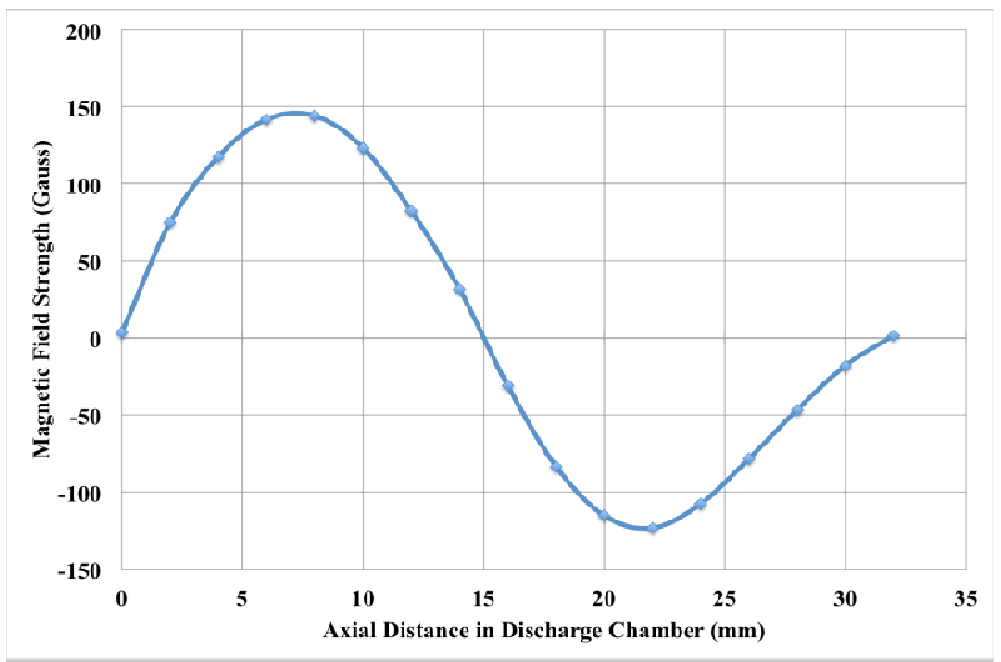

Figure 22: Magnetic Field Strength Axially Through MiXI-CP-V3

As can be seen from Fig. 22, the magnetic field strength increases axially until a point $8 \mathrm{~mm}$ from the anodes base is reached. Therefore, the orifice of the hollow cathode should be at least $8 \mathrm{~mm}$ downstream of the anode base to allow for adequate plasma diffusion into the discharge chamber. However, the magnetic field strength inflects at a point $15 \mathrm{~mm}$ into the discharge chamber, and reaches nearly $-125 \mathrm{G}$ before approaching zero gauss at the grid location $(32 \mathrm{~mm}$ from the anode base). This magnetic field inflection and strength increase is not desired within the discharge chamber because it will cause electrons emitted from the hollow cathode to be reflected from the second peak, and begin to oscillate within the discharge chamber. The electron oscillation severely diminishes the discharge efficiency of the thruster and causes the discharge loss to increase dramatically. The magnetic ring locations and strengths can be moved and analyzed with proper magnetic field modeling programs such as COMSOL or MAXWELL, to eliminate the magnetic field inflection and strength increase in future MiXI variants. The transverse magnetic field must also be examined during proper 
magnetic field analysis to ensure that the magnetic field lines connecting from one ring to another do not penetrate too far into the chamber. If the magnetic field penetrates too far into the chamber, the plasma may become over confined and damage the thruster as discussed in Ch. 2. 


\section{Chapter 4: MiXI-CP-V3 Design}

The basis of the MiXI-CP-V3 design was derived primarily from the $3 \mathrm{~cm}$ discharge chamber and a length over diameter ratio of 1 required by the MiXI design ${ }^{[1]}$. However, the MiXI-CP-V3 design departs from the original MiXI baseline to incorporate a hollow cathode and small plasma confinement magnets selected for use in MiXI-CP-V3. All remaining thruster components were designed to follow the original MiXI design, while implementing the hollow cathode and new magnetic design.

\section{1 - Component Design}

The components of MiXI-CP-V3 consist specifically of an anode, anode pole piece, cap piece, lower magnet mount, magnet shield, cathode isolation sheath, and grid isolation mount. A cross section on the thruster components is shown in Fig. 23 for clarity during this chapter.

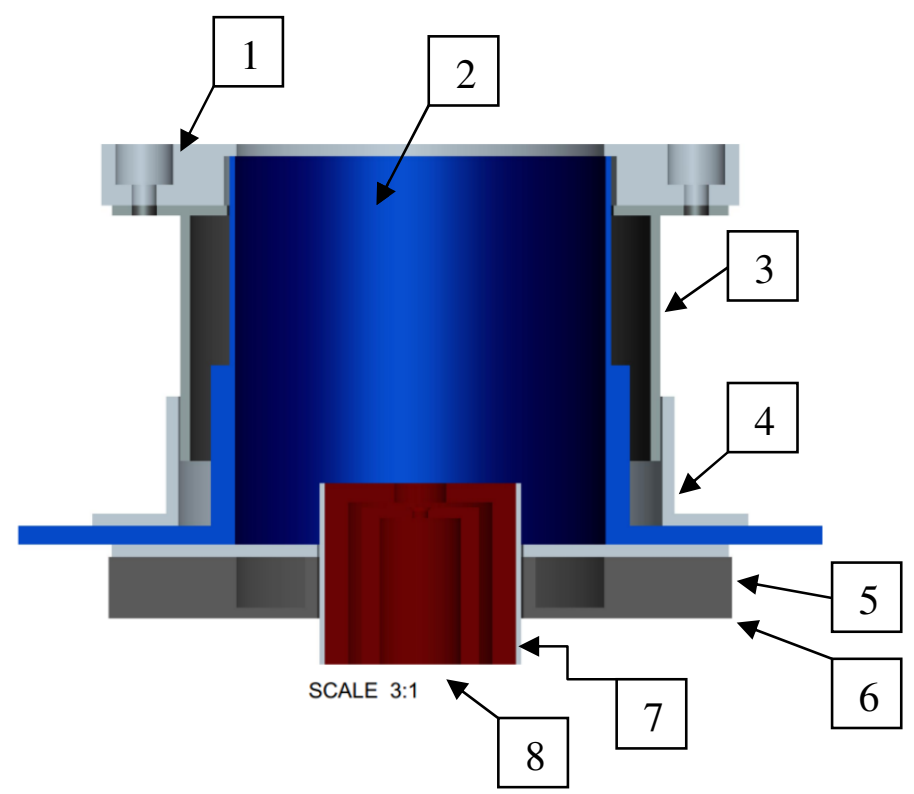

\begin{tabular}{|c|c|}
\hline$\#$ & Component \\
\hline 1 & Grid Isolation Mount \\
\hline 2 & Anode \\
\hline 3 & Anode Pole Piece \\
\hline 4 & Cap Piece \\
\hline 5 & Magnet Sheild \\
\hline 6 & Lower Magnet Mount \\
\hline 7 & Cathode Isolation Sheath \\
\hline 8 & Hollow Cathode \\
\hline
\end{tabular}

Figure 23: Solid Model Cross Section of MiXI-CP-V3 with all Components Labeled 


\subsection{1 - Anode}

The anode for MiXI-CP-V3 is designed to mimic the discharge chamber design of MiXI in terms of size. A stepped anode design was chosen as the optimal anode configuration for several reasons. As discussed in chapter II, the anode wall thickness at the magnetic cusp location is required to be $0.5 \mathrm{~mm}$ thick to increase the performance of the plasma confinement within the discharge chamber; however, the anode thickness was then increase to $1.5 \mathrm{~mm}$ once past the magnetic cusp locations to facilitate anode cooling with an increased volume for heat conduction. Mr. Younger proposed the stepped anode design as a possible solution to the excessive heating of the anode after analysis of MiXI-CP-V1 ${ }^{[4]}$. Even though a CTFC will not be used in MiXI-CP-V3, and the heating will not be as severe, the stepped anode design will still help to mitigate heating at the magnetic cusp locations and keep the magnets below their demagnetization temperature. A flange was added to the bottom of the anode to provide an attachment point for the remaining components of the thruster. A solid model of the anode is shown in Fig. 24.

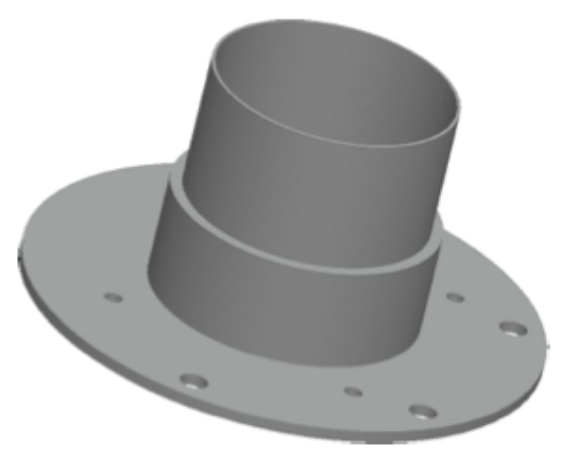

Figure 24: MiXI-CP-V3 Anode Solid Model 
The anode will be used as the primary mounting point for the thruster for simplicity, and as a result, two sets of hole patterns were designed into the flange of the anode. The inner hole pattern consists of four holes spaced 90 degrees from each other to mount the remaining thruster components to the anode. The outer hole pattern consists of five holes mounted 60 degrees apart to mount the entire thruster assembly to the mounting flange located on the hollow cathode. The anode is made out of stainless steel due to its resilience to plasma erosion, structural rigidity and flight heritage.

\subsection{2 - Anode Pole Piece \& Cap Piece}

The anode pole piece is designed to uphold the upper and middle plasma confinement rings and position them around the anode at the magnetic cusp locations. The pole piece is made out of ferrous steel so the magnets will stay attached without additional mounting hardware. The basic design of the pole piece consists of a thin walled, $1 \mathrm{~mm}$ thick cylinder to hold the magnets, and an attachment flange at one end for the accelerator grid isolation piece. The pole piece is designed such that when the magnets are placed on the inner cylinder wall, their surfaces will be touching the anodes outer wall to decree the distance between the cusp and magnet surface. The attachment flange on the anode pole piece also has a $32 \mathrm{~mm}$ diameter hole in its center to allow the anode to pass easily through and help with accelerator grid alignment. The cap piece is made out of stainless steel, and is essentially a circular L-bracket to serve as the mounting point from the cylindrical section of the anode pole piece to the anode lower flange. A 
solid model of the anode pole piece and the cap piece is displayed in Fig. 25 from left to right respectively.
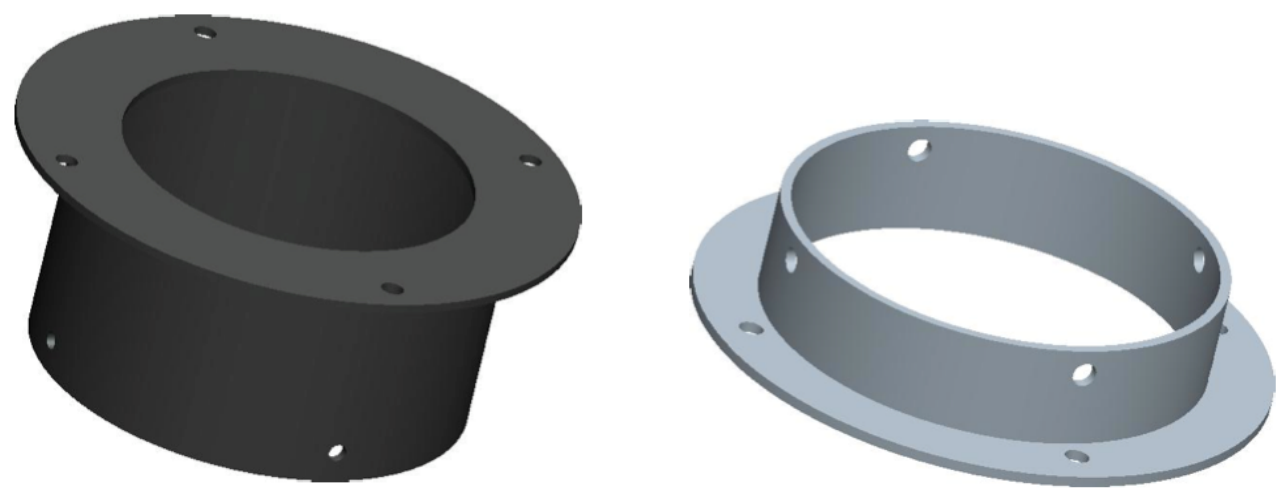

Figure 25: MiXI-CP-V3 Anode Pole Piece and Cap Piece from Left to Right Respectively

\subsection{3 - Lower Magnet Mount \& Magnets Shield}

The lower magnet mount is designed to hold and position the lower plasma confinement ring under the anode base at the proper cusp location. The mount, like the anode pole piece, is made out of ferrous steel to avoid additional mounting components for the magnets. The channel for the magnets was designed to be $4 \mathrm{~mm}$ in depth to accommodate the $4 \mathrm{mmx} 3 \mathrm{~mm}$ magnets specified for the lower plasma confinement ring. The width of the channel was designed to allow the lower magnetic ring to be placed up to $15 \mathrm{~mm}$ radially from the center axis of the anode to allow for magnetic configuration changes in future testing. A hole was added in the center of the mount to allow room for the hollow cathode and the cathode isolation sheath to fit easily inside.

The magnet shield is designed to cover the lower magnetic ring from direct ion bombardment, which can limit the life of the magnets. The shield is made out of stainless 
steel, like the anode, due to stainless steels resilience to plasma erosion and non-ferric nature which will not interfere with the magnetic geometry of the plasma confinement rings. A solid model of the lower magnet mount and magnet shield is shown in Fig. 26 from left to right respectively.
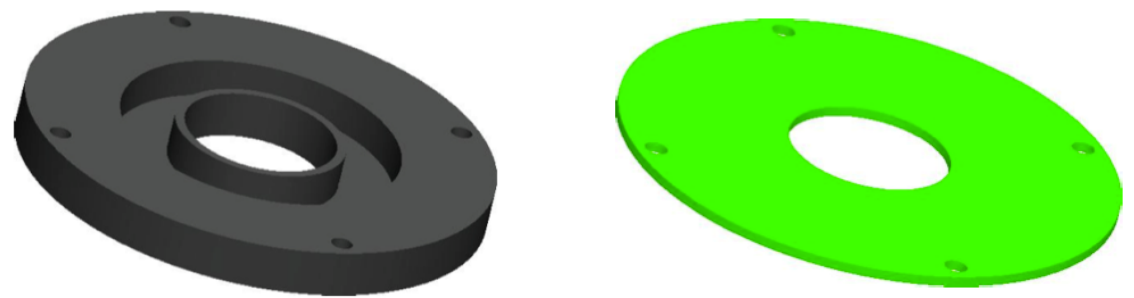

Figure 26: MiXI-CP-V3 Lower Magnet Mount and Magnet Shield form Left to Right respectively (with false coloring)

\subsection{4 - Grid Isolation Mount \& Cathode Isolation Sheath}

The grid isolation mount is designed to electrically isolate the accelerator grids from the rest of the thruster due to the voltage difference between the grids and the anode $^{[2]}$. The grid isolation mount is secured to the anode pole piece via four countersunk holes spaced $90^{\circ}$ apart. The holes are countersunk to ensure that the heads of the mounting screws do not come into contact with the accelerator grids. Likewise, eight holes are counter sunk in the opposite direction to mount the accelerator grids to the isolation mount.

The cathode isolation sheath is designed to isolate the hollow cathode keeper electrode from the anode. Only a portion of the keeper electrode is inserted into the 
anode, however, to prevent propellant loss though the gap between the keeper and the anode, the gap must be minimized as much as possible. To ensure electrical isolation, a thin walled isolator cylinder was designed to cover the portion of the keeper inserted into the thruster and thus isolate it from the magnet mount and magnet shield. Both the grid isolation mount and the cathode isolation sheath are made out MACOR, a machinable ceramic, which allows for complete electrical isolation. A solid model of the grid isolation mount is shown in Fig. 27.

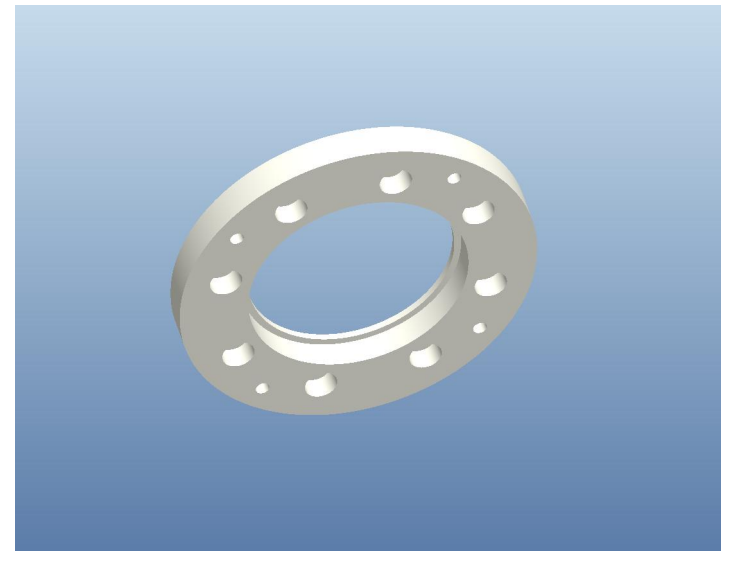

Figure 27: MiXI-CP-V3 Grid Isolation Mount with the Eight countersunk grid mount holes clearly visible

\section{2 - MiXI-CP-V3 Assembly}

The assembly of MiXI-CP-V3 is completed in several different stages to ensure reliable operation during testing: magnetic ring assembly, accelerator grid assembly, thruster component assembly and finally hollow cathode insertion. 


\subsection{1 - Magnetic Ring Assembly}

The magnetic ring assembly involves the accurate placement and positioning of the small SmCo magnets selected for use into the proper 3-ring cusp configuration determined in Chapter II. As discussed earlier, the magnetic ring configuration was designed to mimic the original MiXI magnetic ring design, which called for a 3-ring cusp design with two rings around the anode, classified as the upper and middle magnetic rings, and the third ring around the cathode at the anodes base, classified as the lower magnetic ring ${ }^{[1]}$. Due the inner circumference of the anode pole piece $30,3 \mathrm{mmx} 3 \mathrm{~mm}$ SmCo magnets were required in the upper and middle magnetic rings with the north polarities of the upper ring facing into the discharge chamber and the north polarities of the middle ring facing away from the discharge chamber. The lower magnetic ring requires $20,4 \mathrm{~mm} \times 3 \mathrm{~mm}$ SmCo magnets with their north polarities facing into the discharge chamber like the upper ring.

The upper magnetic ring is assembled by placing three of the $1 \mathrm{~mm} \times 3 \mathrm{~mm}$ magnets on top of each other, and placing the resulting $3 \mathrm{~mm} \times 3 \mathrm{~mm}$ stack (north face oriented towards the discharge chamber) onto the anode pole piece. The magnet can then be maneuvered to the correct location on the anode pole piece to produce the proper magnetic cusp. This process was repeated for the remaining magnets in the upper magnetic ring. A similar process was repeated for the magnets in the middle magnet ring, with the only exceptions being the direction of the magnetic polarity and the final position of the ring on the anode pole piece. The lower magnetic ring was assembled by 
stacking four, $1 \mathrm{~mm} \times 3 \mathrm{~mm}$ magnets, resulting in a $4 \mathrm{~mm} \times 3 \mathrm{~mm}$, which was then placed (north polarity oriented into the discharge chamber) onto the magnet mount. The magnets were then maneuvered to the correct position on the magnet mount to produce the proper magnetic cusp. This process was repeated for the remaining magnets in the lower magnetic ring. The fully assembled upper and middle magnetic rings attached to the anode pole piece are shown in Fig. 28.

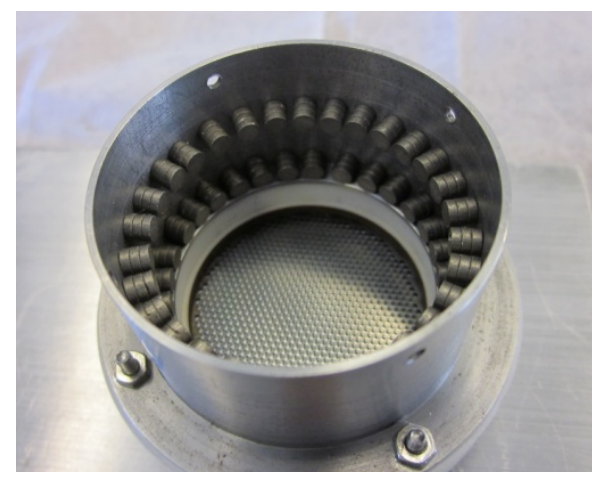

Figure 28: Anode Pole Piece with Fully Assembled Upper and Middle Magnetic Rings

\subsection{2 - Accelerator Grid Assembly}

The accelerator grids used for MiXI-CP-V3 were donated by Dr. Wirz to Cal Poly for MiXI development and testing during the development of MiXI-CP-V1 $1^{[4]}$. The grids are similar to the SHAG grid design used by Dr. Wirz in both the MiXI and MiXI-II thruster ${ }^{[1,5]}$. The grids are both $0.27 \mathrm{~mm}$ thick, with an outer diameter of $50 \mathrm{~mm}$. Both the screen and accel grid contain 892 individual aperture holes contained in a circular area of $706.8 \mathrm{~mm}^{2}$, with a diameter of $30 \mathrm{~mm}$ (the width of the discharge chamber). The aperture holes of the screen grid are $0.38 \mathrm{~mm}$ in diameter while the aperture holes in the accel grid 
are $0.19 \mathrm{~mm}$ in diameter. Each grid contains four small holes for that are used to secure the grid in its proper location, as well as four larger holes that are designed to allow the mounting screws from the screen grid to avoid contact with the accel grid. The staggered hole pattern allows for complete electrical isolation between the grids, while also allowing for secure grid attachment. The screen and accel grid from MiXI-CP-V3 (also MiXI-CP-V1 and MiXI-CP-V2) are pictured in Fig. 29.

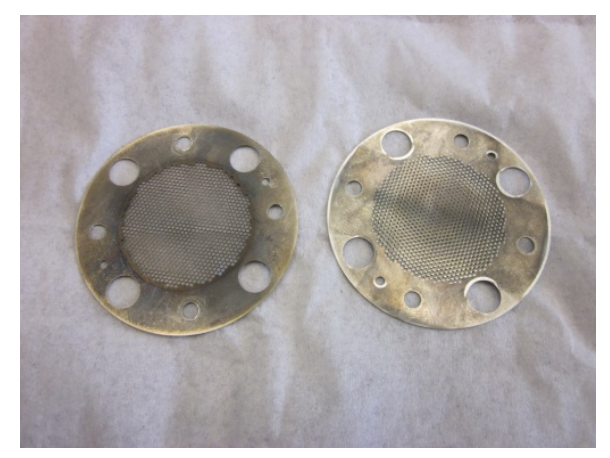

Figure 29: MiXI-CP-V3 Screen Grid and Accel Grid from Left to Right Respectively

The spacing between the grids is extremely important to the performance of the ion optics of an ion thruster. Generally in gridded ion thruster, the screen and accel grid need to be placed extremely close to one another (usually less than the diameter of the aperture holes) to adequately focus the ion beam exiting the thruster and preserve the grids. Previous development of MiXI by Dr. Wirz and a team from Caltech demonstrated that the optimal grid spacing for the MiXI SHAG grids was $0.3 \mathrm{~mm}$ (300 micrometers) ${ }^{[5]}$. Attempts were made to space the grids $0.3 \mathrm{~mm}$ apart, however, electrical breakdown at the grids was recorded at a gap distance of $0.3 \mathrm{~mm}$ during initial testing. The electrical breakdown was likely due to warping of the grids from previous testing in MiXI-CP-V1 and MiXI-CP-V2 which caused the grid spacing to vary, and at some points, be close 
enough to cause electrical breakdown across the gap. As s solution, a final grid spacing of $0.6 \mathrm{~mm}$ during testing of MiXI-CP-V3 was implemented to ensure electrical isolation at the grids. The spacing was achieved by placing the accel grid on top of three, $0.2 \mathrm{~mm}$ thick washers placed inside the larger bypass holes in the screen grid. A cross-sectional diagram of the grid spacing is shown in Fig. 30.

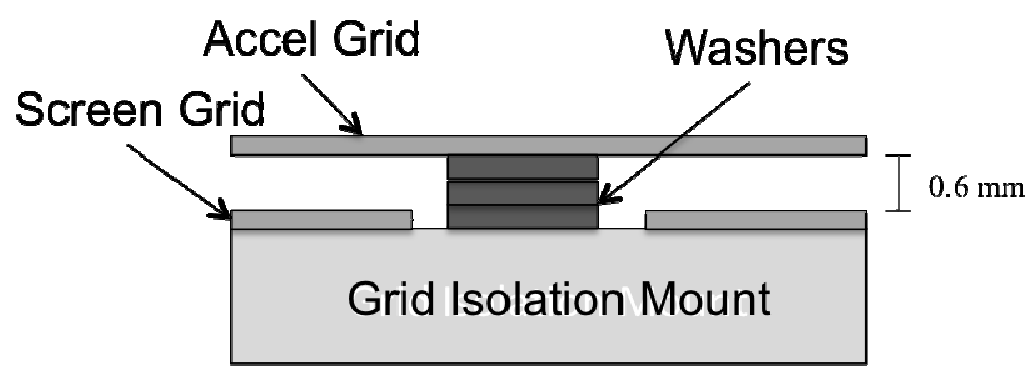

Figure 30: Diagram of the MiXI-CP-V3 Accelerator Grid Spacing

\subsection{3 - MiXI-CP-V3 Final Assembly}

Once the magnetic ring assembly and acceleration grid assembly has been completed, final thruster assembly can be commenced. The thruster components are first assembled into a thruster subassembly containing all components of the thruster excluding the hollow cathode. The subassembly is then attached to the hollow cathode mounting flange using ceramic isolation stand-offs. The thruster sub-assembly is then shifted back until the hollow cathode is inserted into the discharge chamber to a distance of $8 \mathrm{~mm}$ (as required by the magnetic field topography). The hollow cathode keeper electrode is $15.5 \mathrm{~mm}$ in diameter and $40.5 \mathrm{~mm}$ in length for reference. A picture of MiXI-CP-V3 fully assembled is shown in Fig. 31 with two different hollow cathode 
configurations with different mounting schemes. The reason for the hollow cathode repair is discussed in further detail in the hollow cathode section of Appendix I.

It should be noted that due to the mounting flange on the hollow cathode also being used as the negative pole of both the heater and keeper, the mounting bolts of MiXI-CP-V3 required ceramic isolators between the mounting screws and thruster body. The ceramic isolators are pointed out with yellow arrows in Fig. 31 for clarity. It should also be noted that the variation in the amount of ceramic isolators used from the hollow cathode configuration on the right to the left is only a product of the new cathode configuration, and was required to keep the hollow cathode orifice $8 \mathrm{~mm}$ within the discharge chamber to allow for proper plasma diffusion.
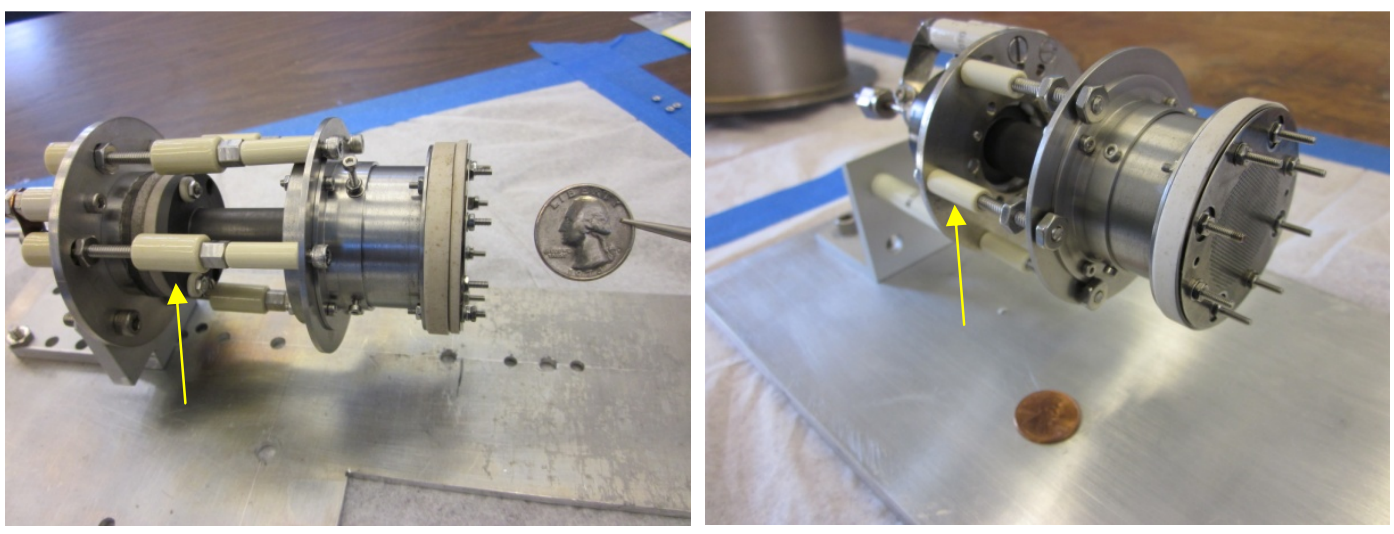

Figure 31: Fully Assembled MiXI-CP-V3 with two Different Hollow Cathode Configurations 


\section{Chapter 5: Thruster Performance}

In order to determine the efficiency and performance parameters of an ion thruster experimentally, current and voltage readings from power supplies powering the thruster and propellant flow rates must be used.

\section{1 - Operational Parameters}

The thrust during testing can be calculated using the equation,

$$
T=J_{B} * \sqrt{\frac{2 * m_{p} * V_{B}}{e}} * \cos \theta
$$

where $\mathrm{T}$ is thrust in units of Newtons ${ }^{[2]}$. It should be noted that the thrust of an ion thruster and electric propulsion thrusters in general, is commonly expressed in units of $\mathrm{mN}$ due the low thrust of ion thrusters. The half angle divergence of the ion beam is the divergence of the beam from the thrusters' central axis. The half angle divergence is a primary concern for electric propulsion thruster, because, as shown in Eq. 7, as the half angle increases the thrust decreases. Large plume divergence angles can lead to spacecraft charging and contamination as the beam comes into contact with components of the spacecraft that are close to the thruster. Spacecraft charging can lead to differential voltage build up across the spacecraft, which in turn can lead to arcing that can severely damage components of the spacecraft.

The mass flow rate of the propellant for a thruster is highly important during a spacecraft design because it dictates how much propellant is used during thruster 
operation. This ultimately leads to an overall propellant mass requirement for a given thruster operational lifetime. The mass flow rate of an ion thruster can be calculated using the equation,

$$
\dot{m}=Q M
$$

where $\dot{m}$ is the mass flow rate of the propellant in units of $\mathrm{kg} / \mathrm{s}, \mathrm{Q}$ is the propellant mass flow rate in particles per second, and $\mathrm{M}$ is the particle mass on $\mathrm{kg}$ per particle ${ }^{[2]}$.

The mass utilization efficiency demonstrates the thrusters' ability to convert incoming neutral propellant into plasma ions used in the ion beam. This is one of the most important performance characteristics of an EP thruster, for it quantifies how effectively the thruster is utilizing the incoming propellant, which affects the required propellant mass for a specific mission. The mass utilization efficiency can be calculated using the equation,

$$
\eta_{m}=\frac{J_{B *} m_{p}}{e * \dot{M}_{p}} * 100
$$

where the mass utilization is expressed in percent ${ }^{[2]}$. It should be noted that $100 \%$ is the theoretical maximum of mass utilization efficiency and it implies a complete conversion of all incoming neutral propellant into plasma ions used in the ion beam.

The specific impulse, known as Isp, is a measure of the efficiency of a thruster. Using Eq. 9, the Isp can now be calculated by 


$$
I s p=\frac{\eta_{m}}{100 * g} * \sqrt{\frac{2 * e * V_{B}}{m_{p}}}
$$

where the Isp is expressed in units of seconds, and $\eta_{m}$ is expressed in percent ${ }^{[2]}$. Again, the coefficient of 100 is unit less and serves to take into account mass utilization efficiency expressed as a percent.

The discharge loss is an important representation of a thrusters' performance. It can be viewed as the electrical energy required to create each ion from during plasma formation. It can be calculated by

$$
\eta_{D}=\frac{V_{d^{*} J_{D}}}{J_{B}}
$$

where $\eta_{D}$ is in units of W/A ${ }^{[2]}$. However, $\eta_{D}$ is commonly expressed in the equivalent units of eV/ion, which allows for a better grasp of the electrical energy used to create each ion. As the discharge loss of a thruster increases, the more costly (in terms of electrical energy) it becomes to produce ions within that thruster. As a result, low discharge loss is extremely desirable, and is required for efficient thruster operation.

Another ion thruster efficiency commonly calculated is the electrical efficiency, which can be expressed as a ratio of the beam power to the power required by the other thruster components (i.e. the discharge, cathode, and accel power). The electrical efficiency is calculated by 


$$
\eta_{E}=\frac{V_{B} J_{B}}{V_{B} * J_{B}+V_{D} * J_{D}+V_{K^{*} J_{K}}+V_{H^{*} J_{H}+V_{A} J_{A}}} * 100
$$

where $\eta_{E}$ is the electrical efficiency expressed in percent, $\mathrm{V}_{\mathrm{K}}$ and $\mathrm{J}_{\mathrm{K}}$ are the keeper voltage and current in volts and amperes respectively, $\mathrm{V}_{\mathrm{H}}$ and $\mathrm{J}_{\mathrm{H}}$ are the heater voltage and current in volts and amperes respectively, $\mathrm{V}_{\mathrm{A}}$ and $\mathrm{J}_{\mathrm{A}}$ are the accel voltage and current in volts and amperes respectively ${ }^{[2]}$. The electrical efficiency is used to express the thrusters' ability to produce a given power of an ion beam for a given input power. This essentially examines the thrusters' ability to utilize its electrical power efficiently in creating thrust.

The total efficiency of an ion thruster can also be expressed by

$$
\eta_{T}=\frac{\eta_{m} * \eta_{E}}{100} \gamma^{2}
$$

where $\eta_{T}$ is the total efficiency in percent, $\gamma$ is the thrust correction term, and both the mass utilization efficiency and electrical efficiency are expressed in percent as well, with the unit less coefficient of 100 allowing for all efficiencies to be expressed in percent ${ }^{[2]}$. The total efficiency serves as a way to relate how much of the supplied electrical energy to the thruster was converted into thrust ${ }^{[2]}$. 


\section{Chapter 6: MiXI-CP-V3 Testing}

In order to establish a baseline understanding of the effects of implementing a hollow cathode and small magnets into the MiXI design, operational testing of MiXI-CP-V3 was performed in the Cal Poly San Luis Obispo Space Environments Laboratory. The following sections describe the facilities, apparatus, and procedures used during testing.

\section{1 - Vacuum Chamber System}

All operational testing for MiXI-CP-V3 took place in the Space Environments Laboratory at Cal Poly San Luis Obispo, and utilized equipment available within the facility. The vacuum chamber used for testing is called the Minimum Atmospheric Experimentation (MAX) chamber, and has a 12inch tall, 18inch diameter cylindrical Pyrex bell jar as a testing chamber. The MAX chamber is shown in Fig. 32 for reference.

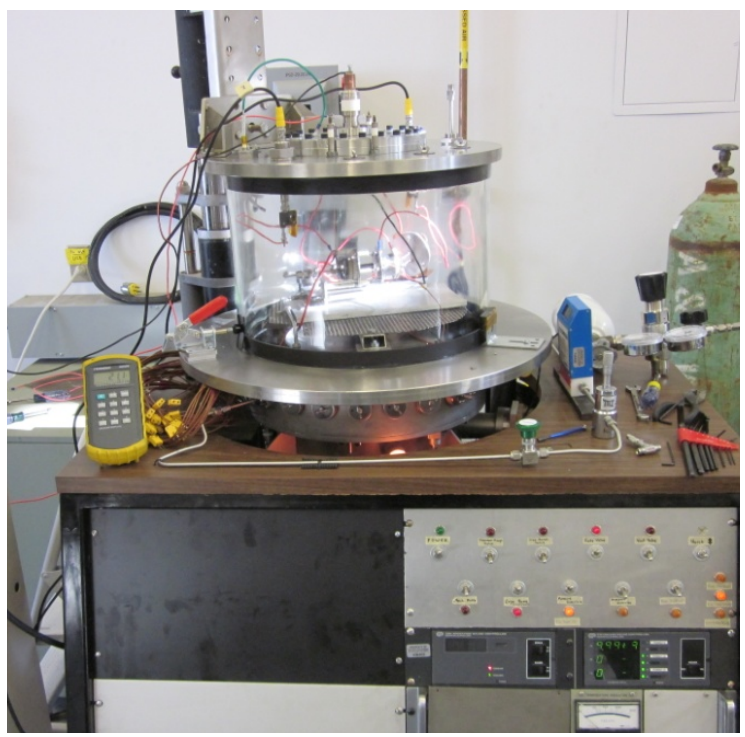

Figure 32: Minimum Atmospheric Experimentation Chamber in the Cal Poly San Luis Obispo Space Environments Laboratory

60 
MAX utilizes a mechanical roughing pump to reach medium vacuum conditions $\left(1 \times 10^{-3}\right.$ Torr - 25Torr) within the chamber, and then switches to a cryo pump to reach high vacuum conditions $\left(1 \times 10^{-7}\right.$ Torr $-1 \times 10^{-3}$ Torr $)$ during operation. A Welch 1397 duo-seal mechanical vacuum pump is used to obtain initial medium vacuum conditions inside the chamber; however, due to contamination at lower vacuum levels, high vacuum is required for ion thruster operation. If the chamber pressure is not below $\sim 5 \times 10^{-6}$ when the hollow cathode heater is turned on, water vapor present within the hollow cathode can poison the $\mathrm{BaO}-\mathrm{W}$ insert and not allow the hollow cathode to light. As a result, a CTI CryoTorr-10 cryo pump is used in conjunction with a CTI 1020R helium compressor to achieve a base pressure of $7.7 \times 10^{-7}$ Torr within the chamber, which will allow for healthy hollow cathode operation. It should be noted that the ion gauges used to measure the high vacuum pressure are calibrated for Nitrogen and as a result a correction factor 2.87 should be multiplied in to obtain the correct pressure during xenon flow operation ${ }^{[17]}$.

The MAX chamber has four BNC electrical feed-throughs, and four isolated conductive rod electrical feed-throughs to allow for voltage and current to be fed into the chamber. The feed-throughs are spaced throughout the upper chamber lid and the chambers' base to allow for a variety of experimental setups within the vacuum chamber. The chamber also contains 2 gas feed-throughs and 26 thermocouples, which allow gases to be inserted into the chamber and enable temperature readings to be taken during operation. 


\section{2 - Propellant Flow System}

The propellant flow system used during testing consists of a propellant tank regulator, digital flow meter, needle valve, shutoff valve, and a propellant flow isolator. Due the required "propulsion-grade" propellant purity for $\mathrm{BaO}-\mathrm{W}$ inserts in hollow cathodes, the pressure regulator on the tank must be a stainless steel two-stage regulator to avoid propellant contamination. A Smith stainless steel two-stage high purity regulator with an outlet pressure range of 0-30PSIG was obtained for testing. The flow meter used is an OMEGA FMA-A2300, and provides a digital read out of the propellant flow with an accuracy of 0.01 SCCM while A VACOA MV-25 needle valve is used to adjust the flow rate of the propellant into the chamber. It should be noted that the propellant flow meter is calibrated for Nitrogen and as a result a correction factor of 1.32 should be multiplied in to obtain proper Xenon flow rate numbers ${ }^{[17]}$. An additional Swagelok diaphragm valve is included as an overarching propellant line shut off valve to use when the test is completed. Due to the complex power system of an ion thruster, the propellant fuel line needs to be electrically isolated to prevent electrical breakdown between the thruster and the chamber. A fuel line isolator was donated from JPL to be used during MiXI-CP-V3 testing. A picture of the all labeled components in the propellant flow system is shown in Fig. 33. 

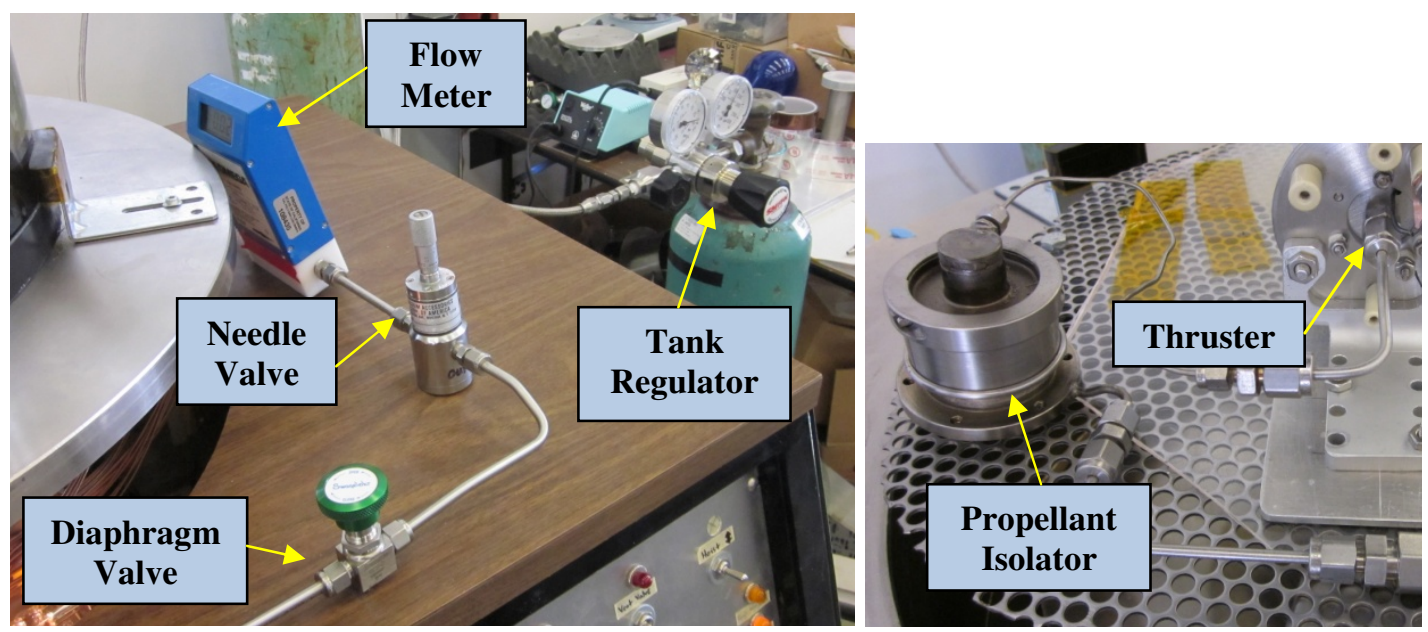

Figure 33: MiXI-CP-V3 Propellant Flow System

The xenon propellant used for testing had been purchased nearly 10 years prior the work described in this thesis. The xenon is "ultra high purity" which is characterized as $99.999 \%$ pure and will be adequate for testing. It is assumed that no contaminants were introduced into the propellant tank in the time between its purchase and use for this project. It should be noted that prior to testing, the propellant line must be purged of all air before being pressurized with the propellant to avoid contamination.

\section{3 - Electrical System}

The electrical system is one of the most important systems of an ion thruster. Ion thruster operation generally requires five-seven power supplies operating simultaneously, depending on whether a hollow cathode or CTFC is being used. Ion thrusters using a hollow cathode, require a power supply for the heater and keeper electrode to operate the cathode. The heater power supply is used to heat the insert inside the hollow cathode to initiate electron emission during thruster start up, where as the keeper electrode helps to initiate the plasma formation and protect the cathode. Due to the heat given off during 
plasma generation within the cathode, the heater is often turned off to prevent the hollow cathode from over-heating; at which point the cathode is said to be 'self heating' as the heat from the plasma adequately heats the insert.

A discharge supply is connected to the anode to apply a positive voltage and attract plasma electrons from inside the discharge chamber. The voltage and current can also be set on the discharge supply to set the plasma current present in the discharge chamber. An accel supply is connected to the accel grid to create the electric field within the chamber to accelerate the ions. Another power supply is attached to the cathode neutralizer to provide beam neutralization. The cathode neutralizer will require two power supplies if a hollow cathode is used, however, only one power supply is required if a CTFC is being used as a neutralizer. MiXI-CP-V3 will be using a CTFC as compared to a hollow cathode as a neutralizer due to the added complexity required by hollow cathodes. A high voltage power supply is then connected to the anode to bias the cathode and discharge power supplies to create the proper voltage difference between the plasma ions and the accel grid. An example of the voltage potential at different components of an ion thruster is shown in Fig. 34. 


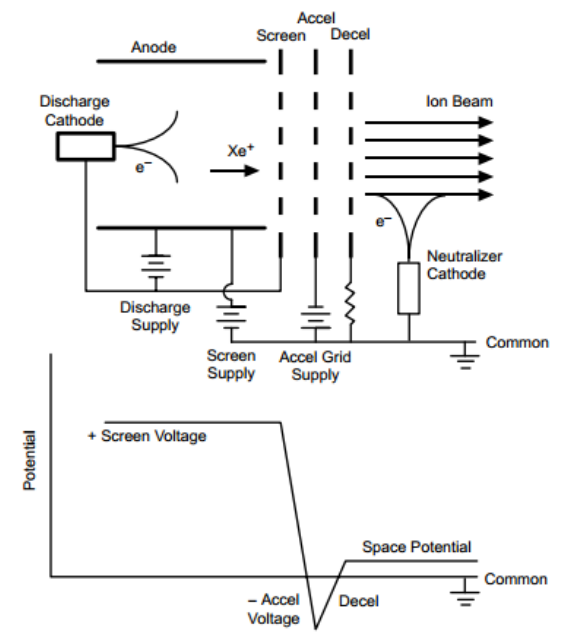

Figure 34: Voltage Potential at Different Components of an Ion Thruster ${ }^{[2]}$

To bias the cathode and discharge supplies, the electrical system requires two circuits to be run simultaneously where one circuit containing the accel, neutralizer, and screen power supplies, is grounded to the spacecraft ground (common ground) of the satellite; whereas the other circuit containing the heater, keeper and discharge supplies, has a floating ground. A floating ground means that the ground of a circuit can be biased up or down in voltage while all components on that circuit continue to operate normally. This is accomplished by isolating the power supplies from the common ground of the system and using the screen supply to provide the voltage to 'float' the system. For MiXI-CP-V3 testing, this involved encasing the floating power supplies in acrylic sheeting, and using a 1:1 transformer to supply the appropriate A/C power. The common ground is generally the earth ground during testing due to safety concerns and simplicity.

A CTFC will be used as the neutralizer cathode for MiXI-CP-V3 testing due to the simplicity that the CTFC offers. The tungsten filament used in the neutralizer is $0.254 \mathrm{~mm}(0.01 \mathrm{inch})$ in diameter to increase the strength of the filament during operation. 
A pre existing CTFC mount will be used to hold the CTFC during testing, and the filament will be positioned 3-5mm away from the accel grid to achieve complete beam neutralization.

An electrical schematic of the MiXI-CP-V3 power system is shown in Fig. 35 with the details of the power supplies listed in Table 4.

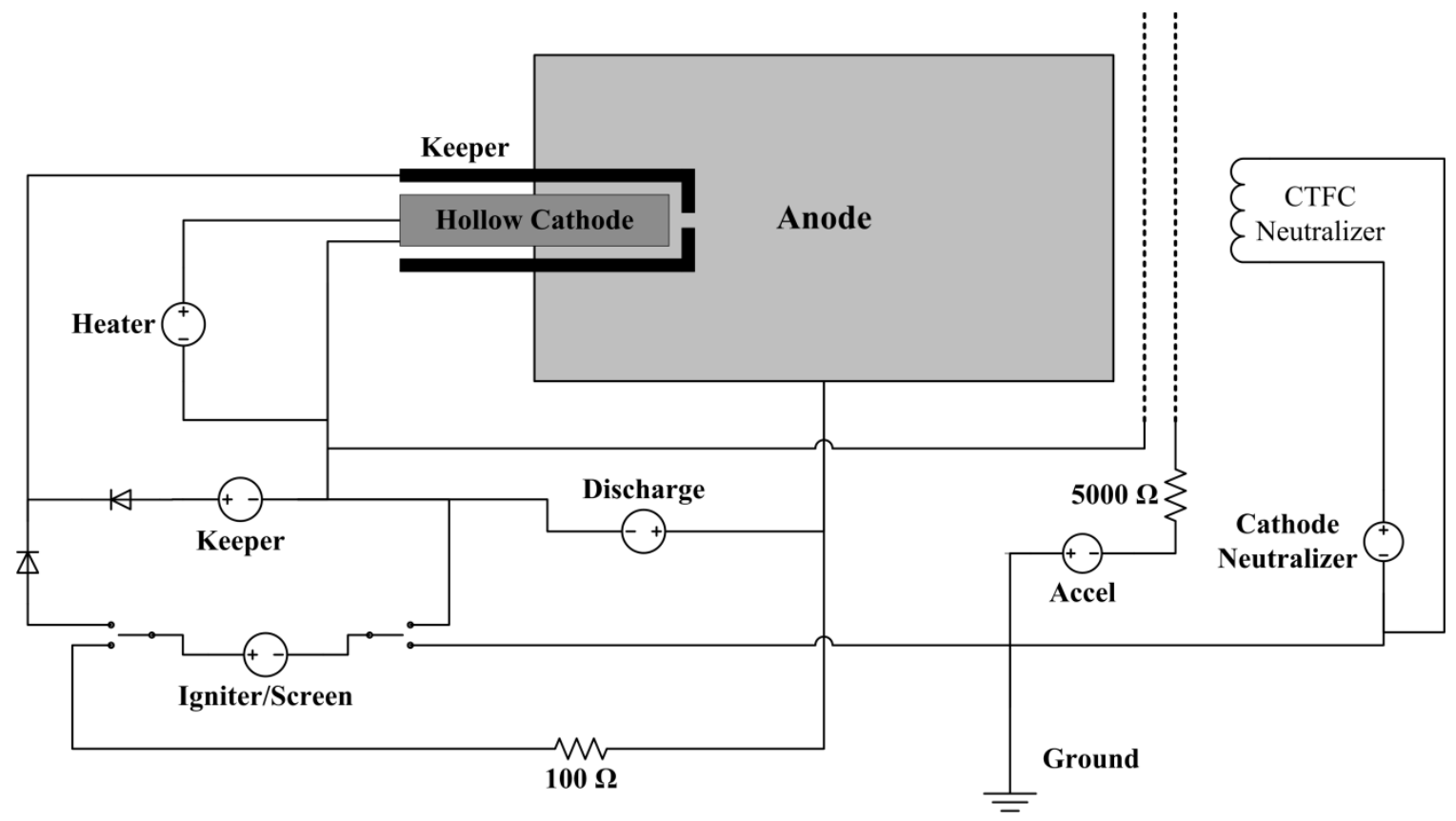

Figure 35: MiXI-CP-V3 Electrical Schematic

Table 4: Power Supplies Utilized for MiXI-CP-V3 Testing

\begin{tabular}{|c|c|c|c|c|}
\hline Power Supply & Model & Quantity & Voltage Range & Current Range \\
\hline Cathode Heater Supply & $\begin{array}{c}\text { Instek GPS-4303 } \\
\text { (Parallel Mode) }\end{array}$ & 1 & $0-30 \mathrm{~V}$ & $0-6 \mathrm{~A}$ \\
\hline Cathode Keeper Supply & $\begin{array}{c}\text { Instek GPS-2303 } \\
\text { (Series Mode) }\end{array}$ & 2 & $0-60 \mathrm{~V}$ & $0-3 \mathrm{~A}$ \\
\hline Discharge Power Supply & HP 6038A & 1 & $0-60 \mathrm{~V}$ & $0-10 \mathrm{~A}$ \\
\hline Screen/Igniter Power Supply & Glassman FC1P120 & 1 & $0-1000 \mathrm{~V}$ & $0-125 \mathrm{~mA}$ \\
\hline Accel Power Supply & GW GPR30H10D & 1 & $0-300 \mathrm{~V}$ & $0-1 \mathrm{~A}$ \\
\hline $\begin{array}{c}\text { Cathode Neutralizer Power } \\
\text { Supply }\end{array}$ & HP 6263B & 1 & $0-20 \mathrm{~V}$ & $0-10 \mathrm{~A}$ \\
\hline
\end{tabular}


It can be seen from Fig. 35 that the screen supply doubles as the hollow cathode igniter supply. This is required for hollow cathode ignition in the Cal Poly Space Environments Laboratory due to an insufficient voltage output from the keeper supply. Generally, 150 volt power supply is required to ignite a hollow cathode depending on the condition of the cathode, however, only two, $60 \mathrm{~V}$ power supplies were available for use, and when attached in series, only produce a net voltage of $120 \mathrm{~V}$. As a result the screen supply doubled as an igniter for the hollow cathode by applying a high voltage to the keeper to initiate the plasma. Diodes were placed in series with the keeper and igniter supplies to prevent the low voltage power supply from becoming reverse-biased and being damaged. As the voltage on the keeper drops into the voltage range of the low voltage supply as plasma current to the keeper increase, the normal keeper supply will take over and the high voltage supply can be turned off. The high voltage power supply can then be disconnected and prepared for use as the screen supply.

The resistors present in the schematic are used to limit the current of potential arcing during thruster startup at the accelerator grids. Arcing typically occurs at the grids during ion thruster startups because of contaminants still present on the accelerator grid surface from instillation or outgassing. As the thruster runs, the grids are cleaned by the plasma, and arcing becomes less frequent and therefore less of an issue.

\section{4 - Testing Procedure}

Prior to testing, all thruster components are cleaned to ensure a minimal amount

of contaminates are present on the thruster during testing and photographed. All handling 
of the thruster after cleaning requires the use of powder free gloves to ensure that no further contaminants are introduced to the thruster. The thruster is then placed into the vacuum chamber and the electrical and propellant flow systems are connected to the thruster accordingly. A thermocouple is also attached to the anode pole piece to measure the temperature of the magnets during testing. The addition of the thermocouple allows the operator to ensure that the magnets do not reach the permanent demagnetization temperature of $300^{\circ} \mathrm{C}$. A picture of the MiXI-CP-V3 thruster with all electrical and propellant flow system components attached is shown in Fig. 36 prior to testing inside the vacuum chamber.

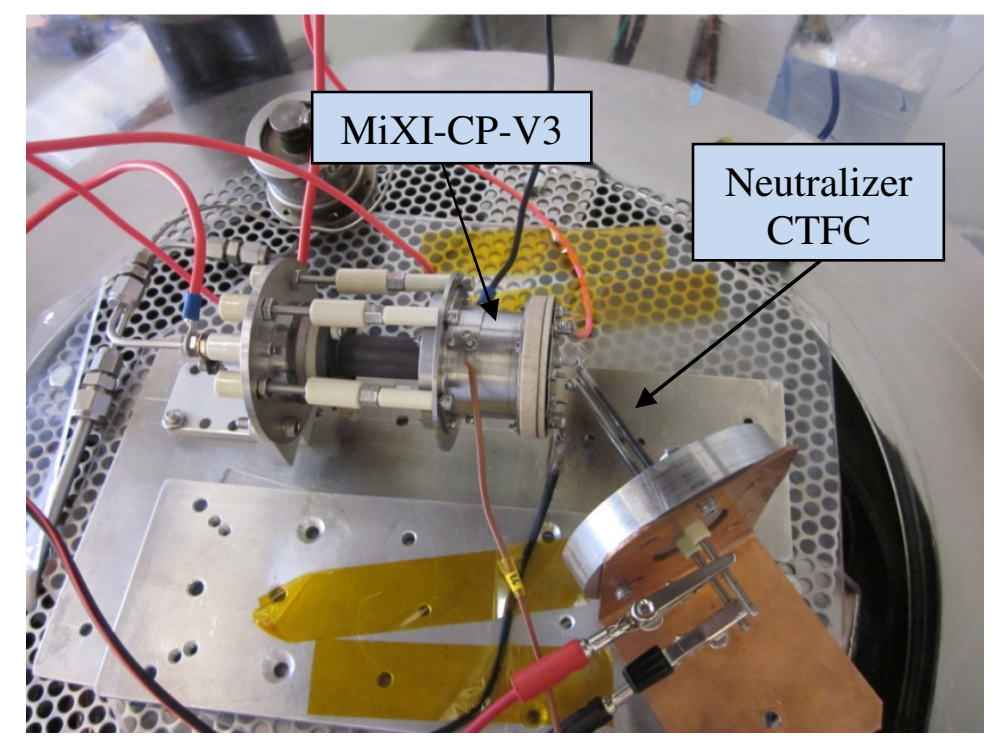

Figure 36: MiXI-CP-V3 Prior to Testing in the Vacuum Chamber

Prior to operation, the thruster was physically examined and an electrical checkout was performed ensure continuity and proper polarity. The chamber was then closed and the vacuum pumps were initiated. Once the vacuum chamber had reached its 
base pressure of $7.7 \times 10^{-7}$ Torr, testing was then allowed to begin. Full vacuum chamber operational procedures can be seen in Appendix II.

\subsection{1 - MiXI-CP-V3 Operation}

The hollow cathode heater supply was set, current controlled, to $6 \mathrm{~A}$ for 30 minutes to allow the insert adequate time for heating. The propellant flow was then set to 4-5 SCCM as an initial set point to facilitate hollow cathode ignition, and the keeper was set to its maximum voltage of $120 \mathrm{~V}$. If the keeper was not able to initiate plasma formation in the hollow cathode, the igniter supply was used to increase the voltage on the keeper until plasma formation began. The igniter supply was then turned off as the keeper voltage dropped below $120 \mathrm{~V}$ and the keeper supply took over operation. The heater supply was then turned off to prevent the cathode from overheating. The discharge supply was now turned on and set to current control and the desired plasma discharge current was set. The propellant flow rate was then lowered to the desired test point and the cathode neutralizer power supply was turned on to neutralize the ion beam once it was created. The accel supply was then turned on to initial the electric field within the discharge chamber and begin ion acceleration. Lastly, the screen supply was turned on to bias the thruster and create the proper beam voltage and corresponding beam current. All power supply readouts were then recorded to determine the performance of the thruster at the operational point being examined. It was discovered during testing that due to the low flow rate of the propellant $(<1$ SCCM), and low discharge current, the cathode heater had to be left on at a low level to facilitate heating the insert because the plasma heating was 
not able to provide a adequate amount of heat to continue electron emission. An example of the typical operational values of the power supplies during testing is listed in Table 5.

Table 5: List of Typical Operational Parameters of MiXI-CP-V3 during Testing

\begin{tabular}{|c|c|c|}
\hline Parameter & Value & Unit \\
\hline Propellant Flow Rate & 0.55 & SCCM \\
\hline Heater Current & 3 & Ampere \\
\hline Heater Voltage & 11.5 & Volts \\
\hline Keeper Current & 1.75 & Ampere \\
\hline Keeper Voltage & 14 & Volts \\
\hline Discharge Current & 0.8 & Ampere \\
\hline Discharge Voltage & 28 & Volts \\
\hline Accel Current & 100 & Ampere \\
\hline Accel Voltage & 0.03 & Volts \\
\hline Screen Current & 0.038 & Ampere \\
\hline Screen Voltage & 750 & Volts \\
\hline Neutralizer Current & 5.5 & Ampere \\
\hline Neutralizer Voltage & 16 & Volts \\
\hline
\end{tabular}

Once the power supply readouts were recorded, the discharge current, beam voltage, or propellant flow rate could then be adjusted to reach a new operational test point. However, to gain a full understanding of the performance of MiXI-CP-V3, at least 6 test points were analyzed for each propellant flow rate by changing only the discharge current and screen voltage for a given flow rate. The testing procedure described earlier was used to examine MiXI-CP-V3 operational parameters at flow rates of 1.0, 0.9, 0.8, and 0.55 SCCM at various discharge currents and beam voltages.

MiXI-CP-V3 testing continued until the anode pole piece temperature reached $300^{\circ} \mathrm{C}$, at which point the thruster was shut down by turning off the power supplies in the reverse order from which they were turned on. The thruster was then allowed to cool to a temperature $<40^{\circ} \mathrm{C}$ at which time testing could resume until all test points were 
examined. A picture of MiXI-CP-V3 during testing is shown in Fig. 37 where the bright light in the center of the thruster the orifice hole of the hollow cathode.

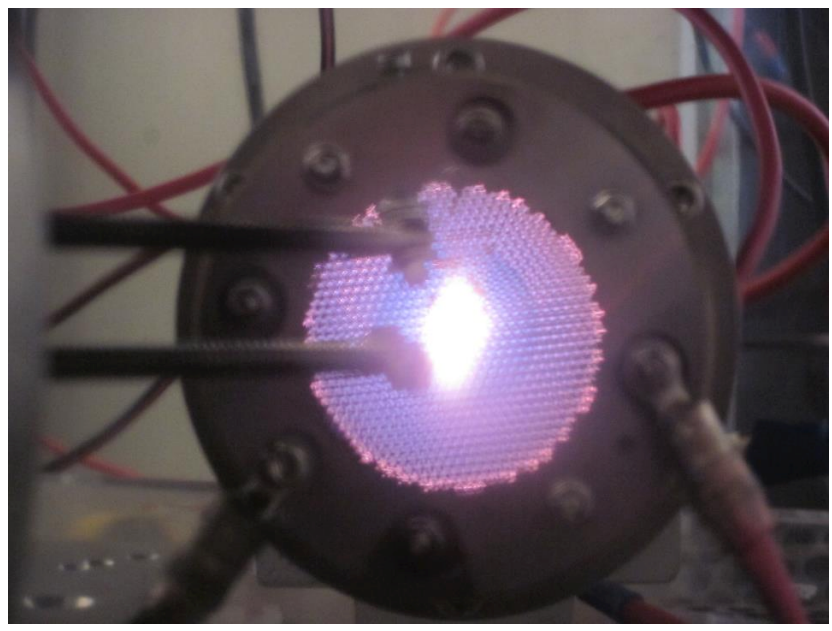

Figure 37: Picture of MiXI-CP-V3 during Testing

Once thruster testing had completed, MiXI-CP-V3 was shut down by turning off all power supplies in the reverse order from which they were turned on, and the thruster was allowed to cool. Once the thruster had cooled, the vacuum chamber was restored to atmospheric pressure and the thruster was disconnected from all propellant flow and electrical system components. The vacuum chamber was then shutdown, and the thruster was examined for any damage or any visible anomalies that may have occurred during testing. 


\section{Chapter 7: Results}

Once testing was complete the performance of the thruster could then be quantified. Analysis of the performance of MiXI-CP-V3 during testing revealed that the thruster operated within the operational parameters of MiXI, and was relatively efficient. Table 6 contains some of the notable performance parameters obtained during MiXI-CP-V3 testing.

Table 6: MiXI-CP-V3 Performance Parameters

\begin{tabular}{|c|c|c|}
\hline Parameter & Value & Unit \\
\hline Propellant & Xenon & N/A \\
\hline Propellant Flow Rate & $0.55-1.06$ & $\mathrm{SCCM}$ \\
\hline Discharge Current & $0.5-1.5$ & $\mathrm{~A}$ \\
\hline Beam Current & $26-41$ & $\mathrm{~mA}$ \\
\hline Beam Voltage & $700-850$ & Volt \\
\hline $\begin{array}{c}\text { Mass Utilization } \\
\text { Efficiency }\end{array}$ & $30-77$ & $\%$ \\
\hline Discharge Loss & $500-1000$ & $\mathrm{eV} / \mathrm{ion}$ \\
\hline Thrust & $1.2-2.0$ & $\mathrm{mN}$ \\
\hline Isp & $1500-3300$ & $\mathrm{Sec}$ \\
\hline Power & $90-150$ & $\mathrm{~W}$ \\
\hline
\end{tabular}

Ion thruster performance is often expressed in a comparison of mass utilization

efficiency and discharge loss to fully illustrate the thrusters' ability to utilize fuel and electricity efficiently to produce thrust. Figure 38 displays the comparison of mass utilization efficiency and discharge loss for the tests completed on MiXI-CP-V3. 


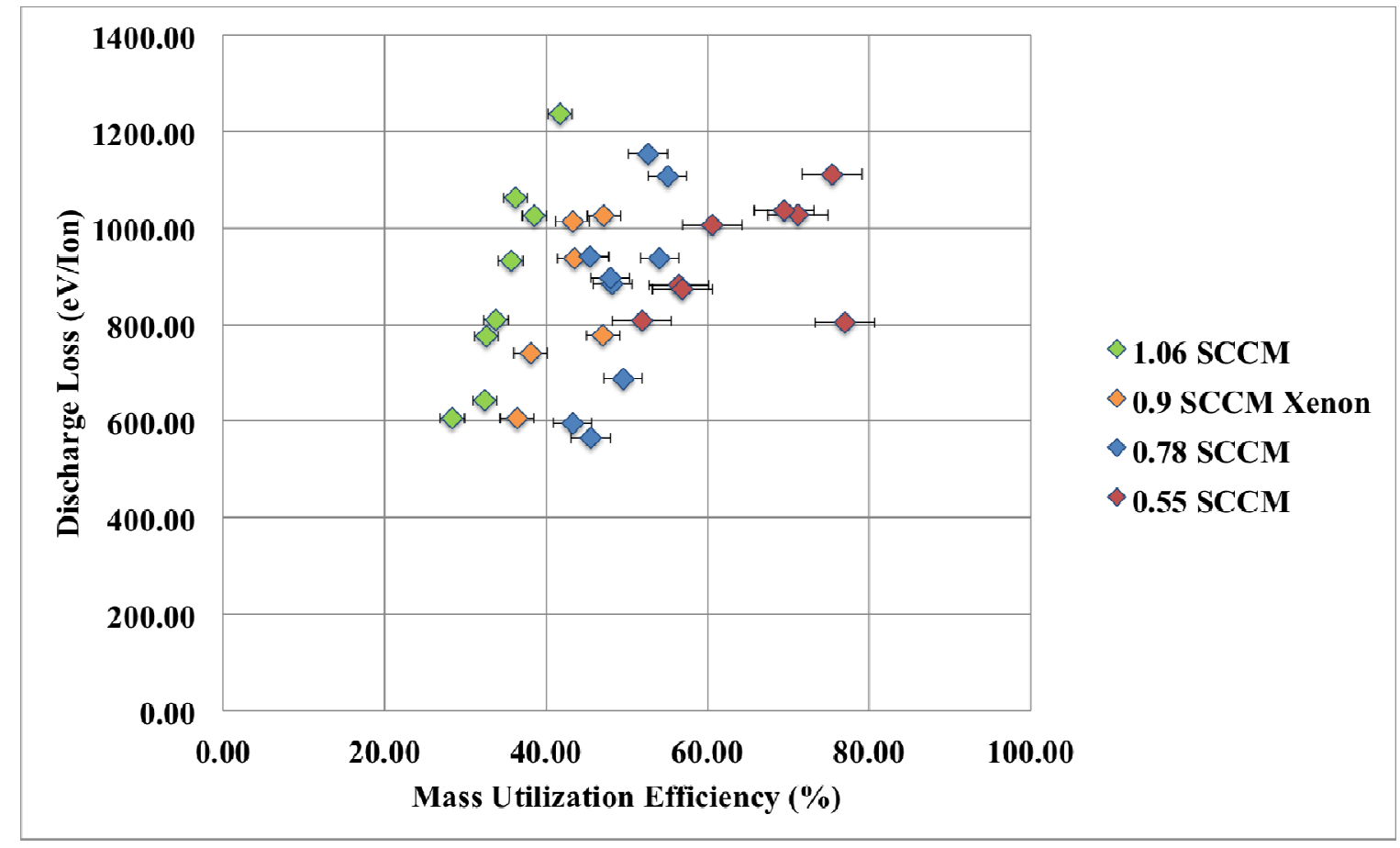

Figure 38: MiXI-CP-V3 Mass Utilization Efficiency vs. Discharge Loss

Several trends can be seen in Fig. 38 that illustrates interesting aspects about the thrusters' operation. As is expected in ion thruster operation, a decrease in the propellant flow rate of the thruster, leads to an overall increase in mass utilization efficiency. This is due to a larger percentage of the propellant flow being ionized and converted directly into beam current as the flow rate decreases. An increase in the mass utilization efficiency for a constant propellant flow rate causes an increase in discharge loss. This occurs because as a larger percentage of the propellant is ionized (analogous to increased mass utilization efficiency), a larger amount of power must be used. This causes the discharge loss to increase dramatically for the thruster. Plotting these two parameters against one another, a general characterization of the thrusters' performance can be obtained. It should be noted that the trends in Fig. 38 lack the flat region where the discharge loss stays 
relatively constant and mass utilization increases dramatically which is common in most EP thruster performance charts. The constant discharge loss in this region is because power being used by the thruster to ionize the fuel is being lost to neutral particle excitation, electron loss, ion loss and the ionization itself. The power being consumed at this region is the lowest amount of power that can be used to ionize the fuel and as a result the discharge loss remains constant as the mass utilization efficiency increases until other losses cause the discharge loss to rise. An example of an ideal thruster performance graph for a $30 \mathrm{~cm}$ plasma generator is shown in Fig. 39 for reference.

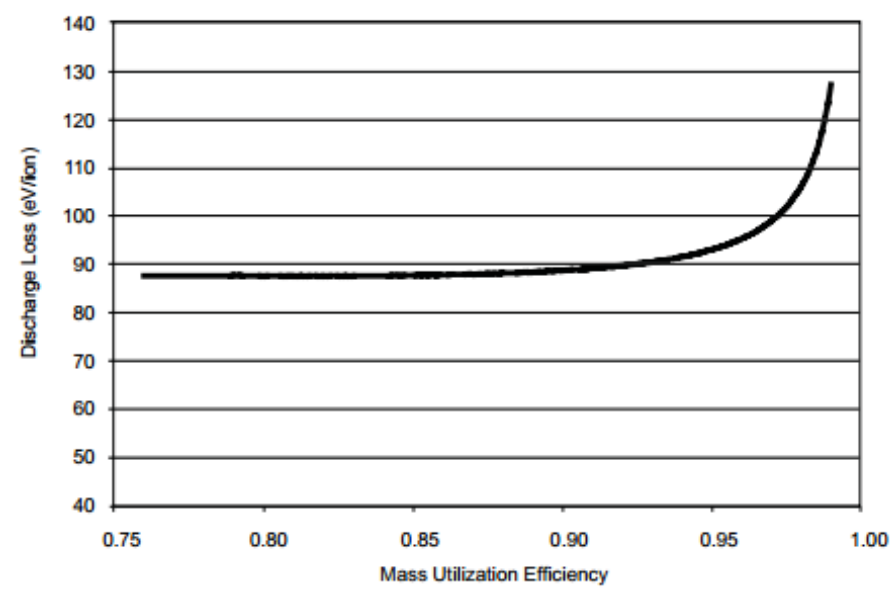

Figure 39: Performance Graph for an Ideal Ion Thruster with a 30cm Plasma Generator Length ${ }^{[2]}$

It should be noted that conventional EP performance plots comparing mass utilization efficiency and discharge loss, are generally made by fixing either the discharge voltage or beam current, and varying the propellant flow rate. The discharge voltage is generally varied by changing the propellant flow rate split between the cathode and anode; however, this is not possible in MiXI-CP-V3 because only cathode propellant flow is present. The beam current is generally varied by adjusting the discharge current, 
which was able to be accomplished in MiXI-CP-V3. As a result, the performance plot shown in Fig. 38 is indicative of MiXI-CP-V3 performance; however, it is not conventional.

Figure 38 also displays that, comparatively to larger ion thrusters such as NEXIS; MiXI-CP-V3 has a relatively high discharge loss ${ }^{[15]}$. This is likely due to the small primary electron collision probability of $51.2 \%$ calculated in chapter II for the thruster. The small collision probability means that a large proportion of the primary electrons are being lost to the anode wall and avoiding collisions with neutral particles. This causes the thruster to require a relatively high primary electron emission current, and thus discharge current, to fully ionize the propellant, as compared to a thruster with a larger primary electron collision probability. Throughout testing, the discharge current was varied from $0.5 \mathrm{~A}$ to $1.5 \mathrm{~A}$ to investigate the thruster performance over a range of discharge currents. It was observed that as the discharge current was increased, the discharge loss also increased. The specific results of this comparison are shown in Fig. 40 for a flow rate of 0.9SCCM with a constant beam voltage of $755 \mathrm{~V}$. 


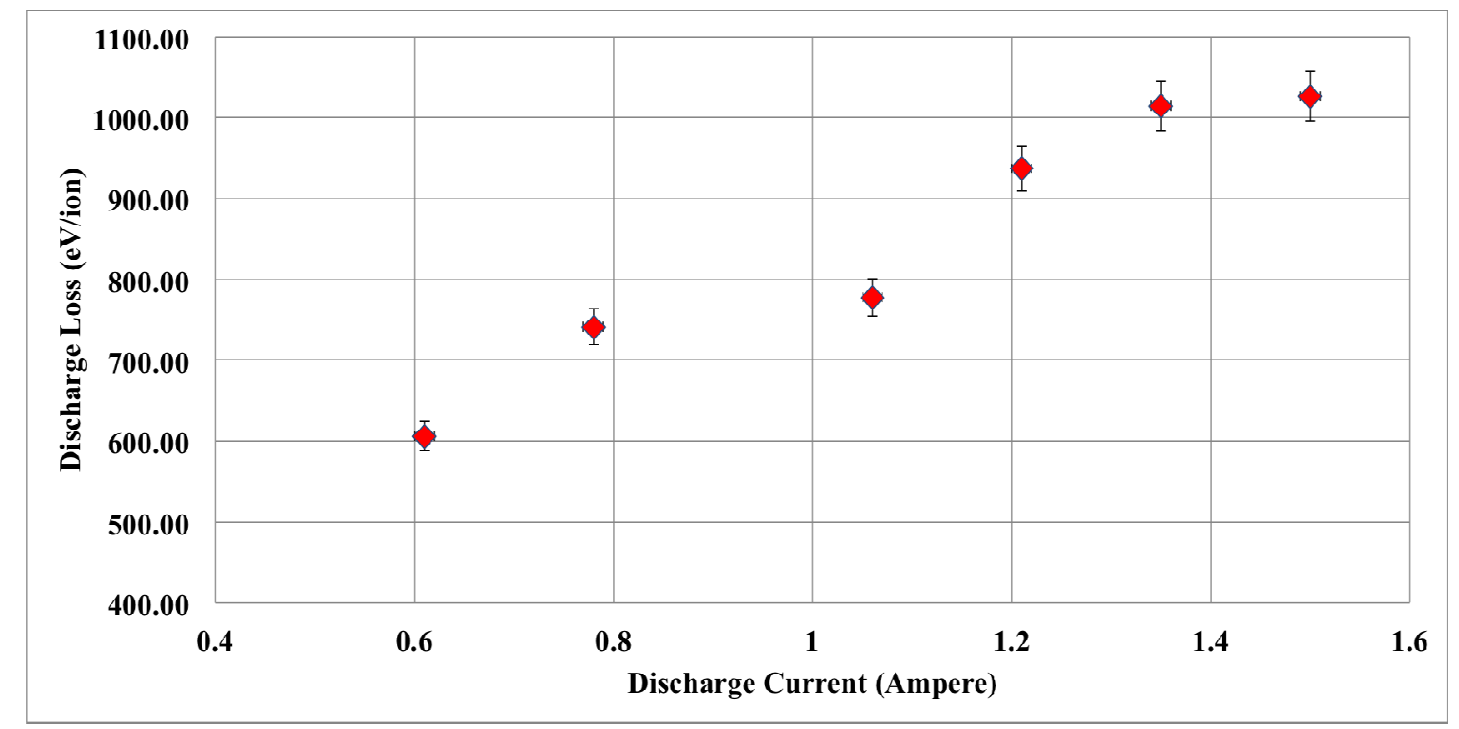

Figure 40: MiXI-CP-V3 Discharge Current vs. Discharge Loss for a Flow Rate of 0.9 SCCM and a Beam Voltage of 755 Volts

This result indicates that for the MiXI-CP-V3 thruster, a discharge current of $<1 \mathrm{~A}$ will lead to a lower discharge loss. It should be noted that the increase of the discharge loss due to increased discharge current is highly unusual. As the discharge current is increased, the ion current going to the grids should also increase because of the larger amount of ions present in the discharge chamber, and thus, decrease the discharge loss. This result indicates that the low transverse magnetic field strength at the wall due to the small magnets being used is causing large ion losses to the anode wall which increases the discharge loss dramatically. The non-optimized axial magnetic field profile shown in fig. 22 is also likely to be causing the large increase in discharge loss, because as the plasma electrons begin to oscillate within the discharge chamber, they are not allowed to properly ionize the neutral gas and are lost to the anode wall quickly. 
Although MiXI-CP-V3 was found to have a lower discharge loss for lower discharge currents, the mass utilization efficiency will in turn decrease (as seen in Fig. 38) as less of the propellant is ionized due to a large fraction of the primary electrons being lost to the anode. Optimal thruster operation then becomes a trade-off between low discharge loss and high mass utilization efficiency, and requires a more in depth analysis into the plasma discharge characteristics of the thruster to determine an overall optimal operation point.

The performance of MiXI-CP-V3 was also analyzed at different beam voltages while keeping all other parameters constant. The beam voltage was varied from $700 \mathrm{~V}$ to $\geq 800 \mathrm{~V}$ over three different discharge currents with a constant propellant flow rate of 0.78SCCM. The results of the comparison are shown in Fig. 41.
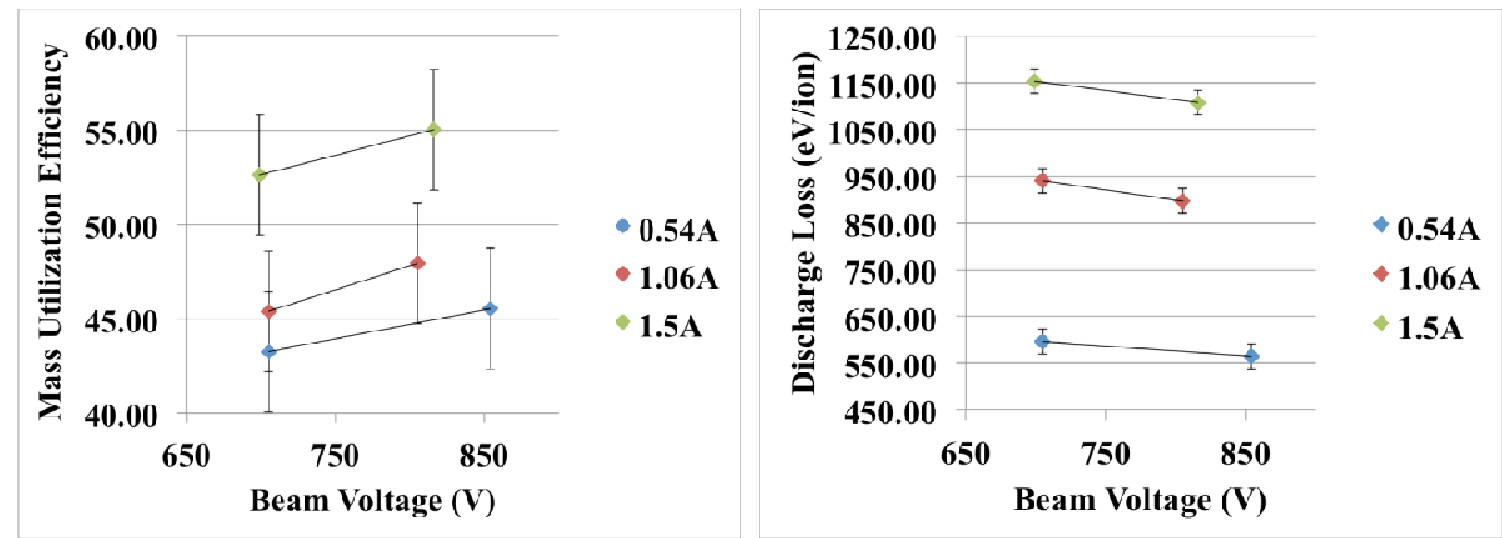

Figure 41: Comparison of Mass Utilization and Discharge Loss vs. Beam Voltage for Varied Discharge Currents at a propellant flow rate of $0.78 \mathrm{SCCM}$

It can be seen from Fig. 41, that an increase in the beam voltage not only decreases the discharge loss of the thruster but also increases the mass utilization 
efficiency. However, it was observed during testing that a beam voltage $>850 \mathrm{~V}$ caused the discharge plasma to become unstable as high voltage primary electrons were lost to the anode wall at an increased rate which interrupted thruster operation. As a result a beam voltage of $800 \mathrm{~V}$ was deemed an optimal operational parameter for MiXI-CP-V3, however in future MiXI designs, a beam voltage of $900-1000 \mathrm{~V}$ is desired and appropriate steps should be taken to achieve it.

The electrical efficiency of the thruster was calculated using Eq. 12 from Chapter V, and it was found to be, on average, around 18\%. The low electrical efficiency is caused by several reasons. As discussed earlier, due to the low propellant flow rate and low discharge current being used within MiXI-CP-V3, the hollow cathode required its heater to remain on during testing at a low level a facilitate heating. The keeper current was also required to be run at a higher level for this same reason. As a result, the thruster required much more power to be operated than would normally be needed in a hollow cathode, and if the heater was turned off the electrical efficiency would increase to $28 \%$ (a 70\% increase). The low electrical efficiency is also due to the low primary electron collision probability. As discussed earlier, the low primary confinement leads to the need for a large discharge current to maintain high mass utilization efficiency. This leads to a relatively inefficient use of electrical power in the plasma generator to create more primary electrons to replace those being lost to the anode. This also led to the large amount of power required for the operation of MiXI-CP-V3 as compared to Dr. Wirzs' MiXI thruster. 


\section{1 - MiXI-CP-V2 \& MiXI-CP-V3 Comparison}

The design and performance parameters of MiXI-CP-V3 and MiXI-CP-V2 were compared to examine how the changes in the MiXI-CP-V3 design affected the thrusters' performance. A comparison of the design differences of the two thrusters is listed in Table 7.

Table 7: Comparison of MiXI-CP-V2 and MiXI-CP-V3 Design Differences

\begin{tabular}{|c|c|c|c|}
\hline Thruster Variant & MiXI-CP-V2 & MiXI-CP-V3 & \\
\hline Parameter & Value & Value & Unit \\
\hline Cathode & CTFC & Hollow Cathode BaO-W & N/A \\
\hline Propellant & Argon & Xenon & N/A \\
\hline Magnet Size & $2 \mathrm{mmx3mm}$ & $3 \mathrm{mmx} 3 \mathrm{~mm}$ & N/A \\
\hline Magnetic Strength at Cusp & 1100 & 3100 & $\mathrm{G}$ \\
\hline Distance to Cusp & 1.5 & 0.5 & $\mathrm{~mm}$ \\
\hline $\begin{array}{c}\text { Primary Electron Collision } \\
\text { Probability }\end{array}$ & $22 \%$ & $52 \%$ & $\%$ \\
\hline Plasma Potential & 2.37 & 0.36 & $\mathrm{~V}$ \\
\hline Screen/Accel Grid Spacing & 0.3 & 0.6 & $\mathrm{~mm}$ \\
\hline
\end{tabular}

The primary differences between the two designs are in the type of cathode used and the magnetic plasma confinement design. The small magnets and larger distance between the magnet surface and the magnetic cusp of MiXI-CP-V2 lead to the low magnetic field strength at the cusp, resulting in the low primary electron confinement. The weak magnetic strength also caused the plasma potential to be much higher than for MiXI-CP-V3, which, although allows for a stable plasma in terms of electron loss to the anode, leads to a loss in efficiency as a large fraction of the primary electrons are lost to the anode. The use of a CTFC and argon within the MiXI-CP-V2 thruster will also cause the thruster to have a much lower mass utilization efficiency and discharge loss due to the small structure of argon atom and the inefficient operation of a CTFC. 
The performance data obtained MiXI-CP-V2 and MiXI-CP-V3 testing is listed in Table 8 to compare the performance of MiXI-CP-V2 and MiXI-CP-V3 under full operating conditions.

Table 8: Comparison of the Performance Parameters of the MiXI-CP-V2 and MiXI-CP-V3

\begin{tabular}{|c|c|c|c|}
\multicolumn{1}{|c}{ Thrusters } \\
\hline Thruster Variant & MiXI-CP-V2 & MiXI-CP-V3 & Unit \\
\hline Parameter & Value & Value & SCCM \\
\hline Propellant Flow Rate & $0.55-1.06$ & $0.45-0.7$ & $\mathrm{~A}$ \\
\hline Discharge Current & $0.5-1.5$ & $0.45-0.8$ & $\mathrm{~mA}$ \\
\hline Beam Current & $26-41$ & $10-19$ & Volt \\
\hline Beam Voltage & $700-850$ & $780-950$ & $\%$ \\
\hline Mass Utilization Efficiency & $30-77$ & $15-40$ & $\mathrm{eV} / \mathrm{ion}$ \\
\hline Discharge Loss & $500-1000$ & $950-1700$ & $\mathrm{mN}$ \\
\hline Thrust & $1.2-2.0$ & $0.3-0.6$ & $\mathrm{Sec}$ \\
\hline Isp & $1500-3300$ & $1800-3500$ & $\mathrm{~W}$ \\
\hline Power & $90-150$ & $70-100$ & \\
\hline
\end{tabular}

It is clear from the performance comparison in Table 7 that the changes and additions made to MiXI-CP-V3 greatly improved the operational performance of the thruster with the mass utilization efficiency nearly doubling and the discharge loss decreasing by nearly $500 \mathrm{eV} /$ ion. However, it should be noted that the overall power usage of MiXI-CP-V2 was less than MiXI-CP-V3. This is likely due to the increased energy required to attain the larger discharge and beam currents as well as the energy required to ionize the larger propellant flow rate of MiXI-CP-V3. Although it is challenging to accurately define which design change from MiXI-CP-V2 to MiXI-CP-V3 lead the increased performance, MiXI-CP-V3 was also operated with UHP argon to compare the effect of using xenon versus argon in the thruster. A graph of the mass utilization efficiency and discharge loss was made for both xenon and argon at a flow rate of 0.9 SCCM using the MiXI-CP-V3 thruster in Fig. 42. 


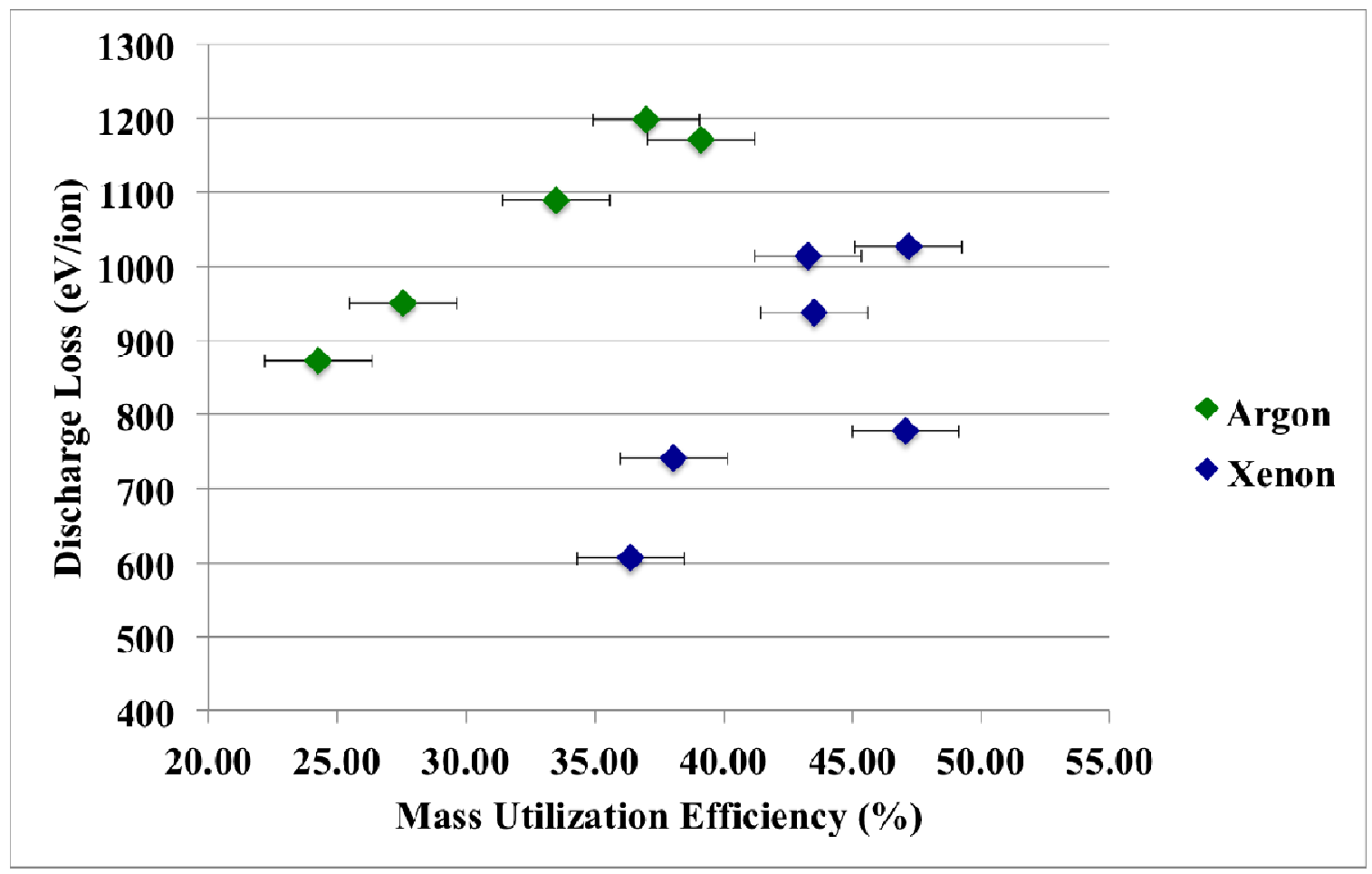

Figure 42: Mass Utilization Efficiency vs. Discharge Loss for Xenon and Argon in the MiXI-CP-V3 Thruster for a propellant flow rate of $0.9 \mathrm{SCCM}$

The use of xenon in the MiXI-CP-V3 thruster resulted in an overall increase in mass utilization efficiency as well as a decrease in discharge loss. However, since the mass utilization efficiency of MiXI-CP-V3 using argon was higher than the mass utilization efficiency of MiXI-CP-V2, it can be deduced that the increase in performance of MiXI-CP-V3 from MiXI-CPV2 (shown in Table 7), can not only be attributed to the use of xenon, but is also due to the implementation of a hollow cathode into MiXI as well as the improved magnetic design using small magnets. 


\section{2 - Error Analysis}

The primary source of error encountered during testing was in the calculation of the propellant mass flow rate. Even though the flow meter used during testing was capable of measuring the propellant flow rate to an accuracy of 0.01 SCCM, the flow rate often moved up and down \pm 0.03 SCCM during a test. This led to the relatively large error in the calculated flow rate and mass utilization efficiency seen in Fig. 38. The overall error in the performance calculations were averaged over each flow rate and are shown in Table 9 where $V_{d}$ is the discharge voltage, $J_{d}$ is the discharge current, and $J_{b}$ is the beam current.

Table 9: Error Propagation of the MiXI-CP-V3 Performance Parameters

\begin{tabular}{|c|c|c|c|c|c|c|}
\hline $\begin{array}{c}\text { Propellant Flow } \\
\text { Rate (SCCM) }\end{array}$ & $\begin{array}{c}\text { Mass Flow } \\
\text { Rate Error }\end{array}$ & $\begin{array}{c}\mathbf{V}_{\mathbf{d}} \\
\text { Error }\end{array}$ & $\begin{array}{c}\mathbf{J}_{\mathbf{d}} \\
\text { Error }\end{array}$ & $\begin{array}{c}\mathbf{J}_{\mathbf{b}} \\
\text { Error }\end{array}$ & $\begin{array}{c}\boldsymbol{\eta}_{\mathbf{m}} \\
\text { Error }\end{array}$ & $\begin{array}{c}\boldsymbol{\eta}_{\mathbf{d}} \\
\text { Error }\end{array}$ \\
\hline 1.06 & $2.8 \%$ & $0.4 \%$ & $1.0 \%$ & $2.9 \%$ & $4.1 \%$ & $3.1 \%$ \\
\hline 0.9 & $3.3 \%$ & $0.3 \%$ & $1.0 \%$ & $2.8 \%$ & $4.4 \%$ & $3.0 \%$ \\
\hline 0.78 & $4.0 \%$ & $0.3 \%$ & $1.1 \%$ & $2.9 \%$ & $4.9 \%$ & $3.1 \%$ \\
\hline 0.55 & $5.3 \%$ & $0.3 \%$ & $1.0 \%$ & $3.0 \%$ & $6.2 \%$ & $3.2 \%$ \\
\hline
\end{tabular}




\section{Chapter 8: Conclusion}

The implementation of a hollow cathode and small plasma confinement magnets into the MiXI design has led to very interesting performance data from the MiXI-CP-V3 thruster as presented in Ch. 7. The increase in discharge loss as the discharge current was increased pointed out that the plasma interaction within the discharge chamber was not performing optimally and led to many insights about the performance of MiXI-CP-V3.

Full thruster testing revealed that although the current 3-ring cusp magnetic field design of MiXI-CP-V3 was deemed optimal for the original MiXI design utilizing a CTFC, it was found to degrade and inhibit the performance of a hollow cathode. The magnetic field inflection and dual magnetic field strength peaks led to many of the plasma electrons emitted from the hollow cathode to oscillate between the magnetic field strength peaks which severely diminished the performance of the hollow cathode. Dr. Wirzs' original MiXI 3-ring magnetic confinement design was acceptable for a CTFC, however it proved to be detrimental to the operation of a hollow cathode.

Furthermore, the small magnets used in the MiXI-CP-V3 design resulted in a low primary electron confinement which allowed for a high discharge loss especially at high discharge currents. The resulting weak transverse magnetic field strength of the small magnets likely yielded weak plasma confinement in between cusps due to the extremely limited penetration of the magnetic field into the plasma.

The addition of a hollow cathode into the MiXI design was also shown to not have solved the extreme thermal heating of the plasma confinement magnets. However 
the analysis and testing of MiXI-CP-V3 represents the first time a hollow cathode has been implemented into the MiXI design, and represents a step forward in the development of MiXI into a viable flight thruster design. The operation of MiXI-CP-V3 has also provided a strong framework for the continuation of miniature electric propulsion research and the continued development of MiXI at Cal Poly.

\section{1 - Future Work}

Moving forward into the design of MiXI, several components of the thruster still need to be optimized and developed for MiXI to become a viable flight thruster. The thermal heat dissipation of the thruster requires further analysis, design modifications, and testing to find a design that does not cause the plasma confinement magnets to overheat and demagnetize in such a small thruster. The magnetic design also requires further analysis into the selection and placement of magnets for plasma confinement using magnetic field solver programs such as COMSOL or MAXWELL to come to a finalized magnetic selection and configuration. The specific interaction of the transverse and axial magnetic fields must be examined in greater detail to find a magnetic field design that will not inhibit hollow cathode operation, and improve the plasma interaction within the discharge chamber. This will help to increase the primary electron collision probability while maintaining plasma stability within the thruster, and get rid of the magnetic inflection point within the discharge chamber that was greatly reducing the efficiency of MiXI-CP-V3. This will help to lower the discharge loss of MiXI while also increasing the mass utilization efficiency as the plasma is properly allowed to diffuse 
throughout the chamber while also increasing plasma confinement performance of the magnetic design.

Although the implementation of a hollow cathode into the MiXI design represented significant progress in the development of a viable plasma generator for MiXI, further development of miniature hollow cathodes or miniature induction cathodes designed for MiXI operation, is required to arrive at a flight MiXI design. The selection of a proper cathode will also help to dictate a proper magnetic field design. 


\section{References}

[1] Wirz, Richard E; "Discharge Plasma Processes of Ring-Cusp Ion Thrusters" California Institute of Technology, Pasadena, California, 2005

[2] Goebel, Dan M.; Katz, Ira; "Fundamentals of Electric Propulsion" John Wiley \& Sons, Hoboken, New Jersey, 2008

[3] http://www.grc.nasa.gov/WWW/ion/past/90s/nstar.htm ${ }_{2}$ Glenn Research Center, NSTAR Ion Thruster, 4/25/2012

[4] Younger, Coleman T; “Thermal Models for a $3 \mathrm{~cm}$ Miniature Xenon Ion Thruster" California State University San Luis Obispo, San Luis Obispo, California, 2010

[5] Wirz, Richard; Sullivan, Regina; Przybylowski, JoHanna; Silva, Mike; "Discharge Hollow Cathode and Extraction Grid Analysis for the MiXI Ion Thruster" AIAA-2006-4498, July, 2006

[6] Knapp, David W; "Development, Design, and Test of a Miniature Xenon Ion Thruster (MiXI)” Senior Project; California State University San Luis Obispo, San Luis Obispo, California, 2012

[7] Martin, Stefan; Rodriguez, Jose; Scharf, Dan; Smith, Jim; MacKinstry, David; Wirz, Richard; Purcell, George; Wayne, Len; Scherr, Larry; Mennesson, Bertrand; Lay, Oliver; “TPF-I Emma X-Array: 2007 Design Team Study” Jet 
Propulsion Lab; California Institute of Technology; April 16, 2007; http://trsnew.jpl.nasa.gov/dspace/bitstream/2014/40342/1/07-1429.pdf; April 30, 2012

[8] Watkins, M; Gross, M; Tapley, B; Bettadpur, S; “Grace Follow-On Mission Status" Jet Propulsion Lab; September 2, 2010;

http://esto.nasa.gov/conferences/space2010/presentations/03_Watkins_GFO.pdf_; May 1, 2012

[9] The CubeSat Program; "CubeSat Design Spacification. Rev.12" Cal Poly San Luis Obispo; May 10, 2012;

http://www.cubesat.org/images/developers/cds_rev12.pdf

[10] Conversano, Ryan W; Wirz, Richard E “CubeSat Lunar Mission Requiring a Miniature Ion Thruster" University of California, Los Angeles, May 3, 2012

[11] http://www.magnet4sale.com/SmCo-Magnets-Dia-3mmX1mm.-572-F-OperatingTemperature.html, Samarium Cobalt disk Magnets, 2/15/2012

[12] Dexter Corporation; "Reference and Design Manual" Magnet Technologies; 1998

[13] Wirz, R.; Goebel, D.; Marrese, C.; Mueller, J.; "Development of Cathode Technologies for a Miniature Ion Thruster," AIAA-2003-4722, 39th Joint Propulsion Conference, Huntsville, AL, 2003

[14] Goebel, D.; Katz, I; Polk, J; Mikellides, I; Jameson, K; Liu, T; "Extending Hollow Cathode Life for Electric Propulsion in Long-Term Missions” AIAA; 2005 
[15] Snyder, J; Goebel, D.; Polk, J; Schneider, A; Senupta, A; "Results of a 2000-Hour Wear Test of the NEXIS Ion Engine" IEPC-2005-281

[16] Polk, J; Anderson, J; Brophy, J; Rawlin, V; Patterson, M; Sovey, J; Hamley, J; "An Overview of the Results from an 8200 Hour Wear Test of the NSTAR Ion Thruster" AIAA 99-24467

[17] MKS Instruments; Gas Correction Factors for Thermal-based Mass-Flow Controller; http://www.mksinst.com/docs/ur/mfcGasCorrection.aspx; 6/7/2012

[18] MKS Instruments; Gas Correction Factors for Ionization Vacuum Gauges; http://www.mksinst.com/docs/ur/GaugeGasCorrection.aspx; 6/7/2012 


\section{Appendix I - Lessons Learned}

Throughout the progression of this thesis, many lessons and tips were discovered that greatly facilitated the operation of MiXI-CP-V3, and if only one thing is taken from this section, it should be to always check, recheck, then do it all over again.

\section{Vacuum Facilities}

The vacuum facilities used for MiXI-CP-V3 testing consisted of a fairly unconventional setup, in that the experiment was positioned on the test stand prior to the bell jar being placed around it, as well as the majority on the electrical feed throughs being placed on the upper lid of the chamber. This required that the thruster be setup in several stages prior to testing. All connections on the base of the chamber were first attached and secured appropriately. The bell jar was then placed carefully around the thruster so no components were touched or moved by the bell jar to avoid thruster contamination. Once the bell jar was in its proper testing position, the remaining electrical connections were attached to the electrical feed throughs on the upper chamber lid and secured appropriately. A similar process (only in reverse) was required when removing the thruster. This two step process caused many of the pre-test and post-test checks to be challenging due to the very small opening from the upper chamber lid to the top of the bell jar. Also, large amounts of caution and patience were required when moving the bell jar for it is fragile and can crack easily (which was learned first-hand). If the bell jar edge touches the thruster, then the thruster will be smeared with vacuum grease and must be cleaned. Bell jar removal specifically required several precautions. 
Due to the imperfect pressure equalization between the experimentation chamber and atmospheric conditions, the upper lid sometimes stuck to the upper gasket of the bell jar. A standard screwdriver was then required to break the seal between the upper chamber lid and bell jar gasket with extreme care so that the upper chamber lid hoist could then be activated and avoid damaging the bell jar.

The operational sequence of the vacuum chamber used for testing also required several precautions to avoid activating systems during the incorrect time. Since the chamber was built fairly recently, many of the conventional safety switches and locks are not in place. This requires the operator of the vacuum system to have intimate knowledge of the inner workings of a vacuum chamber to ensure proper operational procedures. Specific procedures are being put together currently for this vacuum chamber, but extreme precaution must still be taken to avoid chamber malfunction during operation. Furthermore, any chamber being used for ion thruster testing should be cleaned properly prior to testing, for left over outgassing residue from previous experimental testing can cause damage to an ion thruster.

\section{Electrical System}

Due to the complexity of the electrical system required for MiXI-CP-V3 operation, several lessons were learned that made the setup and operation easier. The electrical setup required a large amount of wires to adequately connect all power supplies to the vacuum chamber electrical feed throughs, and as a result a large amount of wire connectors are required. Originally, several different kinds of wire connectors were used 
and once electrical system checks began and rewiring was required, the multiple types of connectors become chaotic. Eventually all wire connections were changed to either BNC or simple ring connectors due to the variety of connections that they allowed. This resulted in a much simpler electrical setup that allowed for easy rewiring when necessary.

Another lesson learned due to the complexity of the electrical system, was the importance of simplifying individual electrical continuity and polarity checks. Due to many of the power supplies being connected on the same circuit, accurate continuity checks when the system is fully assembled become challenging. It was discovered that checking the continuity and polarity as the electrical system was connected yielded the simplest checks. This basically entailed checking each power supply individually both prior to electrical connection as well as after connection to verify everything was working properly. Furthermore, it was discovered that more in depth electrical continuity checks were required to completely verify that the electrical system was connected correctly. For example, the electrical continuity between the screen and accel grid was checked and the grids were shown to be electrically isolated, however, when $20-30 \mathrm{~V}$ was applied across the grids, the electrical isolation was observed to breakdown. This required additional grid spacing to mitigate this issue, and pointed out the need for more in depth electrical system testing prior to thruster operation. In addition, extreme safety precautions should be taken during electrical system operation and checkout to avoid potentially damaging/fatal electrocution events. 
It was also discovered during testing that special care must be taken when positioning the electrical wires attached to the thruster. Post-test observations revealed that the insulation on many of the wires that were too close to the hollow cathode and accel grid began to melt. Acrylic used for electrical isolation placed too close to the hollow cathode, was also found to show signs of heat damage. As a result, caution should be taken when making the final pre-test inspections to make sure that no wires are too close to the hollow cathode and accel grid during testing. In the future, a more streamlined experimental setup is required to simplify the setup process.

Additionally proper analysis should always be done on the electrical schematic to ensure that resistors placed within the circuit, are rated for the proper wattage that will be seen during testing. During an initial full operation test of MiXI-CP-V3, the $1000 \mathrm{ohm}$ resistor in line with the accel grid was found to be melting because it was only rated for $1 \mathrm{~W}$ where as it was actually experiencing $4-5 \mathrm{~W}$. As a rule of thumb, do all and every calculation twice.

\section{Hollow Cathode Operation}

Hollow cathode operation proved to be one of the most challenging aspects of the MiXI-CP-V3 design. As stated in Chapter 3 of this thesis, due to the nature of hollow cathodes, high purity propellant must be used in order to avoid poisoning the insert within the cathode. This resulted in the requirement of using pipe connections and pressure regulators that are able to maintain the high purity of the propellant as it leaves the tank and is inserted into the hollow cathode. It was discovered that only two-stage 
stainless steel pressure regulators are able to be used on the propellant tank to prevent contamination. Pressure fit pipe fittings are also required to maintain propellant purity throughout the fuel line, however, pressure fit fittings are generally used in vacuum systems already, so this requirement is not generally a concern.

Initial testing of the hollow cathode did result in some additional lessons learned, which unfortunately required two separate hollow cathode repairs. It was discovered that the propellant tank must be kept vertically with the gas outlet position on the top of the tank to prevent potential propellant impurities from reaching the fuel line. During initial testing the xenon tank was left on its side, with the gas outlet facing downward. The improper propellant tank position is the likely reason for the poisoning of the first hollow cathode. Once poisoned, the hollow cathode was brought to JPL and the insert was removed and replaced. The insert replacement required that the hollow cathode configuration to change slightly to accommodate the new insert, which also required the mounting scheme of MiXI-CP-V3 to the hollow cathode to change to incorporate the new cathode arrangement. Once testing was resumed after the hollow cathode was repaired, the xenon tank was positioned in the proper orientation and no further poisoning events were observed.

Additionally, a hollow cathode should never be operated in a vacuum chamber that is used for outgassing experiments. Initial hollow cathode testing was attempted within an outgassing chamber, and resulted in the hollow cathode failing to light and even minor poisoning. Hollow cathodes should always be run in 'clean' chambers. 


\section{Appendix II - High Vacuum Operation Procedure}

\section{Pre-Pumping Procedures and Safety Checks}

1. Ensure that all vacuum control panel toggles are switched to the off position.

2. Make sure all service panels, especially the relay cover, are closed and secure.

3. Flip the 120 VAC breaker to the "on" position.

4. Open the ball valve to the pressurized air line.

5. Check the pressurized air regulator and ensure that it reads between 70-75 psi.

6. Turn on the "Main Power" on the vacuum control panel.

7. Turn on the Cryogenic Temperature Indicator.

8. Turn on the Granville-Phillips 375 Vacuum Gauge Controller.

Convectron gauge 2 (CG2) indicates cryopump pressure in torr.

Convectron gauge 3 (CG3) indicates chamber pressure in torr.

\section{Cryopump Roughing Procedure}

1. Turn on the "Mechanical Pump" on the vacuum control panel.

2. Check the sight glass on the back of the Welch 1397/1374 roughing pump to ensure the $\square$ oil level is acceptable. If it is not see manual for procedures.

3. Turn on the "Rough Interlock Valve" on the vacuum control panel.

4. Turn on the "Cryo Rough Valve" on the vacuum control panel. 
5. Monitor the 375 Vacuum Gauge Controller and ensure that cryopump pressure is $\square$ falling.

6. Once the cryo pressure reads $50 \times 10^{-3}-150 \times 10^{-3}$ Torr $(50-150$ milli Torr $)$ proceed to $\square$ Cryopump Compressor Procedure.

Note:

It is preferential for the cryopump pressure to be as low as possible upon cryopump compressor startup. Beginning Cryopump Compressor Procedure at 50 milliTorr has shown marked improvement in pumping speeds. However, if roughing pump performance has degraded, compressor procedures can commence at 150 milliTorr.

7. If cryopump pressure never reaches 150 milliTorr or the pressure is decreasing at an unacceptable rate, proceed to Martin-Victor Cycling Procedure.

\title{
Martin-Victor Cycling Procedure
}

\author{
Note: \\ This procedure is only to be used when the roughing pressure \\ ceases to decrease to the required vacuum or decreases at an \\ extremely slow rate when using the roughing pump.
}

1. Close the roughing valve.

2. Immediately turn off the roughing pump.

3. Wait 30 seconds. 
4. Turn on the roughing pump.

5. Wait 10 seconds.

6. Open the roughing valve. The pressure will initially rise, but then lower below the previous threshold. Repeat these procedures as necessary to achieve the required vacuum.

\section{Cryo Pump Compressor Procedure}

1. Make sure that the compressor is plugged into the $208 \mathrm{~V}, 3$ phase outlet on the vacuum chamber.

2. Verify that the helium pressure on the Compressor is 250 psi.

Note:

If the helium pressure is incorrect do not operate the compressor. If this is the case please refer to the Helium Addition Procedures for the specific compressor.

3. Verify that the cover limit switch is depressed. The compressor will shut off if this is not actuated. Note: If the compressor ceases to operate at any point this is $\square$ the first area the operator should check.

4. Make sure that the "Cold Head" and "Compressor" power switches on the front of $\square$ the compressor are on.

5. Turn on the "Compressor" switch on the vacuum control panel.

6. Verify that the running helium pressure is $285 \mathrm{psi}$. The needle will oscillate by 5 
$\square$ psi. This is normal and not a cause for concern.

7. Observe the cold head motor to ensure that it rotates clockwise. Listen for any $\square$ signs of seizing or grinding.

8. Monitor the Cryo pump temperature indicator and vaerify that the cryo temperature begins to fall.

\section{Note:}

The temperature will begin to fall $\square$ slowly until it reaches a base operating temperature between $10-20 \mathrm{~K}$. This process $\square$ typically takes between 1.5 - 2.5 hours.

9. Once the temperature drops below $150 \mathrm{~K}$, close the cryo roughing valve

10. Turn off the mechanical pump

\section{Note:}

The pressure in the cryo pump must remain below 150 milliTorr throughout cryo pump operation. If the pressure rises, the compresso and cryo pump should be immediately shut off and allowed to return to ambient temperatures before troubleshooting can begin.

11. Monitor the compressor throughout the procedure to ensure that overheating does $\square$ not occur. 


\title{
Experimental Loading Procedure
}

1. Turn on the "Vent Switch" on the vacuum control panel.

2. Monitor the Granville-Phillips 375 Vacuum Gauge Controller to ensure that the $\square$ chamber pressure rises to levels at or above atmospheric pressure (760 torr).

3. Turn on chamber vent valve.

4. Raise the bell jar using the hoist controls

\author{
Note: \\ Use the "slow" buttons when raising or lowering the bell jar \\ within four inches of the chamber. The "fast" buttons can be used \\ to raise or lower the bell jar to loading heights.
}

4. Install the experimental setup according to the goals of your given test.

5. Ensure that all materials being placed in the chamber have acceptable outgassing $\square$ levels to avoid component contamination

6. Check the bell jar gasket to ensure a complete coating of high vacuum grease.

7. Ensure all components of the experiment will not interfere with the vacuum chamber seal or the gate/poppet valve operation

8. Lower the bell jar.

9. Check the perimeter of the bell jar to ensure a uniform seal. 


\title{
Chamber Roughing Procedure
}

1. Turn on the "Mechanical Pump" on the vacuum control panel.

2. Turn on the "Chamber Roughing" on the vacuum control panel.

3. Monitor the chamber pressure on the Granville-Phillips 375 Vacuum Gauge $\square$ Controller.

4. When the chamber pressure reaches 50 milliTorr, shut off the "Chamber $\square$ Roughing” on the vacuum control panel.

\section{Cryotorr Pumping Procedure}

\begin{abstract}
Note:
These procedures can commence once the cryopump temperature is below $20 \mathrm{~K}$ and the chamber pressure at 50 milliTorr. However, the cryopump should be allowed to drop to its lowest base temperature for optimal high vacuum performance
\end{abstract}

1. Turn off the Chamber Rough switch on the vacuum control panel.

2. Turn off the Mechanical Pump switch on the vacuum control panel.

3. Turn on the Pressure Interlock on the vacuum control panel.

4. Open the high vacuum valve by switching on the Gate Valve switch on the vacuum $\square$ control panel. 
5. Within moments the chamber pressure on the Granville-Phillips 375 Vacuum $\square$ Gauge Controller will read 0 millitTorr as the pressure quickly drops. Once this occurs turn on the Ionization Gauge (IG) on the Granville-Phillips 307 Vacuum Gauge Controller.

\section{Note:}

Turning the ion gauge before the chamber pressure reaches 0 milliTorr will result in permanent ion gauge damage

6. Experimentation can commence once the pressure reaches the desired vacuum pressure pending that it is within the capabilities of the vacuum chamber.

\section{Experiment Removal Procedure}

1. Turn off the Granville-Phillips 307 Vacuum Gauge Controller.

2. Switch off the Gate Valve to close the high vacuum valve.

3. Switch off Compressor to turn off the cryo pump.

4. Turn off the Pressure Interlock on the vacuum control panel.

5. Turn on the Vent Valve to vent to chamber.

6. Once the chamber pressure reaches atmospheric levels, raise the bell jar.

7. Remove experimental equipment 


\section{Shut Down Procedure}

1. Lower the bell jar.

2. Follow the chamber roughing procedures and pump the chamber down to below 100 milliTorr because the vacuum chamber should be stored under vacuum

3. Close the chamber roughing valve

4. Shut off the mechanical pump

5. Verify all vacuum chamber components (pumps and valves) are shut off on the vacuum control panel.

6. Turn off the Granville-Phillips 375 Vacuum Gauge Controller.

7. Turn off the air pressure main by closing the ball valve.

8. Turn off the $120 \mathrm{VAC}$ power breaker. 